\title{
INTRODUCTORY NOTE TO RIGHTS AND GUARANTEES OF CHILDREN IN THE CONTEXT OF MIGRATION AND/OR IN NEED OF INTERNATIONAL PROTECTION (INTER-AM. CT. H.R.) BY JORGE CONTESSE*
}

[August 19, 2014]

\section{Introduction}

On August 19, 2014, the Inter-American Court of Human Rights (the Court) issued its Advisory Opinion on the "Rights and Guarantees of Children in the Context of Migration and/or in need of International Protection" (the Opinion). ${ }^{1}$ This key Opinion is the first time that the Court has addressed states' obligations to protect the rights of migrant children, in response to a joint submission by four members of the Organization of American States (OAS).

\section{Background}

The Opinion was requested by the founding states of South America's Mercosur. The states expressed their concern about the lack of interrelation between migratory policies and child protection policies among Latin American states, on one hand, and the pervasive use of a criminal justice approach to address the different challenges posed by child migration, on the other. ${ }^{2}$ In their joint submission to the Court, the applicant states noted that " 25 million people of Latin America and the Caribbean have migrated to countries of Northern America and Europe, and another 6 million people have migrated to other counties in the region."3

Many of these individuals are children, who migrate along with their families but also — and increasingly—unaccompanied. The situation is particularly acute in the northern part of Central America, where United Nations refugee agencies have documented an increased number of asylum seekers-both children and adults - from El Salvador, Honduras, and Guatemala, beginning in 2009. ${ }^{4}$ The UN Refugee Agency has observed that migrant children in need of potential international protection migrate to escape from "violence by organized armed criminal actors and violence in the home."

In recent years, the topic has occupied a prominent place in inter-American human rights law. In 2010, the InterAmerican Commission on Human Rights addressed some of these issues with the release of a report on immigration in the United States. ${ }^{6}$ A few years later - following the heavy influx of migrants in 2013 and 2014 - the Commission made an in loco visit to the southern border of the United States. ${ }^{7}$ Such developments in the Americas mirrored the importance that United Nations human rights bodies have assigned to the issue of international child migration, as reflected in the 2012 Report by the Committee on the Rights of the Child on "The Rights of All Children in the Context of International Migration." ${ }^{8}$ However, there were no official pronouncements from the Inter-American Court, as no contentious cases on international child migration have been submitted for its consideration. ${ }^{9}$

The request for the advisory opinion prompted significant interest from a number of stakeholder participants. Several OAS member states, the Inter-American Commission on Human Rights, the Inter-American Children's Institute, international agencies, nongovernmental organizations, and academic institutions submitted briefs and participated actively in a public hearing that the Court convened in Mexico City in October 2013. ${ }^{10}$

\section{The Opinion}

In its submission, the applicant states requested the Inter-American Court, in general, to expound Article 19 of the American Convention on Human Rights, concerning the obligation to adopt measures of protection in favor of all children. ${ }^{11}$ In particular, the states submitted nine questions to the Court, with the view that the Court provide "a new interpretation" of the United Nations Convention on the Rights of the Child in connection with the specific needs of children in the context of international migration. ${ }^{12}$ Using an intersectional approach, the Court addresses the need to balance two regulatory regimes that at times may be in tension: migratory policy and the norms protecting children.

* Assistant Professor, Rutgers Law School. 
The Court provides guidelines - in some instances, with great detail — on how to strike a balance between these two regulatory regimes. The legal standards and policy guidelines that the Court identifies may be grouped as follows: determination of procedures that states should adopt to identify the different risks for the rights of migrant children, as well as the need to grant asylum or refugee status; due process protections for immigration proceedings; the scope of the principles of nondetention of migrant children and nonrefoulement; and the right of children to family life and unity in cases where their parents are being removed based on migratory reasons. ${ }^{13}$

In addressing these matters, the Court uses the principle of the best interest of the child, relying on the work of the Committee of the Rights of the Child, other UN agencies, and the Court's own case law. Such an approach is of great significance, as the opinion makes explicit that the legal protections for children must always prevail, implying that a migrant child must be treated, first and foremost, as a child. Migratory regulations, therefore, should not trump the migrant child's best interests.

Significantly, the Court articulates an absolute prohibition on the use of detention measures against children, "as a precautionary measure [or due to a] failure to comply with the requirements to enter and remain in a country."14 Using a proportionality test as an interpretive method, the Court finds deprivation of liberty to be "inappropriate when children are unaccompanied or separated from their family," 15 and demands that states always seek less harmful alternatives. ${ }^{16}$

On the principle of nonrefoulement - the "cornerstone of international refugee protection" 17 - the Court relies on the work of the United Nations High Commissioner for Refugees, declaring that the principle "constitutes a norm of customary international law." 18 Following the Court's contentious decision in the case of Pacheco Tineo Family v. Bolivia, ${ }^{19}$ it finds that such a principle does not only derive from the specific norms of refugee law, but also from the text of the American Convention on Human Rights, in particular, Article 22(8). The Court interprets the provision in a broad way, noting that it encompasses not only refugees and asylum seekers but, generally, "any alien." 20 The Court defines the term as including not only nonnationals, but also "persons who are not considered nationals ... either because they have lost ex lege their nationality or because a decision has deprived them of this nationality." 21

Such expansive reading of the American Convention is used in other areas as well. For instance, regarding Article 5 of the Convention, which establishes the right to humane treatment, the Court finds that the provision includes states' obligation

not to deport, return, expel, extradite, or remove in any other way to another State a person who is subject to its jurisdiction, or to a third State that is unsafe, when there are grounds for believing that they would be in danger of being subjected to torture, or cruel, inhuman or degrading treatment. ${ }^{22}$

In line with the case law of the European Court of Human Rights, the UN Human Rights Committee, and the InterAmerican Commission on Human Rights, the Court also finds that states may not deport or expel someone with a serious health condition who, if deported or expelled, may not have access to the treatment he or she needs. ${ }^{23}$

On the question of the child's right to family life, the Court follows its own case law and further broadens the notion of family, encompassing not just the child's parents but also "uncles and aunts, cousins, and grandparents" and "members of the extended family, provided they have close personal ties [with the child]." 24 The Court again uses a proportionality test to determine that states may not expel one or both parents for administrative immigration offenses when "the child has a right to nationality of the country" from which his or her parents may be expelled. ${ }^{25}$ In all cases, the Court articulates detailed procedural guidelines for states to assess risks and to determine whether or not the child is in need of international protection.

\section{Conclusion}

The Opinion is important for a number of reasons. It was the first time that four Organization of American States members jointly requested an advisory opinion, giving significant political strength to the petition. The multiple briefs and interventions that followed the initial submission make clear that the issue is of paramount concern not just to these states, but more generally to human rights actors in the Americas and elsewhere. 
More significantly, the Opinion provides detailed guidelines on "State obligations concerning migrant children [that] have not been clearly and systematically established." ${ }^{26}$ Such standards, the Court observes, should have "legal relevance" to the work of all branches of government within all states that have adopted the American Declaration on the Rights of Man - e.g., the United States - and not just those that have ratified the American Convention. ${ }^{27}$ It remains to be seen how practitioners and officials will make use of the legal standards set forth by the Inter-American Court.

\section{ENDNOTES}

1 Rights and Guarantees of Children in the Context of Migration and/or in Need of International Protection, Advisory Opinion OC-21/14, Inter-Am. Ct. H.R. (ser. A) No. 21 (Aug. 19, 2014) [hereinafter Opinion].

2 Mercosur is a South American trade bloc defined as "a process of regional integration initially established by Argentina, Brazil, Paraguay and Uruguay." The government of Venezuela joined Mercosur in 2012 but was suspended in December 2016. Bolivia is currently in the process of joining Mercosur. In 2009, Mercosur established the Institute of Public Policies on Human Rights, "with the aim of providing technical cooperation and assistance in the formulation, design, implementation and articulation of public policies on human rights." See Inst. of Pub. Policies on Human Rights, Presentation of the Mercosur Institute of Public Policies on Human Rights Cross-Regional Meeting for Advancing the Protection of Children from Violence (Jun. 30, 2014), available at http://www. ippdh.mercosur.int/wp-content/uploads/2014/08/Presentationof-the-MERCOSUR-Institute-of-Public-Policies-on-HumanRights-1.pdf [hereinafter Mercosur].

3 Opinion, supra note 1, ๆ 2.

4 UN High Comm'r for Refugees, Children on the Run: Unaccompanied Children Leaving Central America and Mexico and the Need for International Protection, 4 (2014), available at http://www.refworld.org/docid/532180c24.html [hereinafter Children on the Run].

$5 \quad I d$. at 6.

6 Report on Immigration in the U.S.: Due Process and Detention, Inter-Am. Comm'n H.R., OEA/Ser.L/V/II., doc. 78/10 (Dec. 30, 2010).

7 In fiscal year 2013, the U.S. Customs and Border Protection agency reported having apprehended 12,908 family units. The following fiscal year, that number went up to 66,142 an increase of 412 percent. That same year, 66,127 unaccompanied children were apprehended. Press Release, Inter-Am. Comm'n on Human Rights, IACHR Visits Southern Border of United States Concerned About Situation of Unaccompanied Children and Families, Inter-Am. Comm'n H.R. Press Release No. 105/14 (Sept. 22, 2014).

8 UN Human Rights Office of the High Comm'r, Comm. on the Rights of the Child, Report of the 2012 Day of General Discussion: The Rights of All Children in the Context of International Migration (Sept. 28, 2012), available at http:// www2.ohchr.org/english/bodies/crc/docs/discussion2012/
2012CRC_DGD-Childrens_Rights_InternationalMigration. pdf.

In 2003, the Court issued an advisory opinion on the Juridical Status and Rights of Undocumented Migrants, where it established that mechanisms to control entry into a country's territory "must always be applied with strict regard for the guarantees of due process and respect for human dignity." Advisory Opinion OC-18/03, Inter-Am. Ct. H.R. (ser. A) No. 18 (Sept. 17, 2003).

10 Opinion, supra note 1, 127.

11 Article 19 states: "Every minor child has the right to the measures of protection required by his condition as a minor on the part of his family, society, and the state." Organization of American States, American Convention on Human Rights, Nov. 22, 1969, 1144 UNTS 123.

12 Mercosur, supra note 2.

13 Opinion, supra note $1, \mathbf{q} 3$.

14 Id. ๆๆ 144-60.

$15 \quad$ Id. $\uparrow 157$.

16 In a decision against Panama, the Court had found that "measures of deprivation of liberty of a punitive nature to control migratory flows" are incompatible with the American Convention on Human Rights. Vélez Loor v. Panama, Preliminary Objections, Merits, Reparations, and Costs, Judgment, Inter-Am. Ct. H.R. (ser. C) No. 132, ๆף 163-72 (Nov. 23, 2010).

17 Children on the Run, supra note 4, at 8.

18 Opinion, supra note 1, ๆ 211.

19 Pacheco Tineo Family v. Plurinational State of Bolivia, Preliminary Objections, Merits, Reparations and Costs, Judgment, Inter-Am. Ct. H.R. (ser. C) No. 272 (Nov. 25, 2013).

20 Opinion, supra note 1, ๆ 215.

$21 \quad$ Id. ๆ 218.

$22 \quad I d .9225$

23 Id. ๆ 229.

$24 \quad I d .9272$.

25 Id. ๆ 280.

$26 \quad I d .927$.

$27 \quad I d .932$. 
Copyright (C) 2017 by The American Society of International Law

DOI:10.1017/ilm.2017.32

RIGHTS AND GUARANTEES OF CHILDREN IN THE CONTEXT OF MIGRATION AND/OR IN NEED OF INTERNATIONAL PROTECTION (INTER-AM. CT. H.R.)*

[August 19, 2014]

\title{
INTER-AMERICAN COURT OF HUMAN RIGHTS
}

\author{
ADVISORY OPINION OC-21/14 \\ OF AUGUST 19, 2014
REQUESTED BY THE ARGENTINE REPUBLIC, THE FEDERATIVE REPUBLIC OF BRAZIL, THE REPUBLIC OF PARAGUAY AND THE ORIENTAL REPUBLIC OF URUGUAY

\section{RIGHTS AND GUARANTEES OF CHILDREN IN THE CONTEXT OF MIGRATION AND/OR IN NEED OF INTERNATIONAL PROTECTION}

the Inter-American Court of Human Rights (hereinafter "the Inter-American Court", "the Court" or "the Tribunal"), composed of the following Judges:**

Humberto Antonio Sierra Porto, President;

Roberto F. Caldas, Vice President;

Manuel E. Ventura Robles, Judge;

Diego García-Sayán, Judge;

Eduardo Vio Grossi, Judge, and

Eduardo Ferrer Mac-Gregor Poisot, Judge;

also present,

Pablo Saavedra Alessandri, Secretary, and

Emilia Segares Rodríguez, Deputy Secretary,

pursuant to Article 64(1) of the American Convention on Human Rights (hereinafter "the American Convention" or "the Convention") and Articles 70 to 75 of the Rules of Procedure of the Court (hereinafter "the Rules of Procedure"), issues the following Advisory Opinion structured as follows:

* This text was reproduced and reformatted from the text available at the Inter-American Court of Human Rights website (visited Aug. 1, 2017), http://www.corteidh.or.cr/docs/opiniones/seriea_21_eng.pdf.

** Judge Alberto Pérez Pérez did not participate for reasons of force majeure, in the deliberation and signature of this Advisory Opinion. 
TABLE OF CONTENTS

I PRESENTATION OF THE REQUEST $\ldots \ldots \ldots \ldots \ldots \ldots \ldots \ldots \ldots$

II PROCEEDINGS BEFORE THE COURT $\ldots \ldots \ldots \ldots \ldots \ldots \ldots \ldots \ldots$

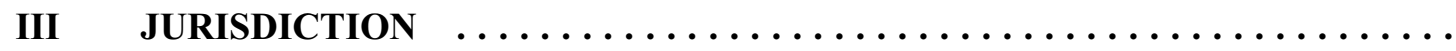

IV GENERAL CONSIDERATIONS $\ldots \ldots \ldots \ldots \ldots \ldots \ldots \ldots \ldots \ldots \ldots$

V INTERPRETATION CRITERIA $\ldots \ldots \ldots \ldots \ldots \ldots \ldots \ldots \ldots \ldots$

VI GENERAL OBLIGATIONS AND GUIDING PRINCIPLES $\ldots \ldots \ldots \ldots \ldots$

VII PROCEDURES TO IDENTIFY INTERNATIONAL PROTECTION NEEDS OF MIGRANT CHILDREN AND, AS APPROPRIATE, TO ADOPT MEASURES OF SPECIAL PROTECTION $\ldots \ldots \ldots \ldots \ldots \ldots \ldots \ldots \ldots \ldots \ldots \ldots \ldots \ldots \ldots \ldots$

VIII GUARANTEES OF DUE PROCESS APPLICABLE IN IMMIGRATION PROCEEDINGS INVOLVING CHILDREN ... . . . . . . . . . .

IX PRINCIPLE OF NON-DEPRIVATION OF LIBERTY OF CHILDREN OWING

TO THEIR IRREGULAR MIGRATORY SITUATION ............ [ [ILM Page 870]

$X$ CHARACTERISTICS OF THE PRIORITY MEASURES FOR THE COMPREHENSIVE PROTECTION OF THE RIGHTS OF CHILD MIGRANTS AND GUARANTEES FOR THEIR APPLICATION $\ldots \ldots \ldots \ldots \ldots \ldots$

XI BASIC CONDITIONS FOR PLACES TO ACCOMMODATE CHILD MIGRANTS AND STATE OBLIGATIONS CORRESPONDING TO CUSTODY FOR MIGRATORY REASONS $\ldots \ldots \ldots \ldots \ldots \ldots \ldots \ldots \ldots \ldots \ldots$

XII GUARANTEES OF DUE PROCESS IN MEASURES THAT ENTAIL RESTRICTION OR DEPRIVATION OF PERSONAL LIBERTY OF CHILDREN

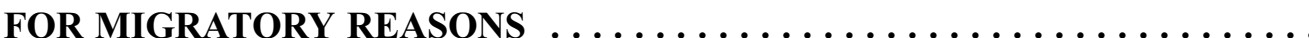

XIII PRINCIPLE OF NON-REFOULEMENT $\ldots \ldots \ldots \ldots \ldots \ldots \ldots \ldots \ldots \ldots$

XIV PROCEEDINGS TO ENSURE THE RIGHT OF CHILDREN TO SEEK AND RECEIVE ASYLUM

[ILM Page 844] [ILM Page 846] [ILM Page 850] [ILM Page 852]

[ILM Page 855] [ILM Page 857]

[ILM Page 859]

[ILM Page 865]

[ILM Page 873]

[ILM Page 874]

[ILM Page 876]

[ILM Page 880]

[ILM Page 886]

XV RIGHT TO FAMILY LIFE OF CHILDREN IN THE CONTEXT OF PROCEDURES FOR THE EXPULSION OR DEPORTATION OF THEIR PARENTS FOR MIGRATORY REASONS $\ldots \ldots \ldots \ldots \ldots \ldots \ldots \ldots$ 


\section{PRESENTATION OF THE REQUEST}

1. On July 7, 2011, the Argentine Republic (hereinafter "Argentina"), the Federative Republic of Brazil (hereinafter "Brazil"), the Republic of Paraguay (hereinafter "Paraguay") and the Oriental Republic of Uruguay (hereinafter "Uruguay"), which will hereinafter be referred to jointly as "the applicant States," based on Article 64(1) of the American Convention and in accordance with the provisions of Article 70(1) and 70(2) of the Rules of Procedure, submitted a request for an Advisory Opinion on migrant children (hereinafter "the request") for the Court to "determine the precise obligations of the States in relation to the possible measures to be adopted regarding children, their immigration status or the status of their parents in light of the interpretation of Articles 1(1), 2, 4(1), 5, 7, 8, 11, 17, 19, 22(7), 22(8), 25 and 29 of the American Convention on Human Rights; Articles 1, 6, 8, 25 and 27 of the American Declaration of the Rights and Duties of Man; and Article 13 of the Inter-American Convention to Prevent and Punish Torture."1

2. The applicant States explained the considerations that gave rise to the request and, among these, indicated that:

It is estimated that around 25 million people of Latin America and the Caribbean have migrated to countries of Northern America and Europe, and another 6 million have migrated to other countries in the region. An increasing number of them, yet to, be determined, are children and adolescents, some of which migrate together with their parents (or with one of them), at the same time that others migrate unaccompanied and separately. [...]

[The] boys and girls that migrate due to different reasons, such as family reunification; migration in search of better economic, social or cultural conditions; migration in order to reduce extreme poverty, environmental degradation; or to escape from violence or other forms of abuse and persecution. $[\ldots]$

[M]igrant persons with an irregular immigration status, on one hand, and children, on the other hand, are vulnerable social groups. Both groups require, therefore, a special commitment on the part of States who must respect, protect and guarantee their fundamental rights [taking into consideration] a transversal focus on age that takes into account the rights of children affected by migration. $[\ldots]$

[Currently] the application of custodial measures to migrants (adults and children) based on the breach of migratory norms constitutes a problem that creates a profound concern at different national and international levels. [...]

Having stated the principle of non-criminalization, there are still many pending issues in relation to the recognition of human rights of migrants and, in particular, the recognition and protection of the human rights of migrant children. [...]

In this scenario, it is essential for the [...] Inter-American Court of Human Rights to clearly define precise standards, principles and obligations that States must comply with in relation to the human rights of migrants, especially in relation to the rights of migrant children and children born to migrant parents $[\ldots]$ in the following issues: 1 . Procedures for the determination of the needs for international protection and of special protection measures for migrant children and adolescents; 2. System of guarantees that must be applied to migratory proceedings involving migrant children and adolescents; 3 . Standards for the application of precautionary measures in a migratory proceeding on the basis of the principle of non-detention of migrant children. 4. Measures of protection of rights that must be applied on a priority basis and which do not entail restrictions on personal liberty. 5. The State's obligations in the case of custody of children based on migratory reasons. 6. Due process guarantees before measures that entail deprivation of liberty of children within the framework of migratory proceedings. 7. Principle of non-refoulement in relation to migrant children. 8. Procedures for the identification and treatment of children who may request for asylum or refugee status. 9. Right to a family life of the children when their parents are removed due to migratory reasons. 
3. Based on the above, the applicant States submitted the following specific questions to the Court:

[1.] Which are, in light of Articles 1, 2 5, 7, 8, 19, 22(7) and 25 of the American Convention and Articles 1, 25 and 27 of the American Declaration of the Rights and Duties of Man, the procedures that should be adopted in order to identify the different risks for the rights of migrant children; to determine the needs for international protection and to adopt, if applicable, the special protective measures required?

[2.] Which are, in light of Articles 1, 2, 7, 8, 19 and 25 of the American Convention and Article 25 of the American Declaration on the Rights and Duties of Man, the due process guarantees that should govern immigration proceedings in which migrant children are involved?

[3.] In light of Articles 1, 7, 8, 19 and 29 of the American Convention and Article 25 of the American Declaration of Rights and Duties of Man, in what way should the principle of detention as a last resort precautionary measure be interpreted in the framework of immigration proceedings when children in the company of their parents are involved, and when there are children who are unaccompanied or separated from their parents?

[4.] What characteristics, in light of Articles 2, 7, 19, 25 and 29 of the American Convention and Article 25 of the American Declaration on the Rights and Duties of Man, should adequate alternative measures for the protection of the rights of the child have in order to be the priority response of the State to avoid any kind of restriction on freedom? Which due process guarantees should be offered in the decision-making process regarding alternative measures to detention?

[5.] What are the basic conditions that accommodation facilities for migrant children must satisfy and what are the State's main obligations regarding children (unaccompanied or accompanied) who are under the custody of the State based on immigration reasons, in light of Articles 1, 2, 4 (1), 5, 7, 17 and 19 of the American Convention and Articles 1 and 25 of the American Declaration of the Rights and Duties of Man?

[6.] If custodial measures are applied to children in immigration proceedings, which are, in light of Articles 1, 2, 7, 8, 19 and 25 of the American Convention and Article 25 of the American Declaration on the Rights and Duties of Man, the due process guarantees that should govern immigration proceedings in which migrant children are involved?

[7.] What is the scope and content of the principle of non-refoulement in light of Articles 1, 2, 4.1, 5, 7, 8, 19, 22(7), 22(8) and 25 of the American Convention, Article 13(4) of the Inter-American Convention to Prevent and Punish Torture and Articles 1, 25 and 27 of the American Declaration on the Rights and Duties of Man when a measure that may entail the return of a child to certain country is applied?

[8.] In light of Article 22(7) of the American Convention and Article 27 of the American Declaration on the Rights and Duties of Man, what are the characteristics that the procedures to be used when identifying a potential request for asylum or for recognition of the refugee status of a migrant child should have?

[9.] What is the scope that must be given to the protection of the right of the child not to be separated from his/her parents in the case that a deportation measure could be imposed on one or both parents, as a consequence of their migratory status, in light of Articles 8, 17, 19 and 25 of the American Convention and Articles 6 and 25 of the American Declaration on the Rights and Duties of Man?

4. Argentina appointed Mr. Luis Hipólito Alen as Agent, as well as Mr. Alberto Javier Salgado and Mr. Julio Ayala, as Deputy Agents. Brazil appointed Ambassador Maria Dulce Silva Barros as Agent, and Ms. Juliana de Moura Gomes, Mr. Carlos Eduardo da Cunha Oliveira, Mr. Fábio Balestro Floriano, Mr. Rafael Rodrigues Soares, and Mr. Francisco George de Lima Beserra as Deputy Agents. Paraguay appointed Ms. Inés Martínez Vilanotti and Mr. Ricardo González as Agents. Uruguay appointed Mr. Javier Miranda and Mr. Federico Perazza as Agents. 


\section{PROCEEDINGS BEFORE THE COURT}

5. By notes of September 13, 2011, the Secretariat of the Court (hereinafter "the Secretariat"), under the provisions of Article 73(1) of the Rules of Procedure, forwarded the request to the other Member States of the Organization of American States (hereinafter "the OAS"), to the OAS Secretary General, the President of the Permanent Council of the OAS, the Inter-American Commission on Human Rights (hereinafter "the Inter-American Commission" or "the Commission"), and the Inter-American Children's Institute. In these communications, the Secretariat advised that the President of the Court, after consulting the other members of the Court, had established December 15,2011 , as the last date for the presentation of written observations or other relevant documents in relation to this request. Also, on the instructions of the President, and as established in Article 73(3) of the Rules of Procedure, the Secretariat, in notes of September 23 and 26, 2011, invited diverse international agencies and civil society organizations, as well as academic institutions in the region to forward their written opinion on the points submitted to consultation within the above-mentioned time frame. Lastly, an open invitation was issued to any interested party, via the website of the Inter-American Court, to present a written opinion on the points submitted to consultation. The time frame established above was extended until February 17, 2012, so that they had approximately five months to forward their submissions.

6. On the date the time frame expired, the Secretariat had received the following briefs with observations: ${ }^{2}$

Written observations presented by States of the OAS:

1) Brazil

2) Republic of Costa Rica (hereinafter "Costa Rica")

3) Republic of Ecuador (hereinafter "Ecuador")

4) Republic of Honduras (hereinafter "Honduras")

5) United Mexican States (hereinafter "Mexico")

Written observations presented by organs of the $O A S$ :

6) Inter-American Commission on Human Rights

7) Inter-American Children's Institute

Written observations presented by international agencies:

8) United Nations High Commissioner for Refugees (UNHCR)

9) Regional Office for Latin America and the Caribbean of the Office of the United Nations High Commissioner for Human Rights (OHCHR)

10) Regional Office for Latin America and the Caribbean of the United Nations Children's Fund (UNICEF)

11) Regional Office for Central America, North America and the Caribbean of the International Organization for Migration (IOM)

Written observations presented by State agencies, national and international associations, academic institutions, non-governmental organizations, and civil society:

12) Public Defense Service of the Argentine Republic

13) Comisión de Derechos Humanos del Distrito Federal and Centro para el Desarrollo de la Justicia Internacional, A.C.

14) Inter-American Association of Public Defenders (AIDEF)

15) Women's Link Worldwide

16) Latin American and Caribbean Committee for the Defense of Women's Rights (CLADEM) 
17) International Social Service (ISS) and Red Latinoamericana de Acogimiento Familiar (RELAF)

18) Centro de Direitos Humanos e Cidadania do Imigrante (CDHIC)

19) Centro de Estudios Legales y Sociales (CELS) and Comisión de Apoyo y Orientación a Inmigrantes y Refugiados (CAREF)

20) Grupo Jurídico de Antioquia (GJA)

21) Consejo Uruguayo para las Relaciones Internacionales (CURI)

22) Programa de Defensa e Incidencia Binacional de la Iniciativa Frontera Norte de Mexico, composed of Centro de Derechos Humanos del Migrante A.C, Centro de Recursos Migrantes, Network of YMCA Homes for Migrant Children, and Coalición Pro Defensa del Migrante A.C.

23) María Elena Vásquez Rodríguez, Director of the Program "Niños y niñas sin fronteras" of the Chilean Corporación Colectivo Sin Fronteras; Carlos Roberto Muñoz Reyes, spokesperson of the Network of Children's NGOS of Chile; Julio Esteban Cortés Morales, professor of the Children's Clinic of the Law School of the Universidad Central de Chile, and Iskra Leyva Pavez Soto, professor of the School of Social Work of the Universidad Tecnológica Metropolitana of Chile

24) Committee No. 1309 of the Professional Practice Department of the Law Faculty of the Universidad de Buenos Aires (hereinafter "Committee No. 1309")

25) Human Rights Center of the Universidad Nacional de Lanús

26) Legal Clinic for Migrants and Refugees of the Human Rights Center of the Law Faculty of the Universidad Diego Portales

27) Universidad Colegio Mayor de Nuestra Señora del Rosario

28) Professors of the Law Faculty of the Universidad Nacional Autónoma de Mexico

29) Centro Estratégico de Litigio Latinoamericano, A.C. and the Human Rights Programa of the Universidad Veracruzana

30) Human Rights Center of the Jurisprudence Faculty of the Universidad Católica del Ecuador

31) Democracy and Human Rights Institute of the Pontificia Universidad Católica del Peru

32) Human Rights Study Center of the Law Faculty of the Universidad de San Martín de Porres

33) Human Rights Center and Juridical Research Center of the Universidad Católica Andrés Bello

34) International Human Rights Law Clinic of the Washington College of Law, American University, on behalf of the Women's Refugee Commission, Kids in Need of Defense and the Immigrant Children's Legal Program of the U.S. Committee for Refugees and Immigrants (formerly National Center for Refugee and Immigrant Children)

35) Immigration Law Clinic of the Southwestern Law School

36) Child Law Clinic of the University College Cork

37) Mr. Boris Wilson Arias López

38) Messrs. Ezequiel Heffes and Fernando Alberto Goldar

39) Mr. Luis Peraza Parga

40) Ms. Beatriz Eugenia Sánchez Mojica

41) Messrs. Álvaro Francisco Amaya-Villarreal, Felipe Franco Gutiérrez and Ms. Viviana Ordóñez Salazar

42) Ms. Juliana Poveda Clavijo and Mr. Oscar Yesid Osorio Barragán

7. Once the written proceeding had concluded, on May 11, 2012, the President, pursuant to Article 73(4) of the Rules of Procedure, issued an Order $^{3}$ in which he convened a public hearing and invited the Member States of the OAS, its Secretary General, the President of the Permanent Council, the Inter-American Commission, the InterAmerican Children's Institute, and all those members of different organizations, civil society, academic institutions, and individuals who had forwarded written observations to present their oral comments concerning the request made to the Court. The public hearing was scheduled for June 26 and 27, 2012 at the seat of the Court. 
8. On June 25, 2012, Argentina, in exercise of the Presidency pro tempore of MERCOSUR (Mercado Común del Sur) and on behalf of Brazil and Uruguay, requested that "[ . . . owing to the situation in the Republic of Paraguay, which [was] widely known, the said hearings [be] postponed for a date to be determined."

9. On June 26, 2012, the Secretariat of the Court advised that the Court in plenary had agreed to the request of the three applicant countries to postpone the public hearing in light of the political events in the State of Paraguay. It also advised the applicant States, the other OAS Member States, the Inter-American Commission on Human Rights, and the international and State agencies, national and international associations, non-governmental organizations, and academic institutions that had confirmed their participation in the hearing that they would be duly notified of the new date of the hearing.

10. On May 30, 2013, after consulting the applicant States, the procedure returned to its normal course, and the Secretariat advised that the public hearing on this advisory opinion would take place during one of the sessions to be held during the last quarter of 2013.

11. On September 5, 2013, the President, pursuant to the provisions of Article 73(4) of the Rules of Procedure, issued an Order ${ }^{4}$ in which he convened a public hearing and invited the Member States of the OAS, its Secretary General, the President of the Permanent Council, the Inter-American Commission, the Inter-American Children's Institute, and all the members of the different organizations, civil society, academic institutions, and persons who had forwarded written observations and/or had confirmed their participation, to present their oral comments concerning the request made to the Court.

12. The public hearing was held on October 9 and 10, 2013, in Mexico City, United Mexican States, during the $48^{\circ}$ Special Period of Session of the Inter-American Court of Human Rights.

13. The following persons appeared before the Court:

For Argentina, Luis Hipólito Alen, Assistant Secretary for the Protection of Human Rights of the Ministry of Justice and Human Rights of the Nation, María Julia Loreto, lawyer, of the International Litigation Directorate for Human Rights of the Ministry of Foreign Affairs, Víctor Abramovich Cosarín, Executive Secretary of the MERCOSUR Institute of Public Policies for Human Rights (IPPHR), and Francisco Tropepi, Secretary of the Political Section of the Embassy of the Argentine Republic in the United Mexican States;

For Brazil, Ambassador Maria Dulce Silva Barros, State Agent before the Inter-American Court of Human Rights, Victoria Balthar, International Adviser of the Human Rights Secretariat of the Presidency of the Republic, and Juliana Soares Santos, First Secretary of the Embassy of the Federative Republic of Brazil in the United Mexican States;

For Paraguay, Ambassador Carlos Heriberto Riveros Salcedo, Ambassador Extraordinary and Plenipotentiary of the Republic of Paraguay to the United Mexican States, María Leticia Casati, Counselor of the Embassy of the Republic of Paraguay in the United Mexican States, and Juan José Mancuello, First Secretary of the Embassy of the Republic of Paraguay in the United Mexican States;

For Uruguay, Ambassador Federico Perazza, Deputy Director General for Political Affairs of the Ministry of Foreign Affairs;

For Mexico, Ambassador Juan Manuel Gómez Robledo, Deputy Secretary for Multilateral Affairs and Human Rights of the Secretariat for Foreign Affairs; Laura Vargas Carrillo, Head of the National System for the Integral Development of the Family; Max Alberto Diener Sala, Legal Adviser to the Secretariat of Foreign Affairs; Erasmo Lara Cabrera, Deputy Director General of Cases, Democracy and Human Rights of the Secretariat of Foreign Affairs; Lilian Espinoza Fernández, Director General for Inter-institutional Liaison of the National System for the Integral Development of the Family; Ana Cecilia Oliva Balcarcel, Director General for Protection of Migrants and Liaison with the National Immigration Institute; Lorena Lagarde González, Director of International Affairs of the National System for the Integral Development of the Family; Luis Jardón Piña, 
Director of International Human Rights Litigation of the Secretariat of Foreign Affairs, and Carlos Ramírez Bracho, Private Secretary of the Head of the National System for the Integral Development of the Family;

For Costa Rica, José Carlos Jiménez Alpízar, Legal Adviser to the Ministry of Foreign Affairs, and Worship, and Fernando Ching Chang, Adviser to the Executive President of the National Child Welfare Institute;

For Guatemala, Ambassador José Rodrigo Vielmann de León, Ambassador of Guatemala to the Organization of American States, Rodrigo Villagrán Sandoval, Director, Monitoring of International Human Rights Cases, and Verónica Jiménez, Deputy Director of the Human Rights Directorate of the Ministry of Foreign Affairs;

For Dominican Republic, the Ambassador Fernando Pérez Memén, Ambassador Extraordinary and Plenipotentiary of the Dominican Republic to the United Mexican States, Santo Miguel Román, Deputy Director of the General Directorate of Immigration attached to the Ministry of the Interior and Police, and José Casado-Liberato, Lawyer-Human Rights Analyst for OAS matters of the Ministry of Foreign Affairs;

For Panama, Magdalena Brandao, Human Rights Lawyer of the Legal Affairs and Treaties Directorate of the Ministry of Foreign Affairs, Rosario Granda, Lawyer, José Cedeño, Lawyer, and Rocío Medina, Lawyer;

For the Inter-American Commission, Commissioner Felipe González; Commissioner Rosa María Ortiz, Commissioner, Emilio Álvarez Icaza L., Executive Secretary, Elizabeth Abi-Mershed, Deputy Executive Secretary, Silvia Serrano Guzmán, Adviser, Jorge Humberto Meza, Adviser;

For UNHCR, Juan Carlos Murillo González, Regional Legal Adviser;

For UNICEF, Karla Gallo, UNICEF National Protection Officer in Mexico; For the IOM, Salvador Gutiérrez, Regional Liaison and Policies Officer;

For the Inter-American Association of Public Defenders (AIDEF), Migdalia Brown;

For the Human Rights Commission of the Federal District, and the Centro para el Desarrollo de la Justicia Internacional, A.C., Fernando Coronado Franco, Nancy Jocelyn López Pérez, Patricia Uribe Granados, Edgar Alejandro Gómez Jaimes, Leonardo Mier Bueno and Mario Patrón Sánchez;

For International Social Service (ISS) and the Red Latinoamericana de Acogimiento Familiar (RELAF), Leticia Irene Virosta;

For the Programa de Defensa e Incidencia Binacional de la Iniciativa Frontera Norte de Mexico, composed of the Centro de Derechos Humanos del Migrante A.C, the Centro de Recursos Migrantes, the

Network of YMCA Homes for Child Migrants, and the Coalición Pro Defensa del Migrante A.C., Silvia

Esmeralda Flores Rodríguez;

For the Centro Estratégico de Litigio Latinoamericano A.C. and the Human Rights Program of the Universidad Veracruzana, Rafael Beltrán Ramos and Chasel Colorado Piña;

For Commission No. 1309 of the Professional Practice Department of the Law Faculty of the Universidad de Buenos Aires, Santiago Gabriel Bertinat Gonnet;

For the Universidad Colegio Mayor de Nuestra Señora del Rosario, María Teresa Palacios Sanabria;

For the Human Rights Center of the Universidad Nacional de Lanús, Diego Lorente and Lourdes Rosas Aguilar;

For the Human Rights Center of the Jurisprudence Faculty of the Pontificia Universidad Católica del Ecuador, Adriana Inés Monesterolo Lencioni; 
For the International Human Rights Law Clinic of the Washington College of Law of the American University on behalf of the Women's Refugee Commission, Kids in Need of Defense, and the Immigrant Children's Legal Program of the U.S. Committee for Refugees and Immigrants (formerly National Center for Refugee and Immigrant Children), Richard J. Wilson, Diana Navas, and Jacqueline Zamarripa;

For the Child Law Clinic at University College Cork, Emily Bartholomew;

For the Law Faculty of the Universidad Nacional Autónoma de Mexico, María Leoba Castañeda Rivas, and Messrs. Álvaro Francisco Amaya Villarreal and Luis Peraza Parga.

14. Following the hearing, supplementary briefs were received from: (1) Luis Peraza Parga; (2) UNHCR; (3) Committee No. 1309; (4) Costa Rica; (5) IOM; (6) Guatemala; (7) the Executive Secretary of the MERCOSUR Institute for Public Policies on Human Rights (IPPDH), on behalf of the applicant States; (8) Child Law Clinic of the University College Cork; (9) Pontificia Universidad Católica of Ecuador; and (10) Brazil.

15. The request for an advisory opinion submitted by the applicant States, the written and oral observations of the participating States, the Inter-American Commission, the Inter-American Children's Institute, different international agencies, State agencies, national and international associations, academic institutions, non-governmental organizations, and members of civil society, can be consulted on the Court's website ${ }^{5}$ and also appear summarized in the annex to this opinion. ${ }^{6}$

\section{JURISDICTION}

16. This request has been submitted to the Court by the applicant States in exercise of the authority granted by Article 64(1) of the American Convention. The applicant States are OAS Member States and, therefore, have the right to request the Inter-American Court to provide advisory opinions on the interpretation of this treaty or other treaties concerning the protection of human rights in the States of the Americas.

17. In addition, the Court considers that, as an organ with jurisdictional and advisory functions, it has the authority inherent in its attributes - even when this has not been contested, as in this case - to determine the scope of its own jurisdiction (compétence de la compétence/Kompetenz-Kompetenz). Moreover, under Article 64(1) of the Convention, this also applies as regards the exercise of its advisory or non-contentious function, as in the case of the exercise of its contentious function, ${ }^{7}$ in particular, because the mere fact of having recourse to this function presupposes the acceptance of the Court's right to decide on the scope of its jurisdiction in this regard by the State or States that make the request.

18. The applicant States require an interpretation of the American Convention, of the Inter-American Convention to Prevent and Punish Torture, and of the American Declaration of the Rights and Duties of Man (hereinafter the "American Declaration" or "Declaration").

19. In the case of the American Convention, the advisory function allows the Court to interpret any of its articles, and no part or aspect of this instrument is excluded. Thus, it is plain that, since the Court is the "ultimate interpreter of the American Convention," 8 it is competent to issue interpretations of all the provisions of the Convention, even those of a procedural nature, with full authority. ${ }^{9}$

20. In addition, the Court has considered that Article 64(1) of the Convention, when referring to the Court's authority to provide an opinion on "other treaties concerning the protection of human rights in the States of the Americas," is broad and non-restrictive. In other words:

[...] the advisory jurisdiction of the Court can be exercised, in general, with regard to any provision dealing with the protection of human rights set forth in any international treaty applicable in the American States, regardless of whether it be bilateral or multilateral, whatever the principal purpose of such a treaty, and whether or not non-Member States of the inter-American system are or have the right to become parties thereto. ${ }^{10}$ 
21. In the case of the Inter-American Convention to Prevent and Punish Torture, this instrument has been adopted within the sphere of the OAS and ratified by 18 Member States. ${ }^{11}$ It is undoubtedly a treaty of regional significance that concerns the protection of human rights and, specifically, protection against torture in the States of the Americas.

22. In addition, Article 64(1) of the American Convention authorizes the Court to render advisory opinions interpreting the American Declaration, within the scope and framework of its jurisdiction in relation to the Charter of the OAS (hereinafter "the Charter") and the Convention or other treaties concerning the protection of the human rights in the States of the Americas. ${ }^{12}$ Consequently, when interpreting the Convention in the context of its advisory function, the Court will have recourse to the American Declaration when necessary and in the terms of Article 29(d) of the Convention.

23. When affirming its jurisdiction, the Court recalls the broad scope of its advisory function, unique in contemporary international law, owing to which, and contrary to the attributes of other international courts, all the organs of the OAS listed in Chapter X of the Charter and the Member States of the OAS are authorized to request advisory opinions, even if they are not parties to the Convention. ${ }^{13}$ Another characteristic of the breadth of this function relates to the purpose of the consultation, which is not limited to the American Convention, but includes other treaties concerning the protection of human rights in the States of the Americas. Moreover, all OAS Member States may request opinions regarding the compatibility of their domestic laws with the aforesaid international instruments. ${ }^{14}$

24. The request complies formally with the requirements described in Articles $70^{15}$ and $71^{16}$ of the Rules of Procedure, according to which, for a request to be considered by the Court, the questions must be formulated precisely, specifying the provisions that must be interpreted, indicating the considerations that gave rise to the request, and providing the name and address of the agent.

25. On numerous occasions, this Court has established that compliance with the regulatory requirements to submit a request for an advisory opinion does not mean that the Court is obliged to respond to it. ${ }^{17}$ Thus, the Court recalls that its advisory jurisdiction should not, in principle, be used for abstract speculation without a foreseeable application to specific situations that justify the issue of an advisory opinion. ${ }^{18}$

26. In this regard, in the request for an advisory opinion, the applicant States indicated that there is a "lack of legislation and public policies related to different issues that are examined in [the] request. [... A] still-frequent feature in some laws and migratory policies is the lack of the corresponding interrelation with the system of protection of the rights of the child, limiting the capability of public institutions to adequately define the measures that they must adopt whenever a child enters a country in an irregular manner" which usually results in "the absence of adequate procedures to identify the different risk situations faced by those children in mixed migration flows."

27. From this perspective, the Court understands that its answer to the request submitted will be of specific usefulness in the context of a regional reality in which aspects relating to State obligations concerning migrant children have not been clearly and systematically established, based on the interpretation of the relevant norms. This usefulness is revealed by the significant interest indicated by all the participants in this advisory procedure. First the request itself, presented by four States, which offers, based on the unified position of the four States, a basic consensual standard in this regard. In addition, 42 briefs with observations were received, submitted by five OAS Member States, the Inter-American Commission, the Inter-American Children's Institute, four international agencies, and 31 institutions and individual members of different organizations, civil society in general, and academic institutions. Similarly, nine OAS Member States, the Inter-American Commission, three international agencies, and 14 institutions and individual members of different organizations, civil society in general and academic institutions played an active role in the public hearing.

28. While recalling that the advisory function constitutes "a service that the Court is able to provide to all the members of the inter-American system, in order to contribute to compliance with their international commitments" in the area of human rights, ${ }^{19}$ the Court considers it critically important to establish with greater precision the rights and guarantees of children in the context of migration - in other words, child migrants and/or in need of international protection, as well as children of migrants. This will lead to the determination of the specific principles and 
obligations that States must comply with in relation to the human rights of children in order to adopt comprehensive protection measures that are sufficient and pertinent in each situation.

29. In this regard, the Court recalls, as it has on other occasions, ${ }^{20}$ that the interpretation task it must perform in the exercise of its advisory function seeks not only to clarify the meaning, purpose and rationale of international human rights law provisions, but, above all, to support the Member States and organs of the OAS so that they are able to meet their relevant international obligations fully and effectively, and to define and implement public policies in the area of human rights, in this case for children in the context of migration. Thus, the Court's interpretations certainly help strengthen the system for the protection of human rights.

30. Consequently, the Court finds that, not only is it not necessarily restricted to the literal terms of the requests submitted to it, but also, in exercise of its non-contentious or advisory jurisdiction and based on the provisions of Article 2 of the Convention and the purpose of advisory opinions "to contribute to compliance with their international commitments" in the area of human rights (supra para. 28), it may suggest the adoption of treaties or other type of international norms on the issues that are the subject of those opinions, as measures of other nature that are necessary in order to ensure the effectiveness of human rights.

31. Similarly, the Court finds it necessary to recall that, pursuant to international law, when a State is a party to an international treaty, such as the American Convention on Human Rights, such treaty is binding for all its organs, including the Judiciary and the Legislature, ${ }^{21}$ so that a violation by any of these organs gives rise to the international responsibility of the State. ${ }^{22}$ Accordingly, the Court considers that the different organs of the State must carry out the corresponding control of conformity with the Convention, ${ }^{23}$ based also on the considerations of the Court in exercise of its non-contentious or advisory jurisdiction, which undeniably shares with its contentious jurisdiction the goal of the inter-American human rights system, which is "the protection of the fundamental rights of the human being." 24 Furthermore, the interpretation given to a provision of the Convention ${ }^{25}$ through an advisory opinion provides all the organs of the Member States of the OAS, including those that are not parties to the Convention but that have undertaken to respect human rights under the Charter of the OAS (Article 3(1)) and the Inter-American Democratic Charter (Articles 3, 7, 8 and 9), with a source that, by its very nature, also contributes, especially in a preventive manner, to achieving the effective respect and guarantee of human rights. In particular, it can provide guidance when deciding matters relating to children in the context of migration and to avoid possible human rights violations.

32. Given the broad scope of the Court's advisory function, which, as previously indicated, encompasses not only the States Parties to the American Convention (supra para. 23), everything indicated in this Advisory Opinion also has legal relevance for all the OAS Member States that have adopted the American Declaration, irrespective of whether they have ratified the American Convention, ${ }^{26}$ as well as for the organs of the OAS whose sphere of competence relates to the matter that is the subject of the request.

33. In sum, the Court considers that it has jurisdiction to rule on the questions posed by the applicant States and does not find in this request any reasons to abstain from doing so; it therefore admits the request and proceeds to decide it.

\section{GENERAL CONSIDERATIONS}

34. In 2013, there were 231,522,215 migrants worldwide and, of these, 61,617,229 corresponded to the Americas. $^{27}$ Meanwhile, of the total number of migrants on our continent, 6,817,466 were under 19 years of age. ${ }^{28}$ According to data from the end of 2013, around 806,000 persons on the American continent were refugees or persons in similar situations as that of refugees. ${ }^{29}$ During that year, more than 25,300 individual requests for asylum were made for children who were unaccompanied or separated in 77 countries around the world. ${ }^{30}$

35. Children migrate internationally for a wide variety of reasons: to seek opportunities, whether economic or educational; to seek family reunification to reunite with family members who had previously migrated; to move from their place of residence owing to gradual or sudden changes in the environment that adversely affect their life and living conditions; to flee from the impact caused by organized crime, natural disasters, domestic abuse, or extreme poverty; to be transported in the context of a situation of exploitation, including child trafficking; to flee their country, whether it be for a well founded fear of persecution for specified reasons or because their lives, 
safety or freedom have been threatened by generalized violence, foreign aggression, internal conflicts, massive violations of human rights, or other circumstances which have seriously disturbed public order. Although children usually travel with their parents, members of their extended family, or other adults, currently, a growing and significant number are migrating autonomously and unaccompanied. ${ }^{31}$

36. International migration is a complex phenomenon that may involve two or more States, including countries of origin, transit and destination, for both migrants and those seeking asylum or refugee status. In this context and, in particular, that of mixed migration flows that entail population movements of a diverse nature, the characteristics of and the reasons for the journey that children undertake by land, sea or air, to countries other than those of which they are nationals or where they habitually reside, may bespeak both persons who require international protection and others who are moving in search of better opportunities for diverse reasons, which may change during the course of the migratory process. This means that the needs and requirements for protection may vary widely.

37. International protection is understood as the protection that a State offers to a foreign person because, in her or his country of nationality or habitual residence, that individual's human rights are threatened or violated and she or he is unable to obtain due protection there because it is not accessible, available and/or effective. While international protection of the host State is tied initially to the refugee status of the individual, various sources of international law - and in particular refugee law, international human rights law and international humanitarian law - reveal that this notion also encompasses other types of normative frameworks for protection. Thus, the expression international protection comprises: (a) the protection received by asylum seekers and refugees on the basis of the international conventions or domestic law; (b) the protection received by asylum seekers and refugees on the basis of the broadened definition of the Cartagena Declaration; (c) the protection received by any foreign person based on international human rights obligations, and in particular the principle of non-refoulement, as well as complementary protection or other forms of humanitarian protection, and (d) the protection received by stateless persons in accordance with the relevant international instruments.

38. It is only possible to ensure the international protection, in accordance with international commitments arising from international human rights law, international humanitarian law, and refugee law, by admitting a potential asylum applicant into a safe country, by guaranteeing the right to seek and receive asylum, and by respecting the principle of non-refoulement, among other rights, until achieving a durable solution.

39. Given this panorama, in its advisory ${ }^{32}$ and contentious jurisprudence, ${ }^{33}$ this Court has insisted on the fact that, in the exercise of their authority to establish immigration policies, ${ }^{34}$ States may establish mechanisms to control the entry into and departure from their territory of persons who are not their nationals, provided that these policies are compatible with the norms for the protection of human rights established in the American Convention. ${ }^{35}$ Indeed, even though States have a margin of discretion when determining their immigration policies, the objectives sought by such policies must respect the human rights of migrants. ${ }^{36}$ This does not mean that States cannot take any action against migrants who fail to comply with their laws but rather that, when adopting the corresponding measures, States must respect human rights and ensure the exercise and enjoyment of these rights to all persons subject to their jurisdiction, without any discrimination. In addition, States must respect the relevant international obligations resulting from international instruments on international humanitarian law and on refugee law.

40. In this regard, States have undertaken " $\mathrm{t}$ ] o promote the strengthening of human rights as a key component of the immigration policies and practices of the countries of origin, transit, and destination, ensuring the protection of the human rights of migrants within the framework of the laws of each State, regardless of their immigration status, nationality, ethnic origin, gender, or age." 37 They have also reiterated their commitment to those who have the right to international protection of refugees in Latin America. ${ }^{38}$

41. The foregoing signifies the urgent need to adopt a human rights approach to immigration policies ${ }^{39}$ and with regard to the needs for international protection, ${ }^{40}$ assuming that these different branches of international law are interrelated and converging. But, even more, in the case of children an approach aimed at the comprehensive protection and guarantee of their rights must prevail. ${ }^{41}$

42. From this perspective, the Court considers it pertinent, first, to establish the interpretation methodology it will use to respond to the request that has been submitted, and also to establish the general obligations and guiding 
principles that will be applied transversally to each and every one of the questions to be dealt with. Thus, the Court notes that the different questions posed in the request submitted by the applicant States cover a series of stages in the migratory process, starting with the child's initial contact with the authorities of the host State when she or he crosses the border up until the achievement of a durable solution.

43. The first question, which will be dealt with in Chapter VII, refers to the moment following entry and relates to the procedures to identify the need for international protection, based on various situations that may jeopardize the rights of children, and where necessary the adoption of adequate special protection measures.

44. Chapters VIII to XII refer exclusively to immigration procedures relating to an irregular situation in cases in which it is not considered that international protection is required. In this context, the questions dealt with relate to issues concerning the principle of the non-detention of children based on an irregular migratory situation, priority measures that do not involve deprivation of liberty, State obligations when holding children in custody, and the guarantees applicable in both migratory proceedings and in situations that affect personal liberty.

45. Chapter XIII relates to the question concerning the principle of non-refoulement. Non-refoulement is conceptualized as a principle that makes the right to seek and receive asylum effective and as an autonomous right established in the Convention as well as an obligation derived from the prohibition of torture and from other human rights norms and, in particular, the protection of the child.

46. Chapter XIV describes the procedures to ensure the right of children to seek and receive asylum, which only conclude when a durable solution has been achieved, whether voluntary repatriation in safe and decent conditions to the country of origin, local integration in the receiving country, or resettlement in a safe third country.

47. Lastly, Chapter XV refers to the specific situation of children whose parents are faced with expulsion or deportation for migratory reasons, which makes it necessary to establish the scope of the rights of the family and the prohibition of arbitrary or abusive interference in family life.

48. Finally, it should be recalled that one of the inherent faculties of this Court is that of structuring its rulings in the way that it considers most appropriate for the interests of justice and the effects of an advisory opinion. In this Advisory Opinion, the Court has decided, first, to establish a glossary in order to delimit the conceptual scope of the terms used, and will then proceed to analyze the specific matters submitted to its consideration, so as to answer the questions that have been posed in the order presented by the applicant States.

49. For the purposes of this Advisory Opinion, the Court will use the following terms with the meaning indicated:

a) child

b) unaccompanied children

c) separated children

d) emigrant
e) to immigrate
f) immigrant
g) migrant
h) immigration status
i) State or country of origin
j) recipient or host State
k) stateless person
l) asylum seeker

every human being below the age of eighteen years ${ }^{42}$ unless, under the law applicable to the child, majority is attained earlier. The term "child" used in this Advisory Opinion evidently includes adolescents.

children who have been separated from both parents and other relatives, and are not being cared for by an adult who, by law or custom, is responsible for doing so. ${ }^{43}$

children who have been separated from both parents, or from their previous legal or customary primary caregiver, but not necessarily from other relatives. These may, therefore, include children accompanied by other adult family members. ${ }^{44}$

a person who leaves a State in order to move to another and establish himself there. ${ }^{45}$ to enter another State in order to reside there. ${ }^{46}$

a person who enters another State in order to reside there. ${ }^{47}$

a generic term that covers both emigrants and immigrants. ${ }^{48}$

legal status of a migrant, in accordance with the domestic law of the host State. ${ }^{49}$

State or country of which a person is a national or, in case of a stateless person, the State or country of habitual residence.

State to which a person travels, either in transit or the actual destination.

a person who is not considered as a national by any State under the operation of its law.

a person who has sought the recognition of refugee status and whose petition is pending determination. 
m) refugee

n) international protection a person who has a well founded fear of being persecuted for reasons of race, religion, nationality, membership of a particular social group or political opinion, and is outside of her or his country of origin and because of this fear is unable or unwilling to return to her or his country of origin; or a person who lacks a nationality and because of this, is outside of her or his former habitual residence, and is unable or, unwilling to return based on fear. The term "refugee" is also applicable to those who have fled their countries of origin because their lives, safety, or freedom have been threatened by generalized violence, foreign aggression, internal conflicts, massive violations of human rights, or other circumstances which have seriously disturbed public order. the protection that a State offers to a foreign person because, in her or his country of nationality or habitual residence, that individual's human rights are threatened or violated and she or he is unable to obtain due protection there because it is not accessible, available and/or effective.

50. As requested by the applicant States, this Advisory Opinion will now determine, as precisely as possible and in accordance with the provisions consulted, the State obligations with regard to children associated with their migratory status or that of their parents, which, consequently, States must take into consideration when designing, adopting, implementing and applying their immigration policies.

\section{INTERPRETATION CRITERIA}

51. The Inter-American Court's mandate consists, essentially, in the interpretation and application of the American Convention $^{50}$ or other treaties for which it has jurisdiction, ${ }^{51}$ in order to determine, in accordance with both treaty-based and customary international law, the international responsibility of the State under international law. ${ }^{52}$ The Court recalls, as it has on other occasions, ${ }^{53}$ that the task of interpretation which it must perform in the exercise of its advisory function differs from its contentious jurisdiction in that there are no "parties" involved in the advisory procedure, nor is there a litigation to decide. The essential purpose of the advisory function is to obtain a judicial interpretation of one or several provisions of the Convention or other treaties relating to the protection of human rights in the States of the Americas. ${ }^{54}$

52. In order to issue an opinion on the interpretation of the legal provisions referred to in the request, the Court will refer to the Vienna Convention on the Law of Treaties, which reflects the general rules of interpretation of international treaties that are of a customary nature, ${ }^{55}$ and thus involves the simultaneous application of good faith, the natural meaning and context of the terms used in the treaty in question, as well as the object and purpose of the treaty. The pertinent part of this Convention indicates:

Article 31. General rules of interpretation. 1. A treaty shall be interpreted in good faith in accordance with the ordinary meaning to be given to the terms of the treaty in their context and in the light of its object and purpose. [...]

Article 32. Supplementary means of interpretation. Recourse may be had to supplementary means of interpretation, including the preparatory work of the treaty and the circumstances of its conclusion, in order to confirm the meaning resulting from the application of article 31 , or to determine the meaning when the interpretation according to Article 31:

(a) leaves the meaning ambiguous or obscure; or

(b) leads to a result which is manifestly absurd or unreasonable.

53. In the case of the American Convention, the object and purpose of the treaty is "the protection of the fundamental rights of the human being,", 56 and, therefore, it was designed to protect the human rights of the individual regardless of his nationality, vis-à-vis his own State or any other. ${ }^{57}$ On this point, it is essential to recall the specific nature of human rights treaties, which create a legal order under which the States Parties assume obligations towards the persons subject to their jurisdiction. ${ }^{58}$ The violation of such treaties can be claimed by these persons through the action of the Commission ${ }^{59}$ and even before the Court, ${ }^{60}$ all of which means that the norms should also be interpreted based on a model supported by the values that the inter-American system seeks to safeguard from the perspective of the "best approach" for the protection of the individual. ${ }^{61}$ 
54. It is in this sense that the American Convention expressly establishes specific standards of interpretation in its Article $29,{ }^{62}$ which includes the pro persona principle, which means that no provision of the Convention may be interpreted as restricting the enjoyment or exercise of any right or freedom recognized by virtue of the laws of any State Party or by virtue of another convention to which one of the said States is a party, or excluding or limiting the effect that the American Declaration of the Rights and Duties of Man and other international acts of the same nature may have.

55. In addition, the Court has indicated repeatedly that human rights treaties are living instruments, the interpretation of which must evolve with the times and current living conditions. ${ }^{63}$ This evolutive interpretation is consistent with the general rules of interpretation established in Article 29 of the American Convention, as well as those established by the Vienna Convention on the Law of Treaties. ${ }^{64}$

56. Added to the above, it should be recalled that this Advisory Opinion focuses on the rights and guarantees of children at the different stages of the migratory process. In its Advisory Opinion OC-17/02, the Court established that a child should be understood as "every human being below the age of eighteen years unless, under the law applicable to the child, majority is attained earlier." ${ }^{65}$ Children are entitled to the human rights that correspond to all human beings and also enjoy special rights derived from their condition to which specific obligations of the family, society and the State correspond. ${ }^{66}$

57. In this regard, the Court has repeatedly stressed the existence of a "very comprehensive corpus iuris of international law on the protection of the rights of the child," which the Court must use as a source of law to establish "the content and scope" of the obligations that States have assumed under Article 19 of the American Convention ${ }^{67}$ with regard to children; particularly, by specifying the "measures of protection" to which this article refers. ${ }^{68}$ Specifically, the Court has previously emphasized that the Convention on the Rights of the Child ${ }^{69}$ is the most universally ratified international treaty, which "reveals a broad international consensus (opinio iuris comunis) favorable to the principles and institutions protected by this instrument, which reflects the actual evolution of this matter;" been ratified by almost all the Member States of the Organization of American States. In the context of this Advisory Opinion, the Court wishes to underscore that although it is not incumbent on the Court to issue a direct interpretation of the Convention on the Rights of the Child, because its provisions are not the subject of the request, the principles and rights recognized therein undoubtedly contribute decisively to establishing the scope of the American Convention when the individual entitled to the rights is a child. In this regard, the Committee on the Rights of the Child has clarified that "the enjoyment of rights stipulated in the Convention [on the Rights of the Child] are not limited to children who are citizens of a State party and must therefore, if not explicitly stated otherwise in the Convention, also be available to all children - including asylum-seeking, refugee and migrant children - irrespective of their nationality, immigration status or statelessness." ${ }^{, 1}$

58. Based on the matter which is the subject of the request, which relates essentially to children outside of their country of origin and who are under the jurisdiction of a State of which they are not a national or, if they are stateless, which does not correspond to their habitual residence, the Court will take into consideration, as additional sources of international law, other relevant conventions to which the States of the Americas are party in order to make an interpretation that is in harmony with the international obligations in the terms of the provision cited. In particular, the Court will consider the applicable treaties, and the related jurisprudence and decisions, as well as resolutions, rulings, and declarations that have been adopted on an international level.

59. Consequently, since this is a matter in which the rights of the child merge with the rights of migrants in the diverse situations that surround migration, in this Advisory Opinion, the Court will interpret and provide content to the rights recognized in the Convention, in keeping with the evolution of the existing international corpus iuris concerning the human rights of children and of migrants, and with regard to the international protection that States must provide - specifically international refugee law - bearing in mind that the international community has recognized the need to adopt special measures to ensure the protection of the human rights of these vulnerable groups. ${ }^{72}$

60. In brief, in responding to this request, the Court acts in its capacity as a human rights court, guided by the norms that govern its advisory jurisdiction, and proceeds to make a strictly juridical analysis of the questions posed, pursuant to international human rights law, taking into account the relevant sources of international law. In this 
regard, it should be indicated that the corpus iuris of international human rights law consists of a series of rules expressly recognized in international treaties or established in international customary law as evidence of a general practice accepted as law, as well as of the general principles of law and of a series of general norms or soft law, that serve as guidelines for the interpretation of the former, because they provide greater precision to the basic contents of the treaties. The Court will also base its opinion on its own case law, regarding children as well as the rights of migrants, asylum seekers and refugees.

\section{GENERAL OBLIGATIONS AND GUIDING PRINCIPLES}

61. In this regard, and despite referring to them again below, the Court considers that it is extremely important at this point, and as an introduction, to refer explicitly to three provisions of the American Convention that inspire the whole formulation of this Advisory Opinion. The first provision refers to Article 1(1) of the Convention that establishes the State's obligation to respect and ensure the human rights of "all persons subject to [the] jurisdiction" of the State in question, that is, of every person in the territory ${ }^{73}$ or who is in any way subjected to its authority, responsibility or control - in this case upon trying to enter the territory - and without any discrimination for the reasons stipulated in the norm. ${ }^{74}$ Thus, the word "jurisdiction" used by this article refers to every person regarding whom the State exercises either its territorial jurisdiction ${ }^{75}$ or its personal jurisdiction ${ }^{76}$ and even, its jurisdiction concerning public services. ${ }^{77}$ Nevertheless, this Advisory Opinion will only consider the situation as it relates to the first element, particularly in its factual dimension, which is the effective subjection of the person, in this case of the foreign child, to the jurisdiction of the said State from the moment that this child tries to enter its territory.

62. The second consideration regarding the content of this provision of the Convention is that the said territorial jurisdiction of the State is limited by the undertaking that it has made, in exercise of its sovereignty, ${ }^{78}$ to respect and to ensure respect for the human rights of the persons subject to its jurisdiction. This means, then, that the motive, cause or reason why the person is in the State's territory has no relevance as regards the State's obligation to respect and to ensure that her or his human rights are respected. In particular, it has no significance whatsoever in this regard whether or not the entry of that person into the State's territory was in keeping with the provisions of its laws. The respective State must, in all circumstances, respect the said rights, because they are based, precisely, on the attributes of the human personality; ${ }^{79}$ in other words, regardless of whether the person is a national or resident of its territory or whether the person is there temporarily, in transit, legally, or in an irregular migratory situation.

63. However, the Court finds it necessary to add that, although the main obliged in the situation submitted in this Advisory Opinion is the State that receives the foreign child, this does not mean that the child's State of origin does not have any obligation in relation to this situation derived, evidently, from its personal jurisdiction. As will be referred to below (infra paras. 126 to 128 and 202 to 203), the mechanism of consular assistance is inserted in this context. Nevertheless, in this Advisory Opinion, the Court has considered it more adequate not to delve on the obligations of the child migrant's State of origin with regard to this child, which relate to the exercise of its personal jurisdiction and to its jurisdiction with regard to public services. Rather it will restrict itself to the issue raised, which refers to the obligations of the host State, be it of transit or destination, in relation to the migrant children with regard to whom it exercises its territorial jurisdiction or who are otherwise subject to its jurisdiction.

64. Although the Court will not delve into the obligations of the State of origin, it is pertinent to remember that these States must observe the general obligations in the matter and in particular their duty of prevention, which requires the State to generate and secure conditions for their nationals so that they are not forced to migrate, and to address the root causes of migration flows.

65. The second provision that should be cited as an introductory element is Article 2 of the Convention. In this regard, the Court has already referred to the general obligation of the States to adapt their domestic law to the provisions of the American Convention established in that article, which stipulates that the States Parties must adapt their domestic law to the provisions of the Convention in order to ensure the rights recognized therein, which means that the measures of domestic law must be effective (principle of the practical effects or effet utile). ${ }^{80}$ This obligation entails, on the one hand, the elimination of norms and practices of any kind that results in a violation of the guarantees established in the Convention and, on the other hand, the enactment of laws and the implementation 
of practices that encourage the effective observance of these guarantees. ${ }^{81}$ The State obligation to adapt its domestic laws to the provisions of the Convention is not limited to the constitutional or legislative texts but must permeate all the legal provisions of a regulatory nature and result in the practical application of the standards for the protection of the human rights of migrants. ${ }^{82}$

66. The third provision that, in general terms, imbues this Advisory Opinion is Article 19 of the Convention, that equally to Article VII of the Declaration, ${ }^{83}$ concerns the obligation to adopt measures of protection in favor of all children, based on their condition as such, and this has an impact on the interpretation of all the other rights established when the case relates to children. The Court understands that the protection due to the rights of the child, as subjects of law, must take into consideration their intrinsic characteristics and the need to foster their development, offering them the necessary conditions to live and develop their aptitudes taking full advantage of their potential. ${ }^{84}$ In this regard, it should be emphasized at this point that these provisions are one of the few that is contemplated on the basis of, or taking into consideration, the specific and characteristic condition of the beneficiary. ${ }^{85}$ Thus, children exercise their own rights progressively as they develop a greater level of personal autonomy. ${ }^{86}$ For this reason, the Convention stipulates that the pertinent measures of protection for children must be special or more specific than those established for the rest of the population, i.e., the adults. In this regard, it should be recalled that the Court has indicated that children enjoy the same rights as adults and also possess additional rights. Therefore, Article 19 "should be understood as an additional, supplementary right that the treaty establishes for individuals that, owing to their physical and emotional development, require special protection." ${ }^{87}$ To this end, the Convention and the Declaration vest a preferential treatment for children, precisely because of their special vulnerability and, in this way, endeavors to provide them with the adequate mechanism to achieve the effective equality before the law enjoyed by adults, owing to their condition as such.

67. However, this article is also almost the only one in the Convention that recognizes an obligation not only upon the State ${ }^{88}$ but also for society and the family. Evidently, it is with regard to the latter that the State has the obligation to ensure that the society and the family adopt the measures of protection that all children require from them. Hence, the right that all children have regarding the adoption of said measures of protection is established in broader terms than other rights embodied in the Convention because, in this case, it is not only a matter of the State respecting a human right or ensuring that it is respected in its territory and by all persons subject to its jurisdiction by adopting the pertinent measures, but also of the corresponding family and society. Thus, the measures of protection that the child requires, owing to its condition as such and that are adopted by the State may be, in themselves, insufficient and must, therefore, be complementary to those that society and the family must adopt. From this point of view, the statute of the child is not limited to the sphere of its relationship with the State, but rather it extends to the relationship that it has or should have with her or his family and with society as a whole. Moreover, the State should enable and guarantee these relationships and, in the case of migrant children, should ensure that adults are not using them for their own migratory purposes and that if, despite everything, this should occur, that the children do not end up prejudiced.

68. Based on all the foregoing, the Court finds that, when designing, adopting and implementing their immigration policies for persons under the age of 18 years, the State must accord priority to a human rights-based approach, from a crosscut perspective that takes into consideration the rights of the child and, in particular, the protection and comprehensive development of the child. The latter should prevail over any consideration of her or his nationality or migratory status, in order to ensure the full exercise of her or his rights ${ }^{89}$ in relation to Articles 1(1), 2, and 19 of the American Convention and VII of the American Declaration.

69. When the protection of the rights of the child and the adoption of measures to achieve this protection is involved, the following four guiding principles of the Convention on the Rights of the Child should transversely inspire and be implemented throughout every system of comprehensive protection: ${ }^{90}$ the principle of nondiscrimination, ${ }^{91}$ the principle of the best interest of the child, ${ }^{92}$ the principle of respect for the right to life, survival and development, ${ }^{93}$ and the principle of respect for the opinion of the child in any procedure that affects her or him in order to ensure the child's participation. ${ }^{94}$ When interpreting the provisions cited in the request, the Court will also apply these guiding principles, as appropriate, in order to respond to each question and to identify the special measures that are required to make the rights of the child effective. 
70. Meanwhile, it should be recalled that, as a guideline, the principle of the best interest entails both its priority consideration in the design of public policies and the drafting of laws and regulations concerning childhood, and in its implementation in all the spheres that related to the life of the child. ${ }^{95}$ In the context of migration, any immigration policy that respects human rights, as well as any administrative or judicial decision concerning the entry, stay or expulsion of a child, or the detention, expulsion or deportation of her or his parents associated with their own migratory status, must give priority to the assessment, determination, consideration and protection of the best interest of the child concerned. Closely related to this, is the obligation to respect fully the right of the child to be heard with regard to all the aspects of immigration and asylum proceedings, and that her or his views be adequately taken into account. $^{96}$

71. However, the Court considers that it is essential to assess not only the requirement of special measures in the terms described above, but also to consider personal factors, such as disability, being a member of an ethnic minority group, or living with HIV/AIDS, as well as the particular characteristics of the situation of vulnerability of the child, such as a victim of trafficking, or separated or unaccompanied, ${ }^{97}$ for the purpose of determining the need for specific additional positive measures. Consequently, in application of the principle of the effet util and the needs for protection in cases of persons or groups in a vulnerable situation, ${ }^{98}$ the Court will also place special emphasis on those conditions and circumstances in which migrant children may find themselves in a situation of additional vulnerability that entails an increased risk of violation of their rights so that the State must adopt measures to prevent and reverse this type of situation as a priority, as well as to ensure that all children, without exception, may fully enjoy and exercise their rights under equal conditions.

\section{PROCEDURES TO IDENTIFY INTERNATIONAL PROTECTION NEEDS OF MIGRANT CHILDREN AND, AS APPROPRIATE, TO ADOPT MEASURES OF SPECIAL PROTECTION}

72. The Inter-American Court has been consulted on the procedures that should be adopted in order to identify the different risks to the rights of child migrants, to determine the needs for international protection, and to adopt, as appropriate, the special measures of protection required in light of Articles $1,{ }^{99} 2,{ }^{100} 5,{ }^{101} 7,{ }^{102} 8,{ }^{103} 19,{ }^{104} 22(7){ }^{105}$ and $25^{106}$ of the American Convention and of Articles I, ${ }^{107} \mathrm{XXV}^{108}$ and XXVII ${ }^{109}$ of the American Declaration of the Rights and Duties of Man.

73. The Court has previously recognized ${ }^{110}$ that both, Article 22(7) of the American Convention on Human Rights and Article XXVII of the American Declaration of the Rights and Duties of Man, have enshrined the subjective right of all persons, including children, to seek and receive asylum, thereby overcoming the historical understanding of this mechanism as a "mere State prerogative" under various inter-American conventions on asylum. ${ }^{111}$

74. In this regard, it is pertinent to recall that the text itself of Articles 22(7) of the Convention and XXVII of the Declaration establishes two criteria for determining those who are entitled to this right; on the one hand, "the legislation of each country," that is, of the country in which asylum is sought and, on the other hand, "international conventions." "112 In other words, it is international conventions or domestic laws that regulate the situations under which an individual may exercise the right to seek and receive asylum and accede to international protection. ${ }^{113}$ Thus, it should be recalled that although the concept of asylum was initially rooted in the notion of the Latin American tradition of asylum, which consisted of diplomatic and territorial asylum and non-extradition for political motives or offenses, ${ }^{114}$ the truth is that, following the adoption of the 1951 Convention relating to the Status of Refugee $^{115}$ (hereinafter the "1951 Convention") and its 1967 Protocol, ${ }^{116}$ the mechanism of asylum assumed a specific form and modality at the universal level: that of the status of refugee.

75. Under the 1951 Convention and its 1967 Protocol, the inclusion criteria for making a determination of refugee status are: (a) to be outside the country of origin, namely the country of nationality or, in case of stateless persons, the country of habitual residence; (b) to have a well-founded fear; (c) of persecution or threat of persecution; (d) based on race, religion, nationality, membership of a particular social group or political opinion; and (e) to be unable or, owing to such fear, to be unwilling to avail oneself of the internal protection of the country of origin. The definition of refugee is integral, which means that each and every one of these requirements must be met in order to obtain recognition. 
76. In addition, with the adoption 30 years ago, in 1984, of the Cartagena Declaration, ${ }^{117}$ which although it is not an agreement between States it has been supported by the OAS since 1985, ${ }^{118}$ the definition of refugee has been expanded as follows:

Third: To reiterate that, in view of the experience gained from the massive flows of refugees in the Central American area, it is necessary to consider enlarging the concept of a refugee, bearing in mind, as far as appropriate and in the light of the situation prevailing in the region, the precedent of the OAU Convention (article 1, paragraph 2) and the doctrine employed in the reports of the Inter-American Commission on Human Rights. Hence the definition or concept of refugee to be recommended for use in the region is one which, in addition to containing the elements of the 1951 Convention and the 1967 Protocol, includes among refugees persons who have fled their countries because their life, safety or freedom have been threatened by generalized violence, foreign aggression, internal conflicts, massive violation of human rights or other circumstances which have seriously disturbed public order.

77. Accordingly, various Members States of the OAS have incorporated the provisions of the international instruments relating to refugees into their domestic law, even basing this on guidelines established by UNHCR, ${ }^{119}$ and have adopted the expanded definition of refugee ${ }^{120}$ to include, in addition to the criteria of the 1951 Convention and its 1967 Protocol, "persons who have fled their countries because their lives, safety or freedom have been threatened by generalized violence, foreign aggression, internal conflicts, massive violation of human rights or other circumstances which have seriously disturbed public order."121

78. In sum, by a harmonious interpretation of the internal and international laws that permeate, in a converging and complementary manner, the content of the right established in Articles 22(7) of the Convention and XXVII of the Declaration, and taking into account the specific standards of interpretation contained in Article 29 of the American Convention (supra para. 54) the Court is of the opinion that the right to seek and receive asylum in the context of the inter-American system is enshrined as an individual human right to seek and receive international protection on foreign territory, including with this expression refugee status in accordance with pertinent instruments of the United Nations or corresponding domestic legislation, as well as asylum in accordance with the different interAmerican conventions on this matter.

79. Additionally, the Court notes that the developments produced in refugee law in recent decades have led to state practices, which have consisted in granting international protection as refugees to persons fleeing their country of origin due to generalized violence, foreign aggression, internal conflicts, massive violations of human rights, or other circumstances which have seriously disturbed public order. Bearing in mind the progressive development of international law, the Court considers that the obligations under the right to seek and receive asylum are operative with respect to those persons who meet the components of the expanded definition of the Cartagena Declaration, which responds not only to the dynamics of forced displacement that originated it, but also meets the challenges of protection derived from other displacement patterns that currently take place. This criterion reflects a tendency to strengthen in the region a more inclusive definition that must be taken into account by the States to grant refugee protection to persons whose need for international protection is evident.

80. Nevertheless, it should be recognized that the elements of the definition of refugee were traditionally interpreted based on the experiences of adults or persons over 18 years of age. ${ }^{122}$ Hence, in view of the fact that children are entitled to the right to seek and receive asylum ${ }^{123}$ and may, in consequence, submit applications for recognition of refugee status in their own capacity, whether or not they are accompanied, the elements of the definition should be interpreted taking into account the specific forms that child persecution may adopt, such as recruitment, trafficking, and female genital mutilation, ${ }^{124}$ as well as the way in which they may experience these situations. ${ }^{125}$ Thus, the Committee on the Rights of the Child has stressed that the definition of refugee must be interpreted in light of age and gender. ${ }^{126}$ Moreover, in addition to the traditional reasons for seeking refuge mentioned above, it is pertinent to be aware of the new factors that lead individuals and, in particular children, to be forcibly displaced from their countries of origin, among which transnational organized crime and the violence associated with the actions of non-State groups stand out. 
81. In the terms of Articles $1(1)^{127}$ and $2^{128}$ of the American Convention, this right to seek and receive asylum entails certain specific obligations on the part of the host State, which include: (i) to allow children to request asylum or refugee status, which consequently means they may not be rejected at the border without an adequate and individualized analysis of their requests with due guarantees by the respective procedure; (ii) not to return children to a country in which their life, freedom, security or personal integrity may be at risk, or to a third country from which they may later be returned to the State where they suffer this risk; and (iii) to grant international protection when children qualify for this and to grant the benefit of this recognition to other members of the family, based on the principle of family unity. ${ }^{129}$ All the above signifies, as the Court has previously underlined, the corresponding right of those seeking asylum to be ensured a proper assessment by the national authorities of their requests and of the risk that they may suffer in case of return to the country of origin. ${ }^{130}$

82. Consequently, owing to the range of situations that may lead a child to emigrate from her or his country of origin (supra para. 35), it is relevant to distinguish between those who emigrate in search of opportunities to improve their standard of living from those who require a form of international protection including, but not limited to protection for refugees and asylum seekers (supra para. 37). Therefore, in order to comply with international undertakings, States are obliged to identify foreign children who require international protection within their jurisdictions, either as refugees or of another type, through an initial evaluation with guarantees of safety and confidentiality, in order to provide them with the adequate and individualized treatment required by means of special measures of protection. The Court considers that the establishment of procedures to identify the needs for protection is a positive obligation of the States and failing to institute them represents a lack of due diligence. ${ }^{131}$

83. The Court considers that, based on the international provisions cited including, in particular, Articles 19 of the Convention and VII of the Declaration, the border authorities should not prevent the entry of foreign children into national territory, even when they are alone, should not require them to produce documentation that they may not have, and should proceed to direct them immediately to personnel who are able to assess their needs for protection based on an approach in which their condition as children prevails. In this regard, it is essential that States allow a child access to the territory as a prerequisite to the initial assessment process. ${ }^{132}$ Furthermore, the Court considers that a database must be created to register children who enter the country in order to ensure an adequate protection of their rights. ${ }^{133}$

84. The Court considers that the initial evaluation process should include effective mechanisms for obtaining information following the child's arrival at the entry place, post or port, or as soon as the authorities are aware of her or his presence in the country, in order to determine her or his identity and, if possible, that of the parents and siblings, in order to transmit this to the State agencies responsible for making the evaluation and providing the measures of protection, based on the principle of the child's best interest. In this regard, the Committee on the Rights of the Child has stipulated that "[a] determination of what is in the best interest of the child requires a clear and comprehensive assessment of the child's identity, including her or his nationality, upbringing, ethnic, cultural and linguistic background, particular vulnerabilities, and protection needs." 134 This information should be obtained by a procedure that takes into account the difference between children and adults, and the treatment should be in line with the situation. ${ }^{135}$

85. This initial assessment procedure must be performed in a friendly environment and must provide guarantees of security and privacy, as well as be performed by qualified professionals who are trained in age and gender sensitive related interviewing techniques. ${ }^{136}$ In addition, States must take into account the basic procedural guarantees in keeping with the principles of the child's best interest and comprehensive protection, which include, but are not limited to, the following: that the interview is conducted in a language the child understands; ${ }^{137}$ that it should be child-centered, gender-sensitive, and guarantee the child's participation; ${ }^{138}$ that the analysis takes into account safety and possible family reunification; ${ }^{139}$ that the child's culture and any reluctance to speak in the presence of adults or family members ${ }^{140}$ is acknowledged; ${ }^{141}$ that an interpreter is provided if required $;{ }^{142}$ that adequate installations and highly qualified personnel are available for interviewing children; ${ }^{143}$ that legal assistance is provided if required; ${ }^{144}$ that clear and comprehensive information is provided on the child's rights and obligations and on the follow-up to the process. ${ }^{145}$ 
86. Since this is an initial stage of identification and assessment, the Court considers that apart from offering certain minimum guarantees, the procedural mechanisms that the States adopt must be designed, in accordance with the practice generally followed, to achieve the following basic priority objectives: (i) treatment in keeping with the child's condition as such and, in case of doubt about the age, assessment and determination of this; (ii) determination of whether the child is unaccompanied or separated; (iii) determination of the nationality of the child or, where appropriate, of her or his statelessness; (iv) obtaining information on the reasons for the child's departure from the country of origin, on her or his separation from the family if this is the case, on the child's vulnerabilities and any other element that reveals or refutes the need for some type of international protection, and (v) adoption of special measures of protection, if necessary and pertinent in view of the best interest of the child. The data should be collected during the initial interview and recorded adequately so as to ensure the confidentiality of the information. ${ }^{146}$

87. The Court will now develop the specific components of these basic priority objectives that should be met during the initial evaluation process; however, this does not mean that the matters to be dealt with must, of necessity, be limited to those indicated by the Court; in other words that they are of a taxative nature, or that they are necessarily successive stages.

Treatment in keeping with the child's condition as such and, in case of doubt about the age, assessment and determination of this

88. Verification of a person's age is a crucial matter, because determination that the person concerned is under 18 years of age, requires that the treatment provided by the State must be urgent, differentiated, and exclusively in keeping with this condition. If there are any doubts about the age, ${ }^{147}$ this must be determined based not only on the physical appearance, but also on the psychological maturity of the individual. ${ }^{148}$ If it is appropriate, an assessment must be conducted in a scientific and safe manner, respecting human dignity that is gender-based and culturally appropriate. ${ }^{149}$ If uncertainty remains about the age, it should be considered that the individual is a child, and she or he should be treated as such, i.e., the State must grant "the individual the benefit of the doubt such that if there is a possibility that the individual is a child, she or he should be treated as such."150

\section{Determination of whether the child is unaccompanied or separated}

89. An early determination of whether a child is unaccompanied or separated from her or his family (supra para. 49) must be conducted immediately upon arrival, ${ }^{151}$ owing to the child's heightened vulnerability in these circumstances; ${ }^{152}$ accordingly, the State must be more thoroughgoing, and several differentiated guarantees apply, which will be described in the following chapters. The reasons for being separated from the family or unaccompanied should also be recorded. ${ }^{153}$

90. In this regard, the Court stresses that the situation of being unaccompanied or separated exposes children to "various risks that affect their life, survival and development such as trafficking for purposes of sexual or other exploitation or involvement in criminal activities which could result in harm to the child, or in extreme cases, in death," $" 154$ especially in those countries or regions where organized crime is present.

91. In particular, children who are unaccompanied or separated from their family and who are away from their country of origin are particularly vulnerable to child trafficking, ${ }^{155}$ exploitation and abuse. ${ }^{156}$ The Court recognizes that female children may be even more vulnerable to trafficking, ${ }^{157}$ especially for purposes of sexual and labor exploitation. ${ }^{158}$ For this reason, it is essential that States adopt all necessary measures to prevent and combat trafficking in persons ${ }^{159}$ including, above all, all those measures of investigation, protection of victims, and mass media campaigns. ${ }^{160}$

92. In particular, States have the obligation to adopt specific border control measures in order to prevent, detect, and prosecute any type of trafficking of persons. ${ }^{161}$ To this end, they must have available specialized officials responsible for identifying all victims of trafficking in persons, paying special attention to women and/or child victims. ${ }^{162}$ To this end, it is essential that the victims' declaration is received in order to establish her or his identity and to discover the reasons why she or he left the country of origin, ${ }^{163}$ taking into consideration that victims of trafficking can be refugees where all conditions are met. ${ }^{164}$ To ensure adequate treatment of victims or potential victims of child 
trafficking, States must provide adequate training for those officials who work at the border, especially concerning matters relating to child trafficking, so as to be able to provide children with effective counseling and comprehensive assistance. $^{165}$

93. When children are accompanied by adults, the border or other authorities must ensure that the children know those accompanying them in order to avoid cases of trafficking and exploitation. ${ }^{166}$ This does not mean, in any way, that in all cases in which a child is traveling independently and is accompanied by an adult who is not a relative, the corresponding authorities should automatically consider this to be a case of trafficking and return the child to her or his country of origin. In this regard, the strictest diligence is required of the border authorities to identify the different situations that require them to intervene in a timely, adequate and fair manner.

\section{Determination of the nationality of the child or, where appropriate, of her or his statelessness}

94. A stateless person is "a person who is not considered as a national by any State under the operation of its law."167 This condition may occur for several reasons, including loss of nationality; deprivation of nationality; the interpretation or application of laws relating to the acquisition of nationality and State succession. On this basis, the Court understands that the condition of statelessness is proven by considering the explanation given, merged with information from the country of origin. The Court reiterates that statelessness results in a condition of extreme vulnerability, ${ }^{168}$ and States have the duty to identify, ${ }^{169}$ prevent and reduce statelessness, as well as protect a stateless person. ${ }^{170}$ Among other measures, States are obliged not to adopt practices or laws relating to the granting of nationality the application of which encourages the increase in the number of stateless person and to grant their nationality to a person born on their territory who would otherwise be stateless. ${ }^{171}$

95. The determination of nationality, or where appropriate, of statelessness, is relevant in diverse situations, such as the following: ${ }^{172}$ (i) when a person's right to stay in a country during expulsion proceedings is questioned; (ii) in identifying the country or countries for which the person claims to have a well-founded fear of persecution, within the meaning of the refugee definition; or (iii) when a person seeks the application of the guarantees established in the 1961 Convention on the Reduction of Statelessness. ${ }^{173}$

96. In the context of migration, the host State of the migrant child is obliged to establish if the child is stateless, whether refugee or not, in order to provide the adequate protection. ${ }^{174}$ Depending on the reasons for leaving the country of habitual residence, the State should refer the child to a procedure for determining refugee status and/or statelessness, or to a complementary protection mechanism. ${ }^{175}$

Obtaining information on the reasons for the child's departure from the country of origin, on her or his separation from the family if this is the case, and on the child's vulnerabilities and any other element that reveals or refutes the need for some type of international protection

97. In order to respond to the specific situation of the child, additional information must be gathered that will allow a determination of the possible need for international protection to be identified based on the child's age, ${ }^{176}$ either as a refugee or another status. Having identified the need for specific protection or the potential need for protection of the person, the State must ensure the case is referred to the competent authorities.

98. If the need for international protection is identified because the inclusion criteria of the refugee definition have been verified, it is the State's obligation to explain the child her or his right to seek and receive asylum under Articles 22(7) of the American Convention and XXVII of the American Declaration in a language that the child can understand, and to refer the child to the entity responsible for this, either a State entity or an international agency such as UNHCR. ${ }^{177}$ In this regard, the Court has previously interpreted that the right to seek and receive asylum, read together with Articles 8 and 25 of the American Convention, guarantees effective access to a fair and efficient procedure for determining refugee status, so that the person applying for refugee status must be heard by the State to which she or he is applying, with due guarantees, by means of the respective procedure ${ }^{178}$ (infra Chapter XIV).

99. The Court recognizes that there may also be cases of mass influx. In this situation, States may conduct an initial assessment based on the account of one of the members of the group and, if it determines that this reveals 
factors that reflect the need for international protection, provide such protection on a group, collective or prima facie basis (infra para. 262).

100. States are also obliged to make an early identification of children that are fleeing for fear of being forcibly recruited, either by parties in an armed conflict or by organized crime structures, so as to be able to clarify whether the case merits the request for asylum or requires complementary protection. ${ }^{179}$

101. Nevertheless, the Court recognizes that not all cases of child migrants reach the level of requiring international protection in the terms of the preceding paragraphs. However, situations may arise where the rights of the child, which are protected internationally, are impaired and result in displacement from the country of origin. For this reason, it is necessary to gather personal information, such as the personal history and the physical and psychological health conditions, as well as the environment in which the migration took place, in order to determine the specific situation of risk of violation of rights in the child's country of origin, of transit or recipient, that warrants complementary protection or reveals other needs for protection or humanitarian assistance, such as those resulting from torture, domestic violence, trafficking or trauma. ${ }^{180}$

102. When assessing the needs for international protection, it should be recalled that "while both girls and boys face many of the same protection risks, they also experience protection challenges specific to their gender." ${ }^{181}$ Consequently, the information should be collected and analyzed taking into account a gender perspective. Thus, it is necessary to identify the specific risks of suffering violations to their rights faced by girls based on their gender, their socio-economic and cultural situation, and their legal status. ${ }^{182}$

\section{Adoption of special measures of protection, if necessary and pertinent in view of the best interest of the child}

103. Once the information has been gathered on the different factors that may cause children to be in a specific situation of vulnerability, the State must determine, in the terms of Articles 19 of the Convention and VII of the Declaration, and in conformity with an evaluation of the best interest of the child, the special measures of protection that are required to ensure their life, survival and development (infra Chapter X). In this regard, the Committee on the Rights of the Child has stated that it is also necessary to assess "particular vulnerabilities, including health, physical, psycho-social, material and other protection needs, including those deriving from domestic violence, trafficking or trauma." $" 183$

104. In this regard, the host State must evaluate - using adequate procedures that allow an individualized determination of the best interest of the child in each specific case - the need and pertinence of adopting comprehensive measures of protection, including those that are conducive to access to health care, both physical and psychosocial, that are culturally appropriate and gender sensitive; ${ }^{184}$ that provide a standard of living adequate for their physical, mental, spiritual and moral development through material assistance and support programs, particularly with regard to nutrition, clothing and housing; ${ }^{185}$ and that ensure full access to education under equal conditions. ${ }^{186}$ And certainly this and the other obligations previously indicated acquire particular relevance in the case of migrant children affected by any physical or mental disability; hence, the host State must be diligent in according them special attention. ${ }^{187}$

105. In the case of children who are unaccompanied or separated from their family, it is essential that States try to trace the members of their family, as long as this has been assessed as being in the best interest of the child. If possible and in keeping with the child's best interest, the State should proceed to reunify such children with their families as soon as possible. ${ }^{188}$

106. Regarding victims or potential victims of child-trafficking who are in a situation of extreme vulnerability, States have the obligation to protect them from a new risk of victimization, ${ }^{189}$ and to provide them with legal and medical assistance, ${ }^{190}$ endeavoring, insofar as possible, to protect the privacy and identity of the victim. ${ }^{191}$ Furthermore, to the extent possible, States must consider the possibility of meeting the said requirements by providing: (a) appropriate housing; (b) counseling and information, in particular as regards their legal rights, in a language that the victims of trafficking in persons can understand; (c) medical, psychological and material assistance; and (d) education and/or training opportunities. ${ }^{192}$ In addition, owing to the special situation of vulnerability of the victims of this 
offense, when appropriate, States must assist them in obtaining authorization to remain on their territory, especially in those cases in which the best interest of the child advise this, or in order to continue with the criminal investigation of the perpetrator of the crime. ${ }^{193}$

107. Lastly, the Court considers that it is crucial that States define clearly and within their institutional structure, the corresponding assignment of responsibilities, respecting the competences of the relevant State organs and, if necessary, adopt pertinent measures to achieve effective inter-institutional coordination in the determination and adoption of the special measures of protection required, grant the competent authorities the adequate budgetary resources, and provide specialized training for its personnel.

\section{GUARANTEES OF DUE PROCESS APPLICABLE IN IMMIGRATION PROCEEDINGS INVOLVING CHILDREN}

108. The Inter-American Court has been consulted with regard to the guarantees of due process of law that should apply in immigration proceedings that involve child migrants in light of Articles $1,{ }^{194} 2,{ }^{195} 7,{ }^{196} 8,{ }^{197}$ $19^{198}$ and $25^{199}$ of the American Convention on Human Rights, and of Article XXV ${ }^{200}$ of the American Declaration of the Rights and Duties of Man.

109. The Court has indicated that the right to due process of law refers to the procedural requirements that should be observed to ensure that people are able to defend their rights adequately vis- $\dot{a}$-vis any act of the State, adopted by any public authority, whether administrative, legislative or judicial, that may affect them. ${ }^{201}$ Due process is also closely related to the notion of justice, ${ }^{202}$ which is reflected in: (i) access to justice that is not merely formal, but that recognizes and resolves the factors of real inequality; (ii) a fair trial; and (iii) the settlement of disputes so that the decision adopted attains the highest level of correctness in the law, that is to say, that a just solution is ensured insofar as possible.

110. Although, under the American Convention, due process is expressed, above all, by the "judicial guarantees" recognized in Article 8 of the American Convention, it is also true that several other provisions of this international instrument, such as Articles 4, 5, 7, 9, 19, 25 and 27 of the Convention, also contain regulations that correspond, substantially, to the procedural and substantive components of due process. Similarly, in the American Declaration due process is expressed in the regulation of Articles XVIII (Right to fair trial), XXV (Right of protection from arbitrary arrest), and XXVI (Right to due process of law). In this chapter, the Court will focus mainly on due process guarantees, interpreted in conjunction with Articles 19 of the Convention and VII of the American Declaration, applicable to migration proceedings, in the understanding that by means of such proceedings controversies are settled regarding the migratory status of a person and may, depending on such determination, result in an expulsion or deportation. Additionally, decisions in this matter can have a profound impact on the life and development of migrant children.

111. With regard to Article 8 of the Convention, the Court has already established that the requirements established in its first paragraph are not only applicable to proceedings before strictly jurisdictional organs - judge or court - but extend to the decisions of administrative organs that have competence to determine the rights of the individual or when they exercise functions of a jurisdictional nature, ${ }^{203}$ as occurs in some countries in relation to immigration proceedings. ${ }^{204}$

112. The full range of basic guarantees of due process of law is applicable in the determination of rights and obligations of a "civil, labor, fiscal or any other nature." 205 Thus, in proceedings such as those that may result in the expulsion or deportation of aliens, the State cannot issue administrative orders or adopt judicial decisions without respecting specific basic guarantees, the content of which is substantially the same as those established in paragraph 2 of Article 8 of the Convention. ${ }^{206}$

113. Furthermore, guarantees of due process apply to any person regardless of their age and migratory status in a country. In this regard, the Court has stipulated that due process of law is a right that must be guaranteed to everyone, irrespective of their migratory status. ${ }^{207}$ This means that the State must guarantee that any alien, even a migrant in an irregular situation, has the possibility of asserting his rights and defending his interests effectively and in conditions of procedural equality with other justiciables. ${ }^{208}$ 
114. The guarantees recognized in Article 8 of the Convention must be respected and ensured to all persons, without distinction, and must be correlated with the specific rights established in Article 19 of this instrument, so that they are reflected in any administrative or judicial proceedings in which any right of a child is in dispute. ${ }^{209}$ Thus, the special protection derived from Articles 19 of the Convention and VII of the Declaration, signifies that the State's observance of the guarantees of due process result in some guarantees or components that are differentiated in the case of children, based on the recognition that they do not participate in migratory proceedings under the same conditions as an adult. ${ }^{210}$ Consequently, such proceedings must be adapted to children and accessible to them. $^{211}$

115. In short, as this Court has maintained previously, ${ }^{212}$ although due process and its correlative guarantees are applicable to everyone, in the case of child migrants their exercise supposes, owing to the special conditions in which the children find themselves, the adoption of certain specific measures in order to ensure access to justice in conditions of equality, to guarantee effective due process, and to ensure that the best interest of the child is a paramount consideration in all the administrative or judicial decisions adopted. ${ }^{213}$ The administrative or judicial proceedings during which decisions are taken on the rights of child migrants and, if applicable, of the persons whose protection or authority they are under ${ }^{214}$ (infra Chapter XV), should be based on the foregoing considerations and be adapted to their situation, needs and rights.

116. However, even though the jurisdictional function falls primarily within the jurisdiction of the judiciary, in some States, other organs or public authorities adopt decisions that affect fundamental rights, such as in immigration proceedings. In these cases, the administration's intervention has insurmountable limits, first and foremost the need to respect human rights, making it necessary for its conduct to be regulated. ${ }^{215}$ Based on these considerations, the Court will now refer to the guarantees that, under international human rights law, must govern any immigration proceedings that involve children, referring especially, when appropriate, to those guarantees that are critically important in this type of proceedings. Consequently, the Court will refer to the following aspects: (i) the right to be notified of the existence of proceedings and of the decision adopted during the immigration proceedings; (ii) the right that immigration proceedings are conducted by a specialized official or judge; (iii) the right of the child to be heard and to participate in the different stages of the proceedings; (iv) the right to be assisted without charge by a translator or interpreter; (v) effective access to communication with consular authorities and to consular assistance; (vi) the right to be assisted by a legal representative and to communicate freely with the representative; (vii) the obligation to appoint a guardian in the case of unaccompanied or separated children; (viii) the right that the decision adopted has assessed the child's best interest and is duly reasoned; (ix) the right to appeal the decision before a higher court with suspensive effect, and $(\mathrm{x})$ reasonable time for the duration of the proceedings.

\section{Right to be notified of the existence of proceedings and of the decision adopted during the immigra- tion proceedings}

117. All migrants have the right to be notified of proceedings against them because, otherwise, it would not be possible to guarantee their right to defend themselves. In the case of child migrants, this extends to every kind of procedure that involves them. For this reason, trained personnel are needed to communicate the child, according to her or his cognitive development, that her or his case is being subjected to administrative or judicial determination. This will ensure that the child can exercise the right to defense; in the sense that the child can understand the proceedings taking place and can contribute with her or his opinions as deemed pertinent. ${ }^{216}$

118. In addition, this Court has already emphasized the importance of serving notice of the final decision so that the right to appeal the decision may be exercised. In this regard, the Court has established that the absence of notification is, in itself, a violation of Article 8 of the Convention, because it places the alien in a situation of uncertainty as regards his legal status and makes it impossible to exercise the right to appeal the adverse judgment. ${ }^{217}$

119. In keeping with the above, and in order to guarantee the right to appeal an unfavorable decision effectively, decisions on entry, permanence or expulsion must be duly notified, which also reinforces the right for the decision to be duly reasoned. ${ }^{218}$

Right that immigration proceedings are conducted by a specialized official or judge 
120. If the immigration proceedings are conducted by a judge or panel of judges, these must evidently comply with the essentials of impartiality and independence. If administrative officials take this type of decision, they must respond before the law, their superiors and, if appropriate, the control mechanisms, for the legality of their decisions.

121. However, in the case of proceedings involving child migrants, the decisions on migratory matters cannot be delegated to non-specialized officials. Consequently, in proceedings involving children, States must guarantee that those who intervene in them are appropriately qualified, so that they can identify the special needs for protection of the child, in keeping with her or his best interest.

\section{Right of the child to be heard and to participate in the different stages of the proceedings}

122. First, it is pertinent to indicate that States have the obligation to enable the child to take part in each and every stage of the proceedings. To this end, the child must have the right to be heard with due guarantees and within a reasonable time by the competent authority. This right must be interpreted in light of Article 12 of the Convention on the Rights of the Child, ${ }^{219}$ which includes appropriate provisions in order to ensure that the child's participation is in keeping with her or his situation, and does not result in prejudice to the child's real interests. ${ }^{220}$ The Court recalls that children must be heard so that the decision taken accords with their best interests, and even the opinions of their parents or guardians cannot replace those of the children themselves. ${ }^{221}$ In this regard, States must take pertinent measures to weigh non-verbal forms of communication, including play, body language, facial expression, and drawing and painting, through which very young children demonstrate understanding, choices, and preferences. ${ }^{222}$ Similarly, the State has the obligation to adopt pertinent measures to guarantee this right to children with disabilities that make it difficult to make their views heard. ${ }^{223}$

123. In the case of child migrants, and particularly in the case of those who are unaccompanied or separated from their family, the right to be heard is especially relevant. Furthermore, any statement by a child must be subject to the corresponding procedural measures of protection, including the possibility of not making a statement, the assistance of legal counsel, and making the statement before the authority legally authorized to receive it. ${ }^{224}$ In this regard, in order to ensure the right to be heard, States must guarantee that the proceedings are conducted in an environment that is not intimidating, hostile, insensitive, or inappropriate to the child's age, and that the staff responsible for receiving the declaration are appropriately trained ${ }^{225}$ so that the child feels respected and safe when expressing her or his views in an appropriate physical, mental, and emotional environment.

\section{Right to be assisted without charge by a translator or interpreter}

124. To be able to guarantee the right to be heard, States must ensure that every child may be assisted by a translator or interpreter if she or he does not understand or does not speak the language of the decision-maker. ${ }^{226}$ In this regard, the assistance of a translator or interpreter shall be considered a basic and essential procedural guarantee in order to comply with the child's right to be heard and to ensure that its best interest constitutes a paramount consideration. ${ }^{227}$ To the contrary, the child's effective participation in the proceedings becomes illusory.

125. This guarantee must receive particular attention in the case of children who belong to indigenous communities in order to respect their cultural identity and to guarantee real access to justice. In this regard, the Court has interpreted previously that, in order to ensure the access to justice of members of indigenous communities, "it is essential that States grant effective protection that takes into account their specific particularities, their economic and social characteristics, and also their situation of special vulnerability, their customary law, values, practices and customs." 228

\section{Effective access to communication with consular authorities and to consular assistance}

126. The Court has understood previously that "the Vienna Convention on Consular Relations recognizes assistance to a national of the sending State for the defense of his rights before the authorities of the host State to be one of the paramount functions of a consular officer." 229 Thus, correlatively, the national of the sending State has the right to contact the consular officer to obtain that assistance. Accordingly, all foreign persons must have effective access to communicate with consular authorities, which should be granted without delay, in order to provide for an effective defense. $^{230}$ 
127. In the case of children, paragraphs (e) and (h) of Article $5^{231}$ of the above-mentioned international instrument, read in light of the Convention on the Rights of the Child, impose on the consular official the obligation to safeguard the interests of the child, in the sense of ensuring that any administrative or judicial decisions adopted by the receiving country has evaluated and taken into consideration the child's best interest.

128. Owing to the special vulnerability of children who are away from their country of origin and, especially, of those who are unaccompanied or separated, access to communication with consular authorities and to consular assistance becomes a right that has particular relevance and that must be guaranteed and implemented on a priority basis by all States. Especially, because of its possible implications on the process of gathering information and documentation in the country of origin, as well as to ensure that voluntary repatriation is only ordered if it is recommended as the result of proceedings held with due guarantees to determine the best interest of the child, and once it has been verified that this can be carried out in safe conditions, so that the child will receive care and attention on her or his return.

\section{Right to be assisted by a legal representative and to communicate freely with said representative}

129. The Court has established that "the circumstances of a particular case or proceedings - the significance, legal character, and context in a particular legal system - are among the factors that bear on the determination of whether legal representation is or is not necessary for a fair hearing." 232

130. The Court considers that States have the obligation to ensure to any child involved in immigration proceedings the right of legal counsel by the offer of free State legal representation services. ${ }^{233}$

131. Moreover, this type of legal assistance must be specialized, as regards both the rights of the migrant ${ }^{234}$ and, specifically, as regards age, in order to guarantee true access to justice to the child migrant and to ensure that the child's best interest prevails in every decision that concerns the child.

\section{Obligation to appoint a guardian in the case of unaccompanied or separated children}

132. Additionally, in the case of children who are unaccompanied or separated from their family, the Committee on the Rights of the Child has stated that the appointment of a competent guardian as soon as possible is an extremely important procedural guarantee in order to ensure their best interests. The Court considers it necessary to underline that administrative or judicial proceedings involving children who are unaccompanied or separated from their family may not be undertaken until a guardian has been appointed, ${ }^{235}$ specifically, in order to guarantee the right to personal liberty, free and prompt access to legal and other assistance, as well as to defend their interests and ensure their wellbeing. ${ }^{236}$

133. Indeed, States have the duty to appoint a guardian for children who are identified as being unaccompanied or separated from their family, even in border areas, as promptly as possible. States also have a duty to maintain such guardianship arrangements until they reach the age of majority, which is usually at 18 years of age; until they permanently leave the territory or jurisdiction of the State; ${ }^{237}$ or when appropriate, until the reason for which the guardian was appointed ceases to exist. The guardian must be sufficiently aware of the interests and situation of the child, and should have the authority to be present in all planning and decision-making processes, including immigration and appeal hearings, care arrangements and all efforts to search for a durable solution. ${ }^{238}$

134. Furthermore, the guardian should have the necessary expertise in the field of child care to ensure that the best interest of the child is safeguarded. In addition, the guardian should act as a link between the child and the pertinent entities in order to ensure that the child's legal, social, health, psychological, material and educational needs are covered appropriately. ${ }^{239}$

135. In the case of unaccompanied children, agencies or individuals whose interests could potentially be in conflict with those of the child should not be eligible for guardianship. ${ }^{240}$ In the case of a child separated from her or his family, "guardianship should regularly be assigned to the accompanying adult family member or non-primary caretaker, unless there is an indication that it would not be in the best interest of the child to do so, for example, where the accompanying adult has abused the child." 241 
136. Based on the above, States must create review mechanisms to monitor the quality of the exercise of guardianship in order to ensure that the best interest of the child is being represented throughout the decision-making process and, in particular, to prevent abuse. ${ }^{242}$

\section{Right that the decision adopted has assessed the child's best interest and is duly reasoned}

137. It is also essential that all decisions taken in migratory proceedings involving children must be duly justified, that is to say, are accompanied by the exteriorization of the reasoned justification that allows conclusions to be reached. ${ }^{243}$ The duty to provide the reasoning is one of the due guarantees to safeguard the right to a fair trial. ${ }^{244}$ The Court recalls that the obligation to provide the reasons for a decision is a guarantee related to the proper administration of justice, which protects the right of the individual to be tried for the causes established by law, and accords credibility to juridical decisions in a democratic society. ${ }^{245}$ Accordingly, the decisions adopted by the domestic organs that may affect human rights must be duly reasoned because, otherwise, they would be arbitrary. ${ }^{246}$

138. Thus, the reasoning for a ruling and for certain administrative acts should reveal the facts, rationale, and norms on which the authority based its decision, in order to preclude any indication of arbitrariness. ${ }^{247}$ In addition, it should show that the arguments of the parties have been taken in account and that all the evidence has been analyzed.

139. Consequently, and particularly in the case of children, the decision must explain in detail the way in which the opinions expressed by the child were taken into account and also the way in which her or his best interest was assessed. ${ }^{248}$ In this regard, the Committee on the Rights of the Child has stressed the close relationship that exists between the best interests of the child and the right to be heard, stating that "there can be no correct application of article 3 [(best interest of the child)] if the components of article 12 [(right to participate and for the views of the child to be given due weight)] are not respected." ${ }^{249}$ Likewise, article 3 reinforces the functionality of Article 12, facilitating the essential role of children in all decisions in decision affecting their lives." 250

\section{Right to appeal the decision before a higher court with suspensive effect}

140. This Court reaffirms the right of everyone to appeal all final decisions of an administrative or judicial nature adopted in immigration proceedings, especially those that order expulsion or deportation from a country or that deny permission to enter or remain in the country. In other words, when confronted with an adverse decision, the person must have the right to submit the case to review before the competent judicial authority and appear before it to this end. ${ }^{251}$ If the decision was adopted by the administrative authority, the review by a judge or panel of judges is a basic requirement to ensure adequate control and examination of administrative decisions that affect fundamental rights. ${ }^{252}$

141. The Court underscores that this right has special relevance in cases in which children consider that they have not been duly heard or that their views have not been taken into consideration. Thus, the review body must permit, among other matters, ascertaining whether the decision gave due weight to the principle of the best interest of the child. ${ }^{253}$

142. In addition, in order to ensure that the right to file an appeal before a judicial authority and to judicial protection are effective, the judicial remedy by which a migratory decision is contested must have suspensive effect, so that if a deportation order is involved, this must be suspended until the court before which the appeal was filed has issued a judicial ruling. ${ }^{254}$ Only in this way can the rights of child migrants be truly protected.

\section{Reasonable time for the duration of the proceedings}

143. Lastly, and owing to the particular degree of harm that this type of proceedings could have on a child, it is particularly important to emphasize that the duration of the proceedings up until the adoption of the final decision must respect a reasonable time, which means that the administrative or judicial proceedings relating to the protection of the human rights of the child "must be handled with exceptional diligence and speed by the authorities." 255 This not only reveals the need to defend and to protect the best interest of the child ${ }^{256}$ but also contributes to maintaining the situation of uncertainty for the least possible time in order to lessen the impact on the child's physical, mental and emotional integrity to the greatest extent possible. Nevertheless, the duration should be sufficient to ensure that the 
child is heard adequately. Thus, the right of the child to be heard cannot be impaired based merely on justifications related to the speed of the proceedings.

\section{PRINCIPLE OF NON-DEPRIVATION OF LIBERTY OF CHILDREN OWING TO THEIR IRREGULAR MIGRATORY SITUATION}

144. The Inter-American Court has been consulted on the interpretation that should be given to the ultima ratio (last resort) principle of detention as a preventive measure in the context of immigration proceedings when these involve children who are with their parents, as well as in cases involving children who are unaccompanied or separated from their parents, in light of Articles $1,{ }^{257} 7,{ }^{258} 8,{ }^{259} 19^{260}$ and $29^{261}$ of the American Convention, and of Article $\mathrm{XXV}^{262}$ of the American Declaration of the Rights and Duties of Man.

145. In order to deal with this issue, the central purpose of which is the interpretation of the right to personal liberty recognized in Articles 7 of the American Convention and XXV of the Declaration, it is pertinent to establish that when referring to the word "detention," the question employs it in a broad sense, equivalent to deprivation of liberty. Thus, the Court will proceed to use the concept of deprivation of liberty, because it is more inclusive. In this regard, the Court adopts a broad approach, in keeping with the development of international human rights law ${ }^{263}$ and autonomous from the provisions of national legislation, ${ }^{264}$ in the understanding that the particular element that allows a measure to be identified as one that deprives a person of liberty, regardless of the specific name it is given at the local level, ${ }^{265}$ is the fact that the person, in this case the child, cannot or is unable to leave or abandon at will the place or establishment where she or he has been placed. Hence, any situation or measure that is characterized by this definition will turn operational the associated guarantees (infra Chapter XII).

146. More specifically, the United Nations High Commissioner for Refugees has understood that, in the sphere of persons seeking international protection, detention means the "deprivation of liberty or confinement in a closed place which an asylum-seeker is not permitted to leave at will, including, though not limited to, prisons or purposebuilt detention, closed reception or holding centres or facilities." ${ }^{, 66}$ Additionally, it has understood that "[d]istinctions between deprivation of liberty (detention) and lesser restrictions on movement is one of 'degree or intensity and not one of nature or substance." 267 Thus, "[r] egardless of the name given to a particular place of detention, the important questions are whether an asylum-seeker is being deprived of her or his liberty de facto and whether this deprivation is lawful according to international law." ${ }^{268}$ This definition is considered because a more limited definition could affect the concept of deprivation of liberty in situations in which freedom of movement is restricted, especially in the various situations that could be contemplated. Depending on the specific situation, this restriction can have effects of such magnitude on the rights of the person, such as the right to seek and receive asylum; thus said restriction resembles a measure of deprivation of liberty owing to the "type, duration, effects, and method of implementation." 269

147. In the context of migration, deprivation of liberty may affect asylum seekers, refugees, stateless persons and irregular migrants. However, the Court finds that the scope of inquiry of this question lies in cases relating specifically to children in an irregular migratory status, caused by an entry or stay in a country without complying with the requirements of domestic legislation; as well as relating specifically to children seeking asylum who have not obtained the recognition of refugee status based on being unable to fulfill the elements necessary to qualify and who are submitted to a judicial process that can end in an expulsion or deportation order to the country of origin or, in the alternative, an order that allows the child to stay. ${ }^{270}$ Moreover, deprivation of liberty as a penalty or a punitive sanction in the area of immigration control is outside the scope of the question and, in accordance with the jurisprudence of this Court, must be regarded arbitrary and thus contrary to the Convention and American Declaration. ${ }^{271}$

148. As can be observed from the wording of the request, the question submitted is based on two premises founded on international human rights law and admitted by the jurisprudence of this Court. These are: (i) the principle of ultima ratio (last resort) of the deprivation of liberty of children, and (ii) the requirement to provide the grounds for the need to use measures of deprivation of liberty of a precautionary nature owing to infringements of immigration laws as an exceptional measure. 
149. It is a principle of international human rights $\operatorname{law}^{272}$ established in the Convention on the Rights of the Child $^{273}$ and developed by this Court in its case law in relation to the right to personal liberty in cases concerning juveniles in conflict with the law, ${ }^{274}$ that the deprivation of liberty, either on remand or as a punishment, constitutes a measure of last resort that should be used, when appropriate, for the shortest appropriate period of time ${ }^{275}$ since the purpose of criminal proceedings in the case of children is fundamentally pedagogical. ${ }^{276}$ Thus, deprivation of liberty in the context of juvenile criminal justice must respect the principles of legality, exceptionality, and the shortest appropriate period of time. ${ }^{277}$ Moreover, the exceptional nature of detention on remand operates more strictly because the rule should be liberty and, if the need for a precautionary measure is verified, the application of alternative measures should be given priority. ${ }^{278}$

150. On the grounds that the offenses concerning the entry or stay in one country may not, under any circumstances, have the same or similar consequences to those derived from the commission of a crime, and in recalling the different procedural purposes between migration and criminal proceedings, the Court considers that the principle of ultima ratio of the imprisonment of children is not within the scope of the consultation that was put forward, namely in the arena of immigration proceedings. ${ }^{279}$

151. In addition, in the case of Vélez Loor v. Panama, the Court established the incompatibility with the American Convention of measures of deprivation of liberty of a punitive nature in order to control migratory flows, in particular those of an irregular nature. ${ }^{280}$ Specifically, it determined that the detention of an individual owing to failure to comply with the immigration laws should never be for punitive purposes so that the measures of deprivation of liberty should only be used when they are necessary and proportionate in a specific case in order to ensure the appearance of the person at the immigration proceedings or to guarantee the implementation of a deportation order and only for the shortest time possible. ${ }^{281}$ Consequently, finding them arbitrary, the Court objected to those immigration policies that focused on the mandatory detention of irregular migrants, without the competent authorities verifying in each specific case, and by an individualized assessment, the possibility of using less restrictive measures that would be effective to achieve the required objectives. ${ }^{282}$

152. On this basis, the consultation requests the Court to interpret, in the light of Articles 7 of the Convention and $\mathrm{XXV}$ of the Declaration, the extent of the use of deprivation of liberty in the context of migration proceedings, disaggregating two distinct cases: children who are with their parents, as well as cases where the children are unaccompanied or separated.

153. In this vein, an analysis must be made of the compatibility of the deprivation of liberty of children for migratory reasons with the provisions of the Convention and of the Declaration indicated in the request, in light of the requirements for implementing a legitimate restriction of the right to personal liberty that the Court has established in its case law, bearing in mind the specific circumstances of the child; in other words, her or his condition as a person who is still developing and her or his best interest. To this end, and based on Article 30 of the Convention, the Court will evaluate: (i) whether the objective of the measures that restrict or deprive liberty are compatible with the Convention; (ii) whether the measures adopted are appropriate to achieve the objective sought; (iii) whether they are necessary, and (iv) whether the measures are strictly proportionate, so that the sacrifice inherent in the restriction of the right to liberty is not exaggerated or excessive in relation to the advantages obtained from this restriction and the achievement of the objective sought. ${ }^{283}$

154. Thus, although deprivation of liberty may seek a legitimate purpose and be appropriate to achieve this, on combining the criteria developed above and based on the principle of the best interest of the child, the Court finds that the deprivation of liberty of children based exclusively on migratory reasons exceeds the requirement of necessity, ${ }^{284}$ because this measure is not absolutely essential in order to ensure their appearance at the immigration proceedings or to guarantee the implementation of a deportation order (supra para. 151). Adding to this, the Court finds that the deprivation of liberty of a child in this context can never be understood as a measure that responds to the child's best interest. $^{285}$ Thus, the Court considers that measures exist that are less severe (infra para. 162) and that could be appropriate to achieve such objective and, at the same time, satisfy the child's best interest. In sum, the Court finds that the deprivation of liberty of a child migrant in an irregular situation, ordered on this basis alone, is arbitrary and, consequently, contrary to both the Convention and the American Declaration. 
155. In view of the special condition of vulnerability of child migrants in an irregular situation, States are obliged, under Articles 19 of the American Convention and VII of the Declaration, to choose measures ${ }^{286}$ that promote the care and well-being of the child to ensure its comprehensive protection, rather than the deprivation of her or his liberty ${ }^{287}$ (infra Chapter X). The Court considers that the parameter for the State's actions should, therefore, aim at ensuring, insofar as possible, the prevalence of the best interest of the child migrant and the guiding principle of respect for the child's right to life, survival, and development, in the terms set out in the following chapter, by measures adapted to the child's needs. ${ }^{288}$

156. Based on the above, the Court understands that the scope of the State's response in light of the best interest of the child acquires specific characteristics depending on the child's particular situation; ${ }^{289}$ in other words, if accompanied by her or his parents or, to the contrary, if unaccompanied or separated from her or his parents (supra para. 49). And this is due, on the one hand, to the special vulnerability of children who are unaccompanied or separated and, on the other, to the fact that the primary responsibility for the care and development of the child corresponds to the parents and, subsidiarily, the State must "undertake to ensure the child such protection and care as is necessary for her or his well-being, taking into account the rights and duties of her or his parents, legal guardians, or other individuals legally responsible for him or her." 290

157. Based on the preceding considerations, the Court finds that, in light of international human rights law, deprivation of liberty is inappropriate when children are unaccompanied or separated from their family, because in this situation, the State is obliged to give priority to facilitating the measures of special protection based on the principle of the best interest of the child, ${ }^{291}$ assuming its position as guarantor with the greatest care and responsibility. ${ }^{292}$ Likewise, the Committee on the Rights of the Child has stated:

In application of article 37 of the Convention and the principle of the best interests of the child, unaccompanied or separated children should not, as a general rule, be detained. Detention cannot be justified solely on the basis of the child being unaccompanied or separated, or on their migratory or residence status, or lack thereof. [...] In consequence, all efforts, including acceleration of relevant processes, should be made to allow for the immediate release of unaccompanied or separated children from detention and their placement in other forms of appropriate accommodation. ${ }^{293}$

158. In addition, the Court has stressed that "[t]he child has the right to life with his or her family, which is responsible for satisfying his or her material, emotional and psychological needs." ${ }^{294}$ In this way, in the case of children who are with their parents, keeping the family together owing to the child's best interest does not represent a sufficient reason to legitimate or justify the exceptional admissibility of the deprivation of liberty of children together with their parents, because of the prejudicial effects on their emotional development and physical well-being. To the contrary, when the child's best interest requires keeping the family together, the imperative requirement not to deprive the child of liberty extends to her or his parents and obliges the authorities to choose alternative measures to detention for the family, which are appropriate to the needs of the children. ${ }^{295}$ Evidently, this entails a correlative State obligation to design, adopt and implement alternative measures to closed detention centers in order to preserve and maintain the family unit and to promote the protection of the family without imposing an excessive sacrifice on the rights of the child by the deprivation of liberty of all or part of the family. ${ }^{296}$

159. All things considered, in the Court's opinion, the deprivation of liberty the sphere of juvenile criminal justice, i.e. when it relates to the perpetration of a conduct defined as an offense, can only be justified in exceptional cases established by law and provided that it is applied as a measure of last resort and for the shortest appropriate time.

160. On the contrary, and also in the Court's opinion, States may not resort to the deprivation of liberty of children who are with their parents, or those who are unaccompanied or separated from their parents, as a precautionary measure in immigration proceedings; nor may States base this measure on failure to comply with the requirements to enter and to remain in a country, on the fact that the child is alone or separated from her or his family, or on the objective of ensuring family unity, because States can and should have other less harmful alternatives and, at the same time, protect the rights of the child integrally and as a priority. 


\section{$X$ CHARACTERISTICS OF THE PRIORITY MEASURES FOR THE COMPREHENSIVE PROTECTION OF THE RIGHTS OF CHILD MIGRANTS AND GUARANTEES FOR THEIR APPLICATION}

161. The Inter-American Court has been consulted about the required characteristics of the appropriate alternative measures for the protection of the rights of child migrants that should constitute the States' priority response in order to avoid any type of restriction to freedom of movement and about the guarantees of due process of law that should be applied in proceedings during which a decision is adopted in this regard, in light of Articles $2,{ }^{297} 7,{ }^{298}$ $19,^{299} 25^{300}$ and $29^{301}$ of the American Convention and of Article $\mathrm{XXV}^{302}$ of the American Declaration of the Rights and Duties of Man.

162. First, the Court interprets that, according to the pertinent international norms, the first characteristic of the concept of alternative measures to detention can be found in its ontology; in other words, such measures must be conceived precisely by opposition to what is understood by a measure of deprivation of liberty and result in a lower level of harmfulness to the rights of the person, such as reporting at regular intervals to the authorities or stay in open centers or at a designated place. ${ }^{303}$

163. However, having previously established the scope of the right to personal liberty (Articles 7 of the Convention and XXV of the Declaration) with regard to child migrants based merely on non-compliance with immigration laws, when interpreting that this involves a general principle of non-deprivation of liberty (supra Chapter IX), the Court reaffirms that liberty is the rule while the immigration situation is decided or safe voluntary repatriation is implemented, and the measures to be decided should not be conceived as alternatives to detention, but rather as measures for priority implementation, whose main objective must be the comprehensive protection of rights, based on an individualized assessment and the best interest of the child.

164. In this regard, the preamble to the Convention on the Rights of the Child establishes that the child requires "special care," and Articles 19 of the American Convention and VII of the Declaration stipulate, respectively, that a child should receive special "measures of protection" and "special protection, care and aid." These measures of protection must, in the Court's opinion, be defined from the perspective of comprehensive protection, i.e. they must promote the full enjoyment of all the rights recognized in the Convention on the Rights of the Child and in other applicable instruments, ${ }^{304}$ especially the right to health, to adequate nutrition, to education, ${ }^{305}$ as well as to play and the recreational activities appropriate to the child's age. In particular, the Court considers that they must be motivated by the promotion of the well-being and development of the child based on three main elements: (i) satisfaction of basic material, physical and educational needs; (ii) emotional care, and (iii) safety, as regards effective protection against any type of abuse, exploitation or form of violence. ${ }^{306}$

165. Thus, the State obligation to have available a set of measures aimed at achieving these objectives is crucial. This obligation has two aspects: on the one hand, it imposes on the Legislature the duty to establish, by the enactment of laws, a series of measures that comply with the guidelines described and, on the other hand, it requires the judge or the competent official to apply said measures in their sphere of action, pursuant to the best interest of the child.

166. Despite the fact that the decision on the legislative and institutional structure for the implementation of said measures corresponds to each State, international human rights law has established an approach to the issue considering that its main objective is the attention and care required by children owing to their special status. Therefore, the Court finds that, in this sphere, the use of the child protection system with its associated services should prevail over that of institutions exercising control of immigration. ${ }^{307}$

167. In the case of unaccompanied or separated children, international law imposes specific obligation on the State based on their particular situation. ${ }^{308}$ Even when specific laws or regulations do not exist for the protection of children in an irregular migratory situation, the guidelines for the alternative care of children ${ }^{309}$ contain standards relating to arrangements for children who are abroad "for whatever reason" 310 and, in particular, for those who are unaccompanied or separated. Since States must guarantee that the child has an appropriate place to stay, it is pertinent to consider said guidelines in relation to reception arrangements. In this regard, solutions based on the family and the community should be given priority over institutionalization. ${ }^{311}$ In addition, States are obliged to adopt the necessary measures to determine the identity and composition of the family of the child in this situation (supra para. 84); to 
trace the family and to promote family reunification, ${ }^{312}$ taking into account the child's views and best interest; ${ }^{313}$ and to ensure safe and voluntary repatriation to the country of origin. If this is not possible, other durable solutions should be taken into account. ${ }^{314}$

168. With regard to children who are members of indigenous communities, the Court has indicated that "to ensure the full and harmonious development of their persona, indigenous children, in accordance with their world vision, require preferably to grow up and to develop within their natural and cultural environment, because they possess a distinctive identity that connects them to their land, culture, religion, and language." ${ }^{15}$ Consequently, when they have been displaced, voluntarily or forcibly, outside their territory and community, the measures of protection must be adopted and implemented taking their cultural context into consideration. ${ }^{316}$

169. Specifically, the Court considers that said set of measures that should be implemented for children based on their irregular migratory status must be established in the domestic law of each State. Likewise, the procedure for implementing the measures must be regulated, ensuring respect for the following basic guarantees: a competent administrative or judicial authority; the views of the children concerning their preference must be taken into account $;{ }^{317}$ the best interest of the child must be a primary consideration in decision-making; ${ }^{318}$ and the guarantee of the right to a review of the decision in case it is considered that it is not the appropriate or the least harmful measure, or that it is being used in a punitive manner. ${ }^{319}$

170. In sum, the Court considers that child migrants and, in particular, those in an irregular migratory situation, who are in more vulnerable circumstances, require host States to take actions specifically designed to provide priority protection for their rights, which must be defined in accordance with the particular circumstances of each specific case; in other words, whether the children are with their family, separated or unaccompanied, and based on their best interests. To this end, States, in compliance with their international obligations in this matter, must design and incorporate into their internal law a set of non-custodial measures to be ordered and implemented while the immigration proceedings are held that promote, above all, the comprehensive protection of the rights of the child, in keeping with the characteristics described above, with strict respect for their human rights and the principle of legality.

\section{BASIC CONDITIONS FOR PLACES TO ACCOMMODATE CHILD MIGRANTS AND STATE OBLIGATIONS CORRESPONDING TO CUSTODY FOR MIGRATORY REASONS}

171. The Inter-American Court has been consulted regarding the basic conditions that must be met for living quarters for child migrants and the main State obligations in relation to the children who are in their custody for migratory reasons, in light of Articles $1,{ }^{320} 2,{ }^{321} 4(1),{ }^{322} 5,,^{323} 7,{ }^{324} 17^{325}$ and $19^{326}$ of the American Convention and Articles I ${ }^{327}$ and $X_{X V}^{328}$ of the American Declaration of the Rights and Duties of Man.

172. The Court finds it essential, first, to reiterate the special position of guarantor assumed by the State with regard to persons who are in their custody or care, to whom it should provide, as a positive obligation, the necessary conditions for a decent life and to receive humane treatment consistent with personal dignity, ${ }^{329}$ pursuant to Articles 4(1) and 5 of the Convention and Articles I and XXV of the Declaration. This applies specifically and in a preferential manner to child migrants who require special measures of protection under Articles 19 of the Convention and VII of the Declaration (supra para. 66).

173. In accordance with the criteria developed above (supra Chapters IX and X), States must, in compliance with its international commitments, prioritize actions that tend to the care of the child with a view to provide comprehensive protection when the child is involved in immigration proceedings. In certain circumstances - when children are with their families and there is evidence of an exceptional, inevitable, and imperative need for precautionary measures during immigration proceedings, and there is no other option that would cause less harm than placing the child in a center where the child can coexist with her or his family; or when children are unaccompanied or separated and there is no possibility of accommodating the child in a family or community environment such that the child would be placed in a accommodation center - then it is possible for States to resort to such measures as placing children in a shelter or accommodation, either for a short period or for as long as necessary to resolve the immigration status. In this regard, the Court recalls that it has already ruled on the need to separate migrants in custody from persons who 
have been accused or convicted of criminal offenses and has established that centers to accommodate migrants must be specifically intended for this purpose. ${ }^{330}$

174. Such accommodation centers may be public or private establishments. However, if the provision of these services is delegated to the private sector, the State has the essential obligation, in particular pursuant to the provisions of Article 1(1) of the Convention, to monitor these centers in order to ensure a real protection of the human rights of the persons subject to their jurisdiction and that public services are provided to those lodged in the center without any kind of discrimination and as effectively as possible. ${ }^{331}$ Likewise, the Court considers that States have the obligation to adopt the necessary measures to regulate and monitor that the places where migrants are lodged comply with technical criteria for their registration and authorization in keeping with the differentiated needs of child migrants and, consequently, that the State system provides a way of supervising such accommodation. ${ }^{332}$

175. In this context, the Court will consider the following State obligations concerning basic conditions and will develop their scope: (i) principle of separation and right to family unity; (ii) open accommodation centers; and (iii) material conditions and an adequate regime that ensure the comprehensive protection of rights.

\section{Principle of separation and right to family unity}

176. The Court has maintained, based on Article 5(5) of the American Convention and 37(c) of the Convention on the Rights of the Child, that children should be separated from adults, because holding them in the same place creates conditions that "are extremely prejudicial for their development and makes them vulnerable before third parties who, because they are adults, may abuse of their dominant situation." 333

177. Furthermore, the Committee on the Rights of the Child has also referred to the applicability of this principle in the case of child migrants, indicating that "the necessary measures should be taken to ensure that the accommodation is adequate for children and is separated from that of the adults, unless the contrary is considered desirable in the best interest of the child." 334 In this regard, the Court considers that, in order to assess the need for separation from adults, it is necessary to know whether the children are unaccompanied or separated, or whether they are with their family, and evaluate the decision in light of their best interests. In the case of unaccompanied or separated children, the Court shares the opinion of the Committee on the Rights of the Child that, in this case, the children require special care from the persons in charge of the center and must never be lodged together with adults. ${ }^{335}$ In the case of children who are with their families, in accordance with Articles 17 of the Convention and VI of the Declaration, which establish the rights of the family, the rule must be that they remain with their parents or those acting in their stead, avoiding the separation of the family unit insofar as possible, ${ }^{336}$ as indicated previously (supra paras. 158 and 160), unless the best interest of the child advises otherwise.

178. In short, in the case of child migrants, under international human rights law, the principle of separation has two dimensions: (i) unaccompanied or separated children should be lodged in places apart from those for adults, and (ii) accompanied children should be lodged with their family members, unless it is more appropriate to separate them in application of the principle of the child's best interest.

179. In addition, the Court considers that in the application of the pertinent international norms the age of the children should be taken into account for their care and attention in the accommodation center, because this is usually an indication of maturity that will determine the common behavior of groups of children, even though each case must be treated on an individual basis, especially in determining each child's needs. Consequently, the Court finds that it is an international obligation of the corresponding State to establish and to ensure that the place where unaccompanied or separated children are lodged is divided according to the specific needs of age groups and differentiated from centers for families, and that human and material resources are assigned accordingly.

Open accommodation centers

180. In the Court's opinion, according to international law in this area and based on the preceding considerations on the scope of Articles 7 of the Convention and XXV of the American Declaration, any measure concerning accommodation should allow entry into and exit from the place where the child is lodged, i.e., accommodation should be 
provided in an environment of non-deprivation of liberty. Likewise, the European Court of Human Rights has affirmed that closed centers are not adapted to the extreme vulnerability of an unaccompanied child migrant, inter alia, because the conditions do not meet her special needs. ${ }^{337}$ Thus, the Court finds that the measures must represent and offer an alternative that is materially and qualitatively different from deprivation of liberty in closed centers, according priority to a treatment that is adapted to the needs for comprehensive protection.

\section{Material conditions and an adequate regime that ensure the comprehensive protection of rights}

181. The obligatory basic conditions that the State must provide for the persons in its custody, according to the norms cited above, include the condition that the accommodation of children should - based on the principle of the child's best interest and comprehensive protection - permit their holistic development. Accordingly, it is essential that the accommodations for child migrants, whether they are with their family or unaccompanied or separated, ensure material conditions and an adequate regime for the children, that at all times ensure the protection of their rights. ${ }^{338}$ In this regard, it is relevant to take into account, in each case, the diversity of the children as regards their ethnic, cultural, linguistic, and religious background. ${ }^{339}$

182. The Court also understands from the international norms that these centers must guarantee lodging, maintenance, medical care, legal assistance, educational support and integral attention to the children. They must also have available a series of specialized care services owing to the specific needs of each child, in order to respond, for example, to children with disabilities, ${ }^{340}$ children living with HIV/AIDS, ${ }^{341}$ babies or infants, ${ }^{342}$ and victims of child trafficking, among others. In addition, they must ensure that they do not create a situation in which children can be subjected to violence, exploitation or abuse.

183. The Court considers that for a place of accommodation to comply with the conditions for the exercise of the rights established in the Convention on the Rights of the Child, it must have a physical infrastructure that permits said development. Some of these conditions are: ensuring that children have a certain degree of separateness so that their privacy is respected; ensuring that the living quarters should provide a place where they can keep their possessions in safety; ensuring that all meals must be provided during the child's stay and that they meet her or his nutritional needs; ensuring access to health care services, either physical and/or psychosocial; ensuring continuous access to education outside the center; ensuring that there is a place for recreation and play; and ensuring that children who wish to take part in cultural, social, and religious activities should have a guardian to accompany them.

184. The personnel of the center must be specialized and receive training in child psychology, protection of the child, and the human rights of the child. ${ }^{343}$

\section{GUARANTEES OF DUE PROCESS IN MEASURES THAT ENTAIL RESTRICTION OR DEPRIVATION OF PERSONAL LIBERTY OF CHILDREN FOR MIGRATORY REASONS}

185. The Inter-American Court has been consulted about the guarantees of due process that should apply in immigration proceedings involving children and adolescents, when measures that restrict their personal liberty are adopted in these proceedings, in light of Articles $1,{ }^{344} 2,{ }^{345} 7,{ }^{346} 8,{ }^{347}, 19^{348}$ and $25^{349}$ of the American Convention and of Article $\mathrm{XXV}^{350}$ of the American Declaration of the Rights and Duties of Man.

186. Taking as starting point, the scope of the right to personal liberty in so far as a general principle of nondeprivation of liberty of migrant children based on the sole breach of domestic immigration laws governs (supra Chapter IX), in this chapter, the Court will specify and detail a number of important safeguards that should become operational in situations relating to the restriction of personal liberty - including severe interference with the freedom of movement, withholding, arrest or brief detention, among others - that may eventually constitute or lead, depending on the circumstances of the particular case, to a measure that results in deprivation of liberty under the understanding that such situations may occur in practice.

187. In order to deal with this issue, first, it is essential to define the concept of "restriction of personal liberty." Thus, the Court understands that restriction of personal liberty is any measure that involves impairment of this right, either through total deprivation by reclusion in a closed place or any other lesser restriction that, owing to its form, duration, effects and method of implementation, entails interference in the right of everyone to personal liberty ${ }^{351}$ 
(supra paras. 145 and 146). The difference between deprivation of liberty and restriction of liberty stems from the level of intensity of the measure. ${ }^{352}$ Thus, in certain circumstances, a "delay," even merely to identify the person, may constitute a deprivation of physical liberty. ${ }^{353}$

188. As indicated previously, the guarantees of due process constitute a series of substantive and procedural requirements that must be met by the procedural bodies in order to ensure that the individual is able to defend his rights adequately in the face of any act of the State that may affect them. ${ }^{354}$ Regarding the guarantees applicable in situations of restriction of liberty, Articles 7 of the Convention and XXV of the Declaration play a crucial role. These provisions, each with its own scope, attempt to recognize the condition of vulnerability of a person caused by a situation of deprivation of liberty, to protect them against any form of illegal or arbitrary interference in physical liberty, ${ }^{355}$ to provide guarantees that represent limits to the exercise of authority by State agents in order to prevent detentions that may be considered illegal or arbitrary, and to provide the person with control mechanisms in the face of the latter. In particular, these provisions contain the normative mandates that prohibit illegal ${ }^{356}$ and arbitrary deten$\operatorname{tion}^{357}$ and establish the following procedural rights and guarantees, among others, in favor of the person who has been retained or detained: to be informed of the reasons for the detention; to be brought promptly before a judge or other official authorized by law to exercise judicial functions; to be tried within a reasonable time or to be released, and the possibility to recourse to a competent court in order that the court may decide without delay on the lawfulness of the person's arrest or detention and order her or his release if the arrest or detention was unlawful.

189. Under Articles 19 of the American Convention and VII of the Declaration, the special guarantees enjoyed by children owing to the greater impact that a measure of deprivation of liberty has on them should be added to the above. In particular, Article 37(d) of the Convention on the Rights of the Child stipulates that "[e]very child deprived of her or his liberty shall have the right to prompt access to legal and other appropriate assistance, as well as the right to challenge the legality of the deprivation of her or his liberty before a court or other competent, independent and impartial authority, and to a prompt decision on any such action."

190. Children, especially when they are foreigners detained in a different social and legal environment from their own and frequently in a country with a language they do not know, experience a situation of extreme vulnerability. ${ }^{358}$ This presence of conditions of real inequality makes it compulsory to adopt compensatory measures that help reduce or eliminate the obstacles and deficiencies that impede or reduce the effective defense of their interests. ${ }^{359}$ This is how the State should ensure the principle of equality before the law and the courts, and the corresponding prohibition of discrimination. ${ }^{360}$ Consequently, the Court will refer to the following aspects: (i) lawfulness of the deprivation of liberty; (ii) prohibition of arbitrary detention or imprisonment; (iii) right to be informed of the reasons for the arrest or detention in a language that the person understands; (iv) right to be taken promptly before a judge or other competent official; (v) right to notify a family member, guardian or legal representative and to communicate with the exterior and, in particular, with the specialized international agencies; (vi) right to information and effective access to consular assistance; (vii) right to legal assistance by a legal representative, and in the case of unaccompanied or separated children, the right to the appointment of a guardian; and (viii) right to have recourse to a competent judge or court for a decision to be taken, without delay, on the lawfulness of the arrest or detention.

\section{Lawfulness of the deprivation of liberty}

191. With regard to the specific guarantee established in Articles 7(2) of the Convention and XXV of the Declaration, the Court reiterates that any restriction or deprivation of liberty should respect the principle of legality, and therefore, the grounds and procedures in domestic law should conform to the principle. Thus, this Court has previously established that the restriction of physical liberty, even for a brief period, including merely for identification purposes, must be "strictly adapted to the relevant provisions of the American Convention and domestic law, provided the latter is compatible with the Convention." 361

\section{Prohibition of arbitrary detention or imprisonment}

192. Regarding the arbitrary nature of a detention referred to in Articles 7(3) of the Convention and XXV of the Declaration, the Court has considered that "no one may be subjected to detention or imprisonment for reasons and by means that - although they are classified as legal - may be considered incompatible with respect for the fundamental 
human rights, because they are, inter alia, unreasonable, unpredictable or disproportionate." 362 Hence, any detention must be carried out in accordance with the provisions of domestic law, and the "domestic law, the applicable proceedings, and the corresponding general explicit or tacit principles [...], in themselves, [must be] compatible with the Convention." 363

193. In the migratory context, and taking into account Article 1(1) of the Convention, the Court places special emphasis on the fact that detention should not have a disproportionate effect on a specific racial, religious, or any other type of group or social condition, without a reasonable and objective justification. ${ }^{364}$ This means that the laws, policies and practices relating to the deprivation of liberty may not establish de jure or generate de facto discrimination against any nationality in particular and, specifically, result in discrimination against anyone for reasons, such as their race, color or national origin. ${ }^{365}$

194. Furthermore, a restriction of liberty for an excessive amount of time may lead to a deprivation of liberty that is incompatible with the provisions of the Convention or the American Declaration in the same way as indefinite deprivations of liberty. ${ }^{366}$

\section{Right to be informed of the reasons for the arrest or detention in a language that the person understands}

195. It has been this Court's consistent case law that information on the "motive and reasons" for the arrest or the detention must be provided "when this occurs," which "constitutes a mechanism to avoid illegal or arbitrary detentions, from the very moment of the deprivation of liberty and, in turn, ensures the individual's right to defend himself." ${ }^{367}$ In the same manner, the observance of the right to be informed of the reasons for the arrest or the detention "permits the person detained to challenge its lawfulness, using the legal mechanisms that all States must offer." 368

196. The information on the reasons for the arrest or detention necessarily presumes, first, providing information on the detention itself; the person must understand that she or he is being arrested or detained. ${ }^{369}$ Second, the agent making the arrest or detention must provide information, in a simple language free of technical terminology, on the essential facts and legal grounds on which the measure is based. ${ }^{370}$ Likewise, in immigration matters, the Court finds that it is relevant that the person be informed of the procedures available to challenge the restriction or deprivation of liberty, in order to obtain her or his release.

197. In this regard, since aliens are involved, the Court considers it relevant to establish that the language used must be one that the person understands. Moreover, in the case of children, a language that is adapted to their maturity and age should be used. Children must be provided with all the necessary information, adapted to their age and maturity, on their rights, the services available to them, and the procedures they may assert. In particular, they should be informed of their right to request asylum; their right to have legal assistance; their right to be heard; their right of access to information on consular assistance; and, if appropriate, of their right to be appointed a guardian. Added to this, States must guarantee that any child subjected to proceedings that may result in an eventual interference in their right to personal liberty is assisted by a translator or interpreter if the child does not understand or does not speak the language of the receiving country.

\section{Right to be taken promptly before a judge or other competent official}

198. Under Articles 7(5) of the American Convention and XXV of the American Declaration, any person detained must be brought promptly before a judge or other official authorized law to exercise judicial functions. ${ }^{371}$ This Court has already interpreted that this guarantee must be met whenever a person is retained or detained for a migratory situation, based on the principles of judicial control and procedural immediacy. ${ }^{372}$ To ensure that this constitutes a real mechanism for controlling illegal or arbitrary detentions, the judicial review must be carried out promptly and in such a way as to guarantee compliance with the law and the detainee's effective enjoyment of his rights, taking into account his special vulnerability. ${ }^{373}$ Furthermore, this Court has already indicated that in order to satisfy the guarantee established in Article 7(5) of the Convention in immigration matters, domestic law must ensure that the official authorized by law complies with the characteristics of impartiality and independence that must govern any organ responsible for deciding the rights and obligations of the individual. ${ }^{374}$ In the case of 
this guarantee, since said official has the task of preventing or ending illegal or arbitrary detentions, ${ }^{375}$ it is essential that she or he is authorized to release the person if the detention is illegal or arbitrary. ${ }^{376}$

Right to notify a family member, guardian or legal representative and to communicate with the exterior and, in particular, with the specialized international agencies

199. The person arrested or detained has the right to notify a third party that she or he is in the custody of the State. ${ }^{377}$ This notification shall be given, for example, to a family member, guardian, or legal representative, as appropriate. $^{378}$

200. The right to establish contact with a family member, guardian, or legal representative, is particularly important in the case of children ${ }^{379}$ and especially in the cases of unaccompanied children. Information on the right to establish contact with a family member, guardian, or legal representative, must be provided at the time of the detention; ${ }^{380}$ however, in the case of children, the necessary measures must also be taken to implement the notification, ${ }^{381}$ taking into account the best interest of the child.

201. In addition, it must be ensured that children are able to communicate with the exterior by any means and, in particular, to contact their family, friends, legal representative, and, if applicable, their guardian. Furthermore, they must be able to receive visits from such persons. ${ }^{382}$ The Court also emphasizes that, when appropriate, the child must be able to contact international agencies such as the United Nations High Commissioner for Refugees (UNHCR), the International Committee of the Red Cross (ICRC), the United Nations Children's Fund (UNICEF) or the International Organization for Migration (IOM). ${ }^{383}$

\section{Right to information and effective access to consular assistance}

202. First, it is pertinent to indicate that child migrants enjoy the right to consular assistance recognized to any individual detained outside his country of origin. ${ }^{384}$ The Court has already stipulated that, from the perspective of the rights of the detainee, there are three essential components of this right that the State must grant the individual: ${ }^{385}$ (i) the right to be notified of her or his rights under the Vienna Convention on Consular Relations, ${ }^{386}$ (ii) the right to effective access to communication with a consular official; and (iii) the right to consular assistance.

203. The exercise of this right means that a detained person, regardless of the modality of the detention, must be notified of the right to establish contact with a third party, such as the consular official, in order to inform others that she or he is in the State's custody. ${ }^{387}$ The possibility of communicating with a consular official of their country, except in the case of asylum seekers, refugees, or other persons beneficiaries of international protection, is also a fundamental guarantee of access to justice and permits the effective exercise of the right of defense, because the consul is able to assist the detainee in taking steps for her or his defense, such as providing or hiring legal assistance, obtaining evidence in the country of origin, verifying the conditions in which the legal assistance is provided and monitoring the situation of deprivation of liberty. ${ }^{388}$

Right to legal assistance by a legal representative, and in the case of unaccompanied or separated children, the right to the appointment of a guardian

204. States are also bound to guarantee to all children whose liberty is restricted owing to immigration matters, the right to defend themselves by offering State legal representation services. ${ }^{389}$ Specifically, States must provide children deprived of liberty with prompt and free access to a legal representative who can give them legal assistance. The Court considers that legal assistance must be provided by a legal professional in order to satisfy the requirements of a technical defense that can advise the person subject to proceedings, inter alia, about the possibility of filing remedies against decisions that affect her or his rights. ${ }^{390}$

205. Also, in the case of children who are unaccompanied or separated from their family, it is extremely important, in order to ensure the right to personal liberty, to appoint a guardian for them in order to defend their interests and to ensure their well-being. ${ }^{391}$ 
Right to have recourse to a competent judge or court for a decision to be taken, without delay, on the lawfulness of the arrest or detention

206. The guarantee contained in Article 7(6) of the American Convention is also applicable. This article indicates that "[a]nyone who is deprived of his liberty shall be entitled to recourse to a competent court, in order that the court may decide without delay on the lawfulness of his arrest or detention and order his release if the arrest or detention is unlawful." ${ }^{392}$ This Court has already indicated that, "given the provisions of Article 27(2) of the American Convention [...] the legal remedies guaranteed in Articles 7(6) and 25(1) of the Convention may not be suspended because they are essential judicial guarantees for the protection of the rights and freedoms whose suspension Article 27(2) prohibits." ${ }^{\text {393 }}$ The Court has ruled on these principles and has determined that Article 7(6) has its own legal content, because it specifically recognizes the right of everyone deprived of liberty to have recourse to a competent judge or panel of judges for a decision to be taken on the lawfulness of the arrest or detention, also known as habeas corpus, which consists in the direct protection of physical and personal liberty by means of a judicial order addressed to the corresponding authorities requiring them to bring the detained person before a judge so that the lawfulness of the detention may be determined and, if appropriate, the release of the detainee be ordered. ${ }^{394}$ Article 7(6) of the Convention clearly establishes that the authority that must determine the lawfulness of the "arrest or detention" must be an independent and impartial "judge or court." ${ }^{395}$ In this regard, the Court's case law has already indicated that these remedies should not only exist formally in law, but must be effective, i.e. they must comply with the objective of obtaining a decision on the lawfulness of the arrest or detention without delay. ${ }^{396}$ In the case of migrant children, this procedure should be of a priority nature in order to obtain a prompt decision on the action filed. ${ }^{397}$

\section{PRINCIPLE OF NON-REFOULEMENT}

207. The Inter-American Court has been consulted with regard to the scope and content of the principle of nonrefoulement when adopting measures that may involve the return of a child to a specific country, in light of Articles $1,{ }^{398} 2,{ }^{399} 4(1),{ }^{400} 5,{ }^{401} 7,{ }^{402} 8,{ }^{403} 19,{ }^{404} 22(7),{ }^{405} 22(8)^{406}$ and $25^{407}$ of the American Convention on Human Rights, Article $13(4)^{408}$ of the Inter-American Convention to Prevent and Punish Torture, and Articles I, 409 $\mathrm{XXV}^{410}$ and XXVII ${ }^{411}$ of the American Declaration of the Rights and Duties of Man.

208. The Court will now proceed to establish the content of the principle of non-refoulement, recalling that children are entitled to all the rights established in the American Convention and the American Declaration. It will also clarify the scope of this principle in cases that could involve the return of a child to a specific State, either her or his country of origin, or a third country from which she or he could subsequently be returned.

209. The Court has already underscored that the principle of non-refoulement constitutes the cornerstone of the international protection of refugees and asylum seekers. ${ }^{412}$ The 1951 Convention relating to the Status of Refugees was the first international instrument to codify in its Article 33(1) the principle of non-refoulement as an effective measure to ensure the exercise of the right to seek and receive asylum ${ }^{413}$ - which under this treaty assumes the specific form of refugee status ${ }^{414}$ - and as an integral component of the international protection guarantees for those seeking asylum and refugees, ${ }^{415}$ by establishing that "[n]o Contracting State shall expel or return ("refouler") a refugee in any manner whatsoever to the frontiers of territories where his life or freedom would be threatened on account of his race, religion, nationality, membership of a particular social group or political opinion."

210. In view of the declarative nature of the determination of refugee status, ${ }^{416}$ the protection provided by the principle of non-refoulement applies to all refugees, even if they have not yet been deemed refugees by authorities based on the requirements of the definition of Article 1 of the 1951 Convention and its 1967 Protocol ${ }^{417}$ or by domestic legislation. In other words, it also applies to asylum seekers, ${ }^{418}$ whose status has not yet been determined, and to refugees who have not yet been recognized officially as such. ${ }^{419}$ It may also be invoked by those who wish to assert their right to seek and receive asylum ${ }^{420}$ and who are either on the border or have crossed it without being admitted officially or legally into the territory of the country, ${ }^{421}$ because, otherwise, this right would become illusory and without content, i.e. without any value or effect. This necessarily means that such persons may not be rejected at the border or expelled without an adequate and individualized analysis of their requests. ${ }^{422}$ 


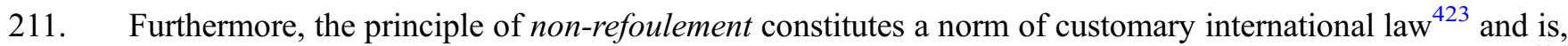
consequently, binding for all States, whether or not they are parties to the 1951 Convention or its 1967 Protocol. ${ }^{424}$ Nevertheless, as has been codified, this principle is not absolute because it allows for exceptions. Indeed, Article 33 of the 1951 Convention indicates the situations that permit a State not to provide the protection of non-refoulement, even when a person complies with the definition of refugee. ${ }^{425}$ However, such situations should be interpreted rigorously and restrictively ${ }^{426}$ and in relation to the obligations derived from non-derogable rights, such as the prohibition of torture (infra paras. 224 to 227).

212. In the sphere of the inter-American system, this principle is reinforced by the recognition of the right of everyone to seek and receive asylum, first in Article XXVII of the American Declaration and then in Article 22 (7) of the American Convention. Consequently, the principle of non-refoulement derives from the fundamental obligations to respect and ensure rights under Article 1(1) of the Convention assumed in relation to each of the protected rights and, in this case, with regard to the right of everyone to seek and receive asylum. Moreover, based on this principle, States are bound not to return ("refouler") or expel a person-asylum seeker or refugee - to a State where her or his life or liberty may be threatened as a result of persecution for specific reasons or due to generalized violence, foreign aggression, internal conflicts, massive violations of human rights or other circumstances which have seriously disturbed public order, ${ }^{427}$ nor to a third State from which she or he may later be returned to the State where she or he suffered this risk - a situation that has been called "indirect refoulement." 428

213. Nevertheless, having recognized that refugee law has been the pioneering branch of international law in adopting the principle of non-refoulement, it is also important to note that, in addition to including the right to seek and receive asylum, the American Convention contains an explicit provision on non-refoulement. In this understanding and in order to respond to this question, the Court will analyze, first, the interpretation of Article 22(8) of the American Convention in order to clarify whether this provision is the same as the principle of non-refoulement as it has been developed in the preceding paragraphs and will then examine other treaty-based provisions that are associated with the principle of non-refoulement. When interpreting these provisions, the Court will also take into account other relevant sources of international law.

214. Article 22(8) of the American Convention establishes the prohibition to deport or return any "alien" to "a country, whether or not it is his country of origin" - in other words, to her or his country of nationality or, in the case of a stateless person, the country of habitual residence, or to a third State - in which "his right to life or personal freedom" are "in danger of being violated because of his race, nationality, religion, social status or political opinions." 429

215. In the case of the Pacheco Tineo Familyv. Bolivia, the Court had the opportunity to interpret this provision, and concluded that: "it may be considered that, under the inter-American system, the right of any alien, and not only refugees or asylees, to non- refoulement is recognized, when his life, integrity and/or freedom are in danger of being violated, whatsoever his legal status or migratory situation in the country where he is. ${ }^{" 430}$ Consequently, the protection of the principle of non-refoulement established in the provision of the American Convention that is being examined covers any alien and not only a specific category among aliens, such as those who are asylum seekers and refugees. A literal interpretation of the wording of the article leads to this conclusion.

216. The travaux préparatoires of the American Convention confirm the meaning given to this provision. It can be seen that the initial proposal to include the principle of non-refoulement in the American Convention was made by the Office of the United Nations High Commissioner for Refugees (UNHCR) as follows: "the right of the refugee never to be expelled to another country where his life and freedom are in danger because of his race, nationality, membership in a specific social group, or owing to his political situation." 431 The text suggested alluded to the right of a "refugee" not to be expelled or returned and not to an "alien," as the text was amended and incorporated in the Convention. ${ }^{432}$ Consequently, the intention of the States to extend the principle of non-refoulement to every alien and not restrict it to refugees is unequivocal.

217. In summary, under the American Convention, the principle of non-refoulement established in Article 22(8) takes on a particular meaning, even though this provision was included in the paragraph following the recognition of the individual right to seek and receive asylum, and is a broader right in its meaning and scope than the one included 
in international refugee law. Thus, the prohibition of refouler established in Article 22(8) of the Convention offers complementary protection to aliens who are not asylum seekers or refugees, in cases in which their right to life or freedom is threatened for the above-mentioned reasons. A reading of the travaux préparatoires of the Convention confirms the interpretation made in accordance with the ordinary meaning to be given to the terms of Article 22(8) of the Convention, in the context of the treaty and in the light of its object and purpose.

218. Following a more thorough examination of the components of the prohibition of refoulement codified in Article 22(8) of the Convention, the Court considers that, based on the interpretation of Article 22 as a whole, the term "alien" included in paragraph 8 , should be understood as any person, ${ }^{433}$ who is not a national of the State in question or who is not considered its national by the State based on its laws. This covers those persons who are not considered nationals by the State based on its laws, either because they have lost ex lege their nationality or because a decision has deprived them of this nationality, provided that this automatic loss or State decision does not violate its international human rights obligations. In keeping with the foregoing, the Court considers that, if a dispute exists with regard to the conformity of such decision or loss with the obligations derived from the American Convention and, in particular with the prohibition against arbitrary deprivation of nationality or other applicable norms, the consideration that the person is a national should prevail until a final decision has been issued in this regard and, consequently, that person cannot be expelled. ${ }^{434}$ In this regard, it should also be recalled that the provision of human rights treaties, such as Article 22(5) of the Convention, expressly prohibit the expulsion of nationals.

219. Regarding this point, the terms of Article 1(1) of the Convention should also be taken into account. Evidently, the fact that a person is subject to the jurisdiction of the State is not the same as being in its territory. ${ }^{435}$ Consequently, the principle of non-refoulement can be invoked by any alien over whom the State in question is exercising authority or who is under its control, ${ }^{436}$ regardless of whether she or he is on the land, rivers, or sea or in the air space of the State.

220. Furthermore, in the context of the principle of non-refoulement, the Court finds it necessary to make some additional clarifications. In this regard, the Committee on the Rights of the Child has stated that "[the] State obligations cannot be arbitrarily and unilaterally curtailed either by excluding zones or areas from a State's territory or by

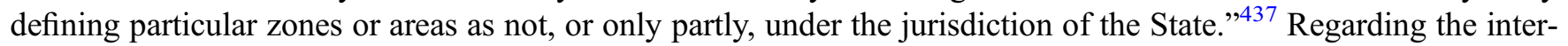
ception of asylum seekers in international waters so as not to allow their requests to be evaluated in potential host States, the Court understands that this practice is contrary to the principle of non-refoulement, because it does not permit the evaluation of each person's specific risk factors. ${ }^{438}$

221. Regarding the risk to the right to life and freedom of the alien, it is pertinent to clarify that this must be real, i.e. it must be a predictable consequence. In this regard, the State must carry out an individualized study to verify and evaluate the circumstances described by the person who asserts that she or he may suffer harm to her or his life or freedom in the country to which the State intends to return her or him-in other words, her or his country or origin or that, if she or he is returned to a third country, runs the risk of being sent, subsequently, to the place where she or he runs that risk. If the person's account is credible, convincing and coherent as regards her or his probable situation of risk, the principle of non-refoulement should be applied.

222. Concerning the risk of violation of the rights of the child, the Court considers that these should be understood and analyzed focusing on age and gender, as well as under the logic established by the Convention on the Rights of the Child, which recognizes the effective and interdependent guarantee of civil and political rights and the progressive full effectiveness of economic, social and cultural rights, ${ }^{439}$ within the framework of which the right to life also incorporates the component of adequate development and survival. In this regard, Articles 6 and 27 of the Convention on the Rights of the Child include in the right to life the State's obligation to "ensure to the maximum extent possible the survival and development of the child." The Committee on the Rights of the Child has interpreted the word "development" in a broad and holistic manner, to include the physical, mental, spiritual, moral, and social development. ${ }^{440}$ These measures acquire fundamental importance because children are at a crucial stage of their physical, mental, spiritual, moral, psychological and social development that will have an impact on the rest of their lives in one way or another. ${ }^{441}$ In this regard, the Committee listed a series of circumstances to be evaluated, which include: ${ }^{442}$ (a) personal and public safety and other conditions, particularly of a socio-economic character, awaiting the child upon return including, where appropriate, a home study conducted 
by social network organizations; (b) availability of care arrangements for that particular child; (c) views of the child expressed in exercise of her or his right to do so under article 12 and those of the caretakers; (d) the child's level of integration in the host country and the duration of absence from the home country; (e) the child's right "to preserve his or her identity, including nationality, name and family relations" (art. 8); (f) the "desirability of continuity in a child's upbringing and to the child's ethnic, religious, cultural and linguistic background" (art. 20); and (g) in the absence of the availability of care provided by parents or members of the extended family, return to the country of origin should, in principle, not take place without advance secure and concrete arrangements of care and custodial responsibilities upon return.

223. Having established the interpretation that this Court accords to Article 22(8) of the Convention, it is necessary to examine the other provisions mentioned in the request, in particular those that refer to the prohibition of torture. Indeed, general international treaties, such as the American Convention, contain provisions that include the legal mandate prohibiting acts of torture and other cruel, inhuman or degrading treatment or punishment.

224. Article 5 of the American Convention expressly recognizes the right to personal integrity, the legal protection of which has the main purpose of the absolute and peremptory prohibition contained in customary international law of torture and cruel, inhuman or degrading treatment or punishment. ${ }^{443}$ This Court has consistently considered in its case law that this prohibition is now a norm of ius cogens. ${ }^{444}$ Thus, an international legal regime has been established of absolute prohibition of all forms of torture, both physical and psychological, and with regard to the latter, it has been recognized that threats and the real danger of a person being subjected to serious physical injuries produces, in certain circumstances, such a degree of moral anguish that it can be considered "psychological torture."

225. Starting with its first judgments, ${ }^{446}$ the Court has ruled on the intrinsic connection between the general obligations to respect and to ensure rights indicated in Article 1(1) of the Convention and the specific rights protected in this instrument that impose, with regard to each of the rights and freedoms recognized, specific obligations that must be determined on a case by case basis and in keeping with the right or freedom concerned. ${ }^{447}$ One of the international obligations associated with the prohibition of torture is the principle of non-return or non-refoulement. ${ }^{448}$ This principle seeks, above all, to ensure the effectiveness of the prohibition of torture in any circumstance and with regard to any person, without any discrimination. Since it is an obligation derived from the prohibition of torture, the principle of non-refoulement in this area is absolute and also becomes a peremptory norm of customary international law; in other words, of ius cogens. 449

226. Hence, Article 5 of the American Convention, read together with the obligations erga omnes to respect and ensure respect for the norms that protect human rights, reveals the obligation of the State not to deport, return, expel, extradite, or remove in any other way to another State a person who is subject to its jurisdiction, or to a third State that is unsafe, when there are grounds for believing that they would be in danger of being subjected to torture, or cruel, inhuman or degrading treatment. ${ }^{450}$

227. In turn, the States have adopted, at both the universal ${ }^{451}$ and the inter-American level, specific international treaties on this issue, which develop the obligations that arise from the norms on prohibition of torture, ${ }^{452}$ by stipulating certain measures that the States must implement internally, because they are considered effective to respond to the ultimate object and purpose of these agreements, which is the prevention and punishment of torture and to ensure non-repetition. ${ }^{453}$ The inter-American system has a specific treaty, the Inter-American Convention to Prevent and Punish Torture, which obliges States Parties to adopt effective measures to prevent and punish torture and other cruel, inhuman or degrading treatment or punishment within their sphere of jurisdiction. One of the measures identified is, precisely, the principle of non-refoulement, included in the fourth paragraph of Article 13, which relates to those required for crimes of torture, in the following terms: "[e]xtradition shall not be granted nor shall the person sought be returned when there are grounds to believe that his life is in danger, that he will be subjected to torture or to cruel, inhuman or degrading treatment, or that he will be tried by special or ad hoc courts in the requesting State." In addition, the principle, as it has been regulated, is also associated with the protection of the right to life and with certain judicial guarantees, so that it is not limited to protection against torture.

228. Nevertheless, an analysis of the principle of non-refoulement, as it has been conceptualized on the basis of the interpretation of Articles 22(7), 22(8) and 5 of the American Convention, and also Article XXVII of the 
American Declaration and Article 13(4) of the Inter-American Convention to Prevent and Punish Torture, calls for an analysis of the connection between these articles and the other provisions. In particular, the request referred to Articles 1 (Obligation to Respect Rights), 2 (Domestic Legal Effects), 4(1) (Right to Life), 7 (Right to Personal Liberty), 8 (Right to a Fair Trial), 19 (Rights of the Child) and 25 (Judicial Protection) of the American Convention, and Articles I (Right to life, liberty and personal security) and XXV (Right to protection from arbitrary arrest) of the American Declaration. Failure to do so would lead to a fragmented interpretation of the provisions that disregards the logic of the interpretive function according to the general rule contained in Article 31 of the Vienna Convention on the Law of Treaties.

229. In this regard, this Court has already emphasized the direct and immediate connection that exists between the rights to life and to personal integrity in the area of human health care. ${ }^{454}$ Thus, it could be considered that the expulsion or return of a person violates international obligations, depending on the particular circumstances of the specific person, such as in cases in which this measures would result in harming or a serious deterioration in the person's health or, even, when it could lead to her or his death. In order to evaluate a possible violation of the Convention or the Declaration, the status of the health or the type of ailment that the person suffers would have to be taken into account, as well as the health care available in the country of origin and the physical and financial accessibility to this, among other aspects. The European Court of Human Rights, ${ }^{455}$ the Human Rights Committee, ${ }^{456}$ and the Inter-American Commission on Human Rights ${ }^{457}$ have all understood this to be so.

230. This Court has also had the occasion to rule under its contentious jurisdiction on the basic guarantees of due process that must be ensured to aliens in administrative proceedings related to an irregular migratory status, ${ }^{458}$ in expulsion or deportation proceedings, either for persons who have entered or remained in a country without complying with the requirements of the immigration laws, or those who are in the country legally, ${ }^{459}$ and in proceedings to determine refugee status. ${ }^{460}$ The Court considers that a flagrant violation of the basic guarantees of due process may result in the violation of the principle of non-refoulement. ${ }^{461}$

231. Moreover, with regard to children, the Committee on the Rights of the Child has concluded that the obligation not to return them is not limited to the real danger that may exist for the child of irreparable harm to her or his rights, contemplated in Articles $6^{462}$ and $37^{463}$ of the Convention on the Rights of the Child, but also applies to other serious violations of the rights guaranteed by this instrument, such as "the insufficient provisions of food or health services," 464 "whether [...] they originate from non-State actors or such violations are directly intended or are the indirect consequence of action or inaction." 465 The Court agrees with the Committee on the Rights of the Child that "[r]eturn to the country of origin shall in principle only be arranged if such return is in the best interest of the child" so that it is prohibited "if it would lead to a 'reasonable risk' that such return would result in the violation of fundamental human rights of the child, and in particular, if the principle of non-refoulement applies."466

232. Consequently, considering the general rule that when an alien alleges before a State that she or he will be at risk if she or he is returned, the competent authorities of that State must, at least, interview the person, giving her or him the opportunity to explain her or his reasons for not being returned, ${ }^{467}$ and make a prior or preliminary assessment in order to determine whether this risk exists. If the risk is verified, she or he should not be returned to her or his country of origin or where the risk exists. ${ }^{468}$ Moreover, in the case of children it is also essential to determine their best interests as indicated previously.

233. Thus, the prohibition to return, expel, deport, repatriate, reject at the border, or not to admit or in any way transfer or remove a child to a State when the child's life, security and/or liberty is at risk of being jeopardized because of persecution or threat, generalized violence or massive violations of human rights, among others, nor where the child is in danger of being subjected to torture or other cruel, inhuman or degrading treatment, or to a third State from which she or he may be sent to one in which these risks may be encountered, receives additional protection in other human rights norms, a protection that extends to another type of gross human rights violations, understood and analyzed from a perspective of age and gender, as well as under the rationale established by the Convention on the Rights of the Child itself, which makes the determination of the best interest surrounded by the due guarantees a central aspect when adopting any decision that concerns the child and, especially, if the principle of non-refoulement is involved. 
234. The foregoing leads to the conclusion that the competence of national authorities to decide who may remain on its territory and, consequently, the power to return a person to his country of origin or to a third country is conditioned by the obligations derived from international law and, in particular, refugee law, international human rights law, the prohibition of torture and Article 22(8) of the American Convention. Indeed, the principle of nonrefoulement is an integral part of these different branches of international law in which it has been developed and codified. However, in each of these contexts, the content of the principle of non-refoulement has a particular sphere of application ratione personae and materiae, and specific correlative obligations, which must be understood to have a complementary nature in the terms of Article 29 of the American Convention and the pro persona principle. Overall, this entails making the most favorable interpretation for the effective enjoyment and exercise of the fundamental rights and freedoms by applying the norm that accords the greatest protection to the human being.

235. Added to this, the Court finds it important to stress that, in order to meet the general obligations to respect and ensure human rights, and - in this case in particular the principle of non-refoulement-it is not sufficient that States merely abstain from violating this principle; rather it is imperative that they adopt positive measures.

236. In situations in which the individual faces a risk of torture, the principle of non-refoulement is absolute. However, situations may exist in which there are substantial reasons to consider that an alien represents a threat to national security or public order, but cannot be returned to the country of origin and there is no safe third country where the person can be returned. ${ }^{469}$ The Court recognizes that, in cases where neither recognition of a refugee status nor regular immigration status is granted, and faced with the impossibility of return, the State must clarify whether the person in this situation only has the right not to be returned or whether, in addition, she or he is entitled to other rights that would make it compulsory for the State to act.

237. The Court considers that some type of standardized protection should exist for persons who have not been recognized as regular migrants nor qualifying under refugee status, but whose return would, however, be contrary to the general obligations of non-refoulement under international human rights law. In the case of M.S.S. v. Belgium and Greece, the European Court of Human Rights considered that the fact that an asylum seeker is left in a precarious situation, with no access to certain minimum living conditions, may constitute a violation of the prohibition of inhuman or degrading treatment. ${ }^{470}$

238. The Court has noted that some countries of the region ${ }^{471}$ have established a mechanism that contemplates a type of protection similar to that granted to asylum seekers and refugees that would prevent a person from being placed in a situation in which her or his life, liberty, safety or integrity would be endangered. This mechanism, known as complementary protection, may be defined as the protection that the authorized entity in the receiving country accords to the alien who is an irregular migrant and who does not meet the conditions under the traditional or broadened definition of a refugee, consisting, mainly, in not returning her or him to the territory of another country where her or his life, liberty, safety or integrity would be threatened. The Court considers that complementary protection is a way in which the State acknowledges the person's situation, identifies his risks, and ascertains his needs. ${ }^{472}$

239. The Court also observes that both refugees and those who receive complementary protection have fled their countries to avoid the violation or the continuing violation of their human rights so that they should obtain similar protection. According to the UNHCR, the privileges and rights derived from international protection should be based on the needs of the applicant and not on the type of international protection granted. ${ }^{473}$

240. Based on the foregoing, the Court considers that complementary protection constitutes a normative development that is consistent with the principle of non-refoulement, by means of which States safeguard the rights of those who do not qualify as refugee or under any other migratory status but who cannot be returned. This complementary protection should recognize the basic rights of the persons protected. The State may limit the exercise of certain rights when granting this protection, provided that this is based on sound and objective reasons and does not violate the principle of non-discrimination.

241. In this context, it is relevant to refer to Article 22 of the Convention on the Rights of the Child, which recognizes the right that States take appropriate measures to ensure that a child who is seeking refugee status or who is considered a refugee in accordance with applicable international or domestic law and procedures, receives the 
appropriate protection and assistance to safeguard her or his rights. In this regard, the Committee on the Rights of the Child established that "[i]n cases in which the requirements for granting refugee status under the 1951 Refugee Convention are not met, unaccompanied and separated children shall benefit from available forms of complementary protection to the extent determined by their protection needs, including the] States' obligations to address the particular protection needs of the unaccompanied and separated child." ${ }^{, 74}$ This necessarily means that they must be ensured, "to the fullest extent, the enjoyment of all human rights granted to children in the territory or subject to the jurisdiction of the State, including those rights which require a lawful stay in the territory."475

242. In conclusion, an interpretation of the provisions relating to the principle of non-refoulement, based on the special protection derived from Articles 19 of the Convention and VII of the Declaration, and considering the regime established by the Convention on the Rights of the Child, leads this Court to affirm the validity of the extremely well established principle of non-refoulement in the case of children, so that any decision about their return to their country of origin or to a safe third country may only be based on their best interests, bearing in mind that the risk of their rights being violated may be manifested in specific and particular ways given their age.

\section{PROCEEDINGS TO ENSURE THE RIGHT OF CHILDREN TO SEEK AND RECEIVE ASYLUM}

243. The Inter-American Court has been consulted on the characteristics required by the proceedings used when a potential request for asylum or recognition of refugee status by a child migrant is identified, in light of Article 22(7) ${ }^{476}$ of the American Convention and Article XXVII ${ }^{477}$ of the American Declaration of the Rights and Duties of Man.

244. In order to ensure the practical effects of the right to seek and receive asylum established in Articles 22(7) of the Convention and XXVII of the American Declaration (supra paras. 73 to 81 and 98 to 99) and to guarantee its exercise in conditions of equality and without discrimination, the Court has emphasized the overriding requirement that States must design and implement fair and efficient proceedings to determine whether the applicant meets the criteria to exercise this right and to request refugee status, taking into account that the definitions contain subjective and objective elements (supra paras. 75, 76 and 80), which can only be ascertained by means of individualized proceedings that permit a proper examination of the asylum request and that prevent returns that are contrary to international law. ${ }^{478}$

245. The applicable treaties on international refugee law and, in particular the 1951 Convention and its 1967 Protocol, do not include explicit references to the procedures to be followed in order to determine refugee status or the procedural guarantees; hence, it corresponds to each State to determine these proceedings and the competent authorities in order to implement this right. Nevertheless, the Court has underscored that any procedure relating to the determination of the refugee status of an individual entails an assessment of and decision on the possible risk of harming the person's most basic rights, such as to life, integrity, and personal liberty. By virtue of "the nature of the rights that could be affected by an erroneous determination of the danger or an unfavorable answer, the guarantees of due process are applicable, as appropriate, to this type of proceeding." ${ }^{479}$ Therefore, this Court has considered that, in application of the principles of non-discrimination and due process of law, predictable proceedings are required that guarantee the applicant's right, including children, to be heard with the due guarantees in accordance with Articles 8 and 25 of the American Convention, ${ }^{480}$ as well as coherence and objectivity in decision-making at each stage of the proceedings to avoid arbitrary decisions. ${ }^{481}$

246. Owing to the special protection derived from Articles 19 of the Convention and VII of the Declaration, the Court understands that the State's obligation to institute and follow fair and efficient proceedings so as to be able to identify potential asylum seekers, and to determine the refugee status of those who meet the requirements to obtain international protection, should also incorporate the components and the specific guarantees developed in light of the comprehensive protection due to all children. In this way, the principles contained in the Convention on the Rights of the Child must "inform both the substantive and procedural aspects of the determination of a child's request for refugee status." 482 Thus, when children are the applicants, they must enjoy, in addition to the general guarantees provided by Articles 8 and 25 of the American Convention, specific procedural and probative guarantees to ensure their access to these proceedings and that just decisions are taken to decide their requests for refugee 
status, ${ }^{483}$ which requires the establishment and implementation of proceedings that are appropriate and safe for children in an environment that creates trust at all stages of the asylum procedure. ${ }^{484}$

247. In order to verify that proceedings concerning requests for asylum or refugee status are appropriate, States must fully apply the guiding principles (supra para. 69). Especially, as regards the best interest of the child being the primary consideration in all actions that affect children and their participation, which includes that those seeking asylum or refugee status have the opportunity to be heard in any administrative or judicial proceeding in which they are involved. Regarding the significant relationship between the right to be heard and the best interest of the child, the Court has already emphasized that this "governs the essential role of children in all decisions that affect their life," 485 including asylum proceedings or those held to determine refugee status. Furthermore, it is relevant to refer to the content of Article 22 of the Convention on the Rights of the Child, ${ }^{486}$ which recognizes the right that States ensure that a child who is seeking refugee status or who is considered a refugee in accordance with applicable international or domestic law and procedures, receives appropriate protection and assistance to safeguard her or his rights.

248. Specifically, the UNHCR Executive Committee has emphasized that the adaptation of such procedures to the specific needs of children include: "relevant evidentiary requirements, prioritized processing of unaccompanied and separated child asylum-seekers, qualified free legal or other representation for unaccompanied and separated children, and consider an age and gender-sensitive application of the 1951 Convention through the recognition of child-specific manifestations and forms of persecution." 487

249. Thus, it is possible to consider that Articles 19, 22(7) and 22(8) of the American Convention, VII and XXVII of the American Declaration, 22 of the Convention on the Rights of the Child, as well as the 1951 Convention, its 1967 Protocol and the regional definition of the Cartagena Declaration, constitute the international corpus iuris for the protection of human rights of children that are asylum seekers and refugees in the American continent. In this context, the Court will now describe the essential components derived from the State obligation to establish and implement fair and efficient procedures to be able to identify potential asylum seekers and, as appropriate, determine refugee status to those who meet the requirements to obtain this type of international protection, taking into account the particular manifestations of the persecution of children (supra para. 80), as well as those specifically required to ensure procedures that are accessible and appropriate for children.

250. In this regard, when child migrants are identified as potential asylum seekers or applicants for refugee status, they should receive the necessary guidance as to the procedure to be followed, ${ }^{488}$ in a language and manner that they can understand. And if it is appropriate, they should be given the opportunity to contact a representative of UNHCR or the entity that performs such functions, in case UNHCR is not in the country. ${ }^{489}$

251. Similarly, the Court has previously indicated that this obligation includes providing the asylum applicant with the necessary facilities, ${ }^{490}$ including the services of a competent interpreter, ${ }^{491}$ as well as, if appropriate, access to legal assistance and representation, ${ }^{492}$ both for submitting the application to the authorities, ${ }^{493}$ and during its processing. In the case of children, legal representation must be free, and those providing it must have received special training. ${ }^{494}$ Equally, in immigration proceedings (supra paras. 132 to 136), in the case of an unaccompanied or separated child, the State has a mandatory obligation to appoint a guardian to safeguard the well-being and best interest of the child. ${ }^{495}$

252. Once the child has been referred to the competent authority, which must be clearly identified within the framework of the established procedure, the latter must examine the request objectively. ${ }^{496}$ To this end, a personal interview is an essential requirement so that the applicant may explain her or his case ${ }^{497}$ and so that the right to be heard is guaranteed. The right of children to express their views and to play a significant role is also important in the context of asylum proceedings or to determine refugee status, ${ }^{498}$ and its scope may depend on whether the child is the applicant, regardless of whether she or he is accompanied, unaccompanied or separated from her or his parents or the persons responsible for taking care of her or him. ${ }^{499}$ If children are unable to be interviewed, the non-verbal means of communication that are most appropriate in each specific case should be used in order to comply with the principle the right to participate. 
253. The Court also considers that the provisions of aforementioned Articles 19 of the Convention and VII of the Declaration are complied with when the practice is followed of granting priority attention first to the interview with unaccompanied children, then to those who are separated, and following this to those accompanied by just one parent and, lastly, to those who arrive as part of a family, ${ }^{500}$ in order to provide an appropriate response and determine the urgency of the need for protection.

254. The interview should be conducted in a place that is adapted to the needs and safety of the child, which means in a place that is not intimidating, and by a professional who has received specialized training. At the start of the interview, the authority should inform the child about what will happen, endeavoring to prevent discomfort and emphasizing that the interview is confidential. In this regard, the Court has determined ${ }^{501}$ that, in order to protect the rights of applicants who may be at risk at all stages of the procedure, protection of the applicant's information and request must be respected, as well as the principle of confidentiality. ${ }^{502}$

255. The Court finds that the interview is not only a means of gathering information on the actual situation of the child applicant and obtaining and verifying the available evidence, but also allows immediate needs for assistance to be identified, such as clothes, food, and health care, among others.

256. The Court recalls that administrative and judicial proceedings concerning the protection of children's human rights must be conducted with exceptional diligence and promptness by the authorities (supra para. 143). For this reason, there should be the least possible delay in recognizing children's refugee status. The Court considers that the State is responsible for providing special protection and care to the child applicant while the decision is being made. This means ensuring accommodation and food, as well as access to health care, psychosocial care, and education. $^{503}$

257. The decision on the request taken by the competent authority as to whether the applicant is granted refugee status based on the factual and legal determinations must expressly include the reasons for the decision, ${ }^{504}$ in order to enable the applicant to exercise his right of appeal, if necessary. In addition, the decision must be communicated to the child in a language and manner appropriate to her or his age, and in the presence of the guardian, legal representative, and/or another support person. ${ }^{505}$ If refugee status is recognized, the competent authority should grant a document certifying this decision.

258. In addition, the Court has indicated that if the applicant is not granted refugee status, she or he should be provided information on how to appeal the decision and given a reasonable time for this, so that the decision adopted is formally reconsidered. ${ }^{506}$ If children are denied refugee status, an effort should be made to avoid or reduce any possible psychological stress or harm. ${ }^{507}$

259. Similarly, the Court has indicated that the remedy of review or appeal must have suspensive effect and must allow the applicant to remain in the country until the competent authority has adopted the relevant decision, including when the appeal is pending. ${ }^{508}$

260. To that end, the Court notes that the issuing of a document that shows the immigration status of the applicant is a safeguard against arbitrary expulsion or refoulement. This document must be issued while the asylum procedure or determination of refugee status is being processed, and should allow access to services without stigmatizing the applicant. $^{509}$

261. In brief, in order to ensure effectively the right recognized in Articles 22(7) of the American Convention and XXVII of the American Declaration, States must adapt the proceedings on asylum or on the determination of refugee status, in order to provide children with a real access to these procedures, allowing their specific situation to be considered. The Court finds that this obligation entails: ${ }^{.10}$ not impeding entry to the country; if risk and needs are identified, the person should be given access to the State entity responsible for granting asylum or recognition of refugee status or other procedures that are suitable for the protection and specific attention to the circumstances of each case; priority processing of requests for asylum made by children as the main applicant; the availability of reception personnel in the entity, who can examine the child to determine her or his state of health; conducting an examination and interview endeavoring not to cause further trauma or revictimization; having available a place to accommodate the applicant, if they do not have one; issuing an identity document to avoid return; studying the case, with sufficient 
flexibility as regards the evidence; assigning an independent and trained guardian in the case of unaccompanied or separated children; if refugee status is granted, proceed to carry out family reunification procedures, if necessary in view of the best interest of the child; and lastly, seeking a durable solution, such as voluntary repatriation, resettlement or social integration, in accordance with the determination of the best interest of the child. ${ }^{511}$

262. It is true that States generally determine cases on an individual basis when granting refugee status. However, in situations of a mass influx of persons, ${ }^{512}$ in which individual determination of refugee status is generally impractical, but there is a pressing need to provide protection and assistance, particularly when children are involved, States should guarantee access to "protection from refoulement, and basic humanitarian treatment," 513 by being able to resort to the group, collective or prima facie recognition. Under this provision, it is necessary to recognize the concept of shared responsibility that implies, first, that the host country is obliged to admit asylum seekers within the territory, without discrimination, and to respect the principles of non-refoulement and non-rejection at borders, and to grant appropriate international protection. Accordingly, the country of origin must endeavor to resolve and eliminate the causes of displacement, in order to ensure a durable solution, in particular, voluntary repatriation.

\section{RIGHT TO FAMILY LIFE OF CHILDREN IN THE CONTEXT OF PROCEDURES FOR THE EXPULSION OR DEPORTATION OF THEIR PARENTS FOR MIGRATORY REASONS}

263. The Inter-American Court has been consulted on the scope that should be given to protecting the right of children not to be separated from their parents in cases in which the deportation of one or both parents could be ordered, owing to their migratory status, in light of Articles $8,{ }^{514} 17,{ }^{515} 19^{516}$ and $25^{517}$ of the American Convention and Articles $\mathrm{VI}^{518}$ and $\mathrm{XXV}^{519}$ of the American Declaration of the Rights and Duties of Man.

264. Article 17 of the American Convention, as well as Article VI of the American Declaration, affirms the family's right to protection, recognizing that the family is the basic element of society that must be protected. The Court has already indicated that this right means not only ordering and directly implementing measures of protection for children, but also promoting, as broadly as possible, the development and strengthening of the family unit, ${ }^{520}$ because the mutual enjoyment of the cohabitation of parents and children is a fundamental element of family life. ${ }^{521}$

265. The Court has also specified that Article 11(2) of the American Convention, ${ }^{522}$ which recognizes the right of everyone to receive protection against arbitrary or abusive interference with his family life, is an implicit part of the family's right to protection. ${ }^{523}$ In this regard, the Court considers that, in order to respond to the request, Articles 17(1) and 11(2) of the Convention, as well as Article VII of the Declaration, must be analyzed together, because the Court must interpret the scope of said right in the context of a specific situation: cases in which one or both parents are subjected to an expulsion proceeding or a deportation as a result of their migratory status, which could represent an interference in the enjoyment of family life by separating the child from one or both parents. In particular, the Court must determine the parameters under which this interference would not be arbitrary or abusive and, consequently, the restriction on family life would be legitimate.

266. This requires the Court to make a series of conceptual clarifications before responding to the question posed. First, the Court notes that the word expulsion is used in the title of the request, while the specific question uses the word deportation. Although the concepts of expulsion and deportation are generally used interchangeably, it is also true that they have their own specific meaning within the framework of the national legislations or in the different branches of international law.

267. In their respective spheres of competence, the United Nations High Commissioner for Refugees (UNHCR) and the International Law Commission have provided definitions of these terms. For the UNHCR, in conformity with Article 32 of the 1951 Convention, expulsion is the removal of a lawful resident from the territory of a State by government authorities. ${ }^{524}$ According to the International Law Commission, the "notion of expulsion may be understood as referring to the exercise of the right or power of a State to require an alien to leave its territory" by way of "a decision or order issued by the appropriate administrative or judicial body in accordance with its national law," "when his or her continuing presence is contrary to the interests of the territorial State." 525 Meanwhile, the 
concept of deportation is related specifically to the enforcement of said decision or order consisting in obligatorily returning the person to his country of origin or the preceding country, and preventing him from returning for a certain time. $^{526}$

268. For its part, the Human Rights Committee has adopted a functional criterion in the application of Article 13 of the International Covenant on Civil and Political Rights ${ }^{527}$ with regard to the expulsion of aliens, as follows: "[the] article is applicable to all procedures aimed at the obligatory departure of an alien, whether described in national law as expulsion or otherwise."

269. For the practical effects of this opinion, the Court will adopt a functional definition such as that of the Human Rights Committee, without this implying a ruling on the validity or grounds for the definitions provided by the UNHCR and the International Law Commission in their respective spheres of competence. Consequently, in the context of this consultation, the Court understands expulsion as any decision, order, procedure or proceeding by or before the competent administrative or judicial organ, irrespective of the name that it is given in national law, related to the obligatory departure of a person from the host State that results in the person abandoning the territory of this State or being transferred beyond its borders. In this manner, when referring to expulsion, the term also encompasses, in specific or internal state terminology, what could be described as a deportation.

270. In this regard, it should be recalled that there may be different situations that can lead to an expulsion. Article 32 of the 1951 Convention provides that the expulsion of a refugee may only be justified by national security or public order. Nevertheless, under international human rights law, the expulsion of nationals is prohibited and "an alien lawfully in the territory of a State [ . . is protected] and may be expelled from it only pursuant to a decision reached in accordance with the law." 529 These provisions are also in force in cases that may result in expulsion or deportation when deciding a dispute on the lawfulness of the person's entry or permanence. ${ }^{530}$

271. The Court understands that the question focuses on the latter situation, i.e. on those cases in which the expulsion of the parent, who is not a national of the host State, is based only on his irregular migratory status, excluding those who may have committed an offense in the country of origin or in the recipient country.

272. It is also pertinent to recall that the family to which every child has a right is, above all, her or his biological family, including extended family, and which should protect the child and also be the priority object of the measures of protection provided by the State. ${ }^{531}$ Nevertheless, the Court recalls that there is no single model for a family. ${ }^{532}$ Accordingly, the definition of family should not be restricted by the traditional notion of a couple and their children, because other relatives may also be entitled to the right to family life, such as uncles and aunts, cousins, and grandparents, to name but a few of the possible members of the extended family, provided they have close personal ties. In addition, in many families the person or persons in charge of the legal or habitual maintenance, care and development of a child are not the biological parents. Furthermore, in the migratory context, "family ties" may have been established between individuals who are not necessarily family members in a legal sense, especially when, as regards children, they have not been accompanied by their parents in these processes. This is why the State has the obligation to determine, in each case, the composition of the child's family unit. ${ }^{533}$ Consequently, in drawing up this opinion and in the context of the situation of migrants, the Court will apply the term "parents" of the child used in the question asked to the Court in a broad sense, including in it those who really constitute part of the child's family and, therefore, are entitled to the protection of the family granted in Articles 17 of the Convention and VI of the American Declaration. In this regard, the Committee on the Rights of the Child has stated that "[ $t]$ he term 'family' must be interpreted in a broad sense to include biological, adoptive or foster parents or, where applicable, the members of the extended family or community as provided for by local custom," 534 in accordance with Article 5 of the Convention on the Rights of the Child. Furthermore, the provisions of Article 9 concerning the separation of children from their parents also extends "to any person holding custody rights, legal or customary primary caregivers, foster parents and persons with whom the child has a strong personal relationship." 535

273. Having established and delimited the subject of this question, it should be recalled that host States have the right to draw up and execute their migration policies, including the control of entry, residence, and expulsion of aliens. ${ }^{536}$ However, when a State adopts a decision that entails any limitation to the exercise of any right of a child, it must take the child's best interest into account and strictly respect the relevant provisions in this 
regard. ${ }^{537}$ Thus, the Court has established that "[a]ny decision pertaining to the separation of a child from her or his family must be justified by the best interest of the child." 538 Specifically, it has understood that "the child must remain in its nuclear family, unless there are decisive reasons, based on the child's best interest, to decide to separate the child from the family." ${ }^{, 39}$ Consequently, the legal separation of a child from her or his family is only admissible if it is justified by the child's best interest, and if it is exceptional and, insofar as possible, temporary. ${ }^{540}$ In this regard, the Convention on the Rights of the Child establishes, as part of the child protection system, the obligation to prevent family separation and to preserve family unity, ${ }^{541}$ but includes two particular situations in which the separation is necessary in the best interest of the child, namely: abuse or neglect of the child by the parents or where the parents are living separately and a decision must be made as to the child's place of residence. ${ }^{542}$

274. Based on the preceding considerations, the child's right to the protection of the family and, in particular, to enjoy family life preserving family unity insofar as possible, should always be given prevalence, except in those cases in which the separation of the child from one or both parents would be necessary owing to the best interest of the child. However, the child's right to family life per se does not override the authority of the States to implement their own immigration policies in keeping with human rights, in the context of proceedings relating to the expulsion of one or both parents. The Convention on the Rights of the Child also contemplates the possibility of family separation owing to the deportation of one or both parents. ${ }^{543}$

275. Consequently, it is possible to observe that two conflicting interests arise in cases in which a decision must be taken on the eventual expulsion of one or both parents: (a) the authority of the State concerned to implement its own immigration policy to achieve legitimate purposes that ensure general welfare and observance of human rights, and (b) the right of the child to the protection of the family and, in particular, to enjoy family life by preserving family unit insofar as possible. However, the just demands of general welfare should in no way be construed so as to enable any hint of arbitrariness to the detriment of rights. In order to weigh the interests in conflict, an assessment must be made of whether the measure: is established by law, ${ }^{544}$ and complies with the requirements of (a) suitability; (b) necessity, and (c) proportionality; in other words, it must be necessary in a democratic society. ${ }^{545}$

276. Concerning the requirement of suitability, the measure must have a legitimate purpose, i.e. a purpose in keeping with the American Convention. ${ }^{546}$ Nevertheless, owing to the nature of the rights that may be affected, this cannot be any kind of purpose, but one that fulfills an essential public interest.

277. The measure must be necessary in the sense that, within the universe of possible measures, there is no other measure that would be equally effective and would be less harmful as regards the right of the child to the protection of the family and, in particular, to maintaining the family unit. To this end, evidently, States must envisage alternatives to expulsion that promote the family unit and regularization of the immigration situation. ${ }^{547}$

278. Lastly, the measure must be strictly proportionate; thus, it must be the one that least restricts the protected right and is closely adapted to the achievement of the legitimate purpose. ${ }^{54}$ Indeed, in order to assess the conflicting interests, it must be taken into account that a measure of expulsion may prejudice the life, well-being, and development of the child, and, therefore, her or his best interest must be a primary consideration. ${ }^{549}$ Thus, in view of the fact that, in abstract, the expulsion of one or both parents would, in almost no circumstance, be in the best interest of the child, but rather would harm them, the State concerned has the obligation to weigh, adequately and strictly, the protection of the family unit against the legitimate interests of the State, and must determine, in the context of each specific case, that the expulsion of one or both parents does not lead to an abusive or arbitrary interference in the family life of the child. ${ }^{550}$

279. To this end, the State will subsequently have to evaluate the specific circumstances of the persons concerned, including in particular: (a) the immigration history, the duration of the stay, and the extent of the ties of the parent and/or the family to the host country; (b) consideration of the nationality, ${ }^{551}$ custody and residence of the children of the person to be expelled; (c) scope of the harm caused by the rupture of the family owing to the expulsion, including the persons with whom the child lives, as well as the time that the child has been living in this family unit, and (d) scope of the disruption of the daily life of the child if her or his family situation changes owing to a measure of expulsion of a person in charge of the child, so as to weigh all these circumstances rigorously in light of the best interest of the child in relation to the essential public interest that should be protected. 
280. In those situations in which the child has a right to nationality - original, ${ }^{552}$ by naturalization, or for any other reason established in domestic law - of the country from which one or both of the parents may be expelled owing to their irregular migratory situation, or in which the child complies with the legal conditions to reside there on a permanent basis, it is axiomatic that the child must conserve the right to continue enjoying her or his family life in said country and, as a component of this, mutual enjoyment of the cohabitation of parents and children. The Court finds, in application of the criteria described above, that the rupture of the family unit by the expulsion of one or both parents due to a breach of immigration laws related to entry or permanence is disproportionate in these situations, because the sacrifice inherent in the restriction of the right to family life, which may have repercussions on the life and development of the child, appears unreasonable or excessive in relation to the advantages obtained by forcing the parent to leave the territory because of an administrative offense.

281. In short, in the Court's opinion any administrative or judicial organ that must decide on family separation owing to expulsion based on the migratory status of one or both parents must, when weighing all the factors, consider the particular circumstances of the specific case, and guarantee an individual decision ${ }^{553}$ - in keeping with the parameters described in the paragraphs above - evaluating and determining the child's best interest. ${ }^{554}$

282. In this regard, the Court finds it essential that, when making this assessment, States ensure the right of children to have the opportunity to be heard based on their age and maturity ${ }^{555}$ and that their views are duly taken into account in those administrative or judicial proceedings in which a decision may be adopted that entails the expulsion of their parents. ${ }^{556}$ If the child is a national of the receiving country, but one or neither of her or his parents is, it is necessary to hear the child in order to understand the impact that the expulsion of the parent(s) may have on her or him. Also, granting the child the right to be heard is fundamental in order to determine whether there is an alternative that is more appropriate to her or his best interest.

\section{OPINION}

283. Based on the foregoing reasons, in interpretation of Articles 1(1), 2, 4(1), 5, 7, 8, 11, 17, 19, 22(7), 22(8), 25 and 29 of the American Convention on Human Rights, Articles I, VI, VII, VIII, XXV and XXVII of the American Declaration of the Rights and Duties of Man, and Article 13 of the Inter-American Convention to Prevent and Punish Torture,

\section{THE COURT,}

\section{DECIDES}

unanimously, that:

1. It has jurisdiction to issue this Advisory Opinion.

\section{AND IS OF THE OPINION}

unanimously, that:

1. In accordance with the request of the applicant States, this Advisory Opinion determines below, as precisely as possible and pursuant to the provisions cited above, the State obligations with regard to children associated with their migratory status, or that of their parents, which, in consequence, States must consider when designing, adopting, implementing and applying their immigration policies, including in them, as appropriate, both the adoption or application of the corresponding norms of domestic law, and also the signature or implementation of the pertinent treaties and/or other international instruments.

2. Bearing in mind, to this end, that a child is any person under 18 years of age, States must accord priority to a human rights-based approach, from a crosscut perspective that takes into consideration the rights of the child and, in particular, the protection and comprehensive development of the child, which should have priority over any consideration of nationality or migratory status, in order to ensure the full exercise of their rights, in the terms of paragraphs 34 to 41 and 51 to 71 . 
3. States are obliged to identify non-national children who require international protection within their jurisdictions, through an initial evaluation with guarantees of safety and confidentiality, in order to provide them with the necessary, suitable and individualized attention based on the child's age, and in case of doubt about the age, assess and determine it; determine whether the children are unaccompanied or separated, as well as their nationality or, where appropriate, their statelessness; obtain information on the reasons for the departure from the country of origin, on the reasons for their separation from their family, if this is the case, as well as information on their vulnerabilities, and on any other element that proves or negates their need for some type of international protection; and adopt, if necessary and pertinent for the best interest of the child, special measures of protection, in the terms of paragraphs 72 to 107.

4. In order to ensure access to justice under equal conditions, to guarantee effective due process, and to ensure that the best interest of the child is a paramount consideration in all the decisions adopted, States must guarantee that the administrative or judicial proceedings in which a decision is taken on the rights of migrant children are adapted to their needs and are accessible to them, in the terms of paragraphs 108 to 115 .

5. The following guarantees of due process, in accordance with international human rights law, must govern any immigration proceedings, whether administrative or judicial, that involve children: the right to be notified of the existence of a proceeding and of the decision adopted in the context of the immigration proceedings; the right that the immigration proceedings are conducted by a specialized official or judge; the right to be heard and to take part in the different procedural stages; the right to be assisted without charge by a translator and/or interpreter; effective access to communication with consular officials and consular assistance; the right to be assisted by a legal representative and to communicate freely with the representative; the obligation to appoint a guardian in the case of children who are unaccompanied or separated; the right that the decision adopted takes into consideration the best interest of the child and is duly reasoned; the right to appeal the decision before a higher court with suspensive effect, and a reasonable time for the duration of the proceedings, in the terms of paragraphs 116 to 143 .

6. States may not resort to the deprivation of liberty of children as a precautionary measure to protect the objectives of immigration proceedings; nor may States base this measure on failure to comply with the requirements to enter and to remain in a country, on the fact that the child is alone or separated from her or his family, or on the objective of ensuring family unity, because States can and should have other less harmful alternatives and, at the same time, protect the rights of the child integrally and as a priority, in the terms of paragraphs 144 to 160 .

7. States must design and incorporate into their respective domestic law a set of non-custodial measures to be implemented while immigration proceedings are being held that prioritize the comprehensive protection of the rights of children, strictly respecting her or his human rights and the principle of legality, and decisions that order such measures should be implemented by a competent administrative or judicial authority in a procedure which complies with specific minimum guarantees, in the terms of paragraphs 161 to 170 .

8. The places for accommodating children should respect the principle of separation and the right to family unity, so that, in the case of unaccompanied or separated children, they should be lodged in places other than those that correspond to adults and, in the case of accompanied children, they should be lodged with their family members, unless separating them is more appropriate in application of the principle of the best interest of the child; in addition, secure material conditions and an adequate regime that ensure the comprehensive protection of rights in a non-custodial environment, in the terms of paragraphs 171 to 184 .

9. In situations of restriction to personal liberty that may eventually constitute or lead, depending on the circumstances of the particular case, to a measure that results in deprivation of liberty, States must respect the specific guarantees that become operational in this context, in the terms of paragraphs 185 to 206. 
10. States are prohibited from returning, expelling, deporting, repatriating, rejecting at the border or not admitting, or in any way transferring or removing a child to a State when the child's life, security and/or liberty is at risk of violation because of persecution or threat thereof, generalized violence or massive violations of human rights, among others, or when the child is at risk of being submitted to torture or other cruel, inhuman or degrading treatments, or to a third State that may send the child to a State in which she or he can run such risks, in terms of paragraphs 207 to 242.

11. As established in the Convention on the Rights of the Child and other provisions for the protection of human rights, any decision on the return of a child to the country of origin or to a safe third country shall only be based on the requirements of her or his best interest, taking into account that the risk of violation of the child's rights may be manifested in particular and specific ways owing to age, in the terms of paragraphs 207 to 242.

12. The State obligation to establish and follow fair and efficient procedures in order to identify potential asylum applicants and to make a refugee status determination through an suitable and individualized analysis of the petitions and their corresponding guarantees, must include the specific components developed in light of the comprehensive protection due to all children, applying fully the guiding principles and, especially those referring to the child's best interest and participation, in the terms of paragraphs 243 to 262 .

13. Any administrative or judicial body that is to make a decision on the separation of family members, due to expulsion based on the immigration status of one or both parents, must employ a weighting analysis that considers the particular circumstances of the case and guarantees an individualized decision, prioritizing in each case the best interest of the child. In situations in which the child has a right to the nationality of the country from which one or both of her or his parents may be expelled, or the child complies with the legal conditions to reside there on a permanent basis, States may not expel one or both parents for administrative immigration offenses, as the child's right to family life is sacrificed in an unreasonable or excessive manner, in the terms of paragraphs 263 to 282 .

14. In view of the fact that the preceding obligations refer to a peculiar, complex and evolving issue of our time, they shall be understood as a contribution to the progressive development of International Human Rights Law, process in which, consequently, this Advisory Opinion is inserted.

Done in Spanish and Portuguese, the Spanish text being authentic, in San José, Costa Rica, on August 19, 2014. 


\section{Humberto Antonio Sierra Porto}

President

Roberto F. Caldas

Diego García-Sayán

Eduardo Ferrer Mac-Gregor Poisot

Pablo Saavedra Alessandri

Registrar
Manuel E. Ventura Robles

Eduardo Vio Grossi

So ordered,

Humberto Antonio Sierra Porto

President

Pablo Saavedra Alessandri

Registrar 


\section{ENDNOTES}

1 The complete text of the request can be consulted via the following link to the Court's website: http://www.corteidh.or.cr/ solicitudoc/solicitud_eng.pdf

2 On June 22, 2012, the State of Nicaragua presented written observations outside the time frame granted to this end. It was therefore advised that it could present the arguments and documentation it deemed pertinent during the public hearing that would be held.

3 Available at: http://www.corteidh.or.cr/docs/asuntos/ oc21110512eng.pdf

4 Available at: http://www.corteidh.or.cr/docs/opiniones/sol_ oc_21_ing.pdf

5 Available at the following link: http://www.corteidh.or.cr/ index.php/observaciones

6 The annex with the summaries is only available in Spanish.

$7 \quad C f$. Case of the Constitutional Court v. Peru. Competence. Judgment of September 24, 1999. Series C No. 55, para. 33, and Case of Jv. Peru. Preliminary Objection, Merits, and Reparations. Judgment of November 27, 2013. Series C No. 275, para. 18.

8 Case of Almonacid Arellano et al. v. Chile. Preliminary objections, merits, reparations and costs. Judgment of September 26, 2006. Series C No. 154, para. 124, and Case of Liakat Ali Alibux v. Suriname. Preliminary Objections, Merits, Reparations, and Costs. Judgment of January 30, 2014. Series C No. 276, para. 87.

9 Cf. Article 55 of the American Convention on Human Rights. Advisory Opinion OC-20 of September 29, 2009. Series A No. 20, para. 18, and Case of Chaparro Alvarez and Lapo Íñiguez v. Ecuador. Preliminary Objection, Merits, Reparations, and Costs. Judgment of November 21, 2007. Series C No. 170 , para. 15.

10 "Other Treaties" Subject to the Advisory Jurisdiction of the Court (Art. 64 American Convention on Human Rights). Advisory Opinion OC-1/82 of September 24, 1982. Series A No. 1, first operative paragraph.

11 The following States are Parties to this treaty: Argentina, Bolivia, Brazil, Chile, Colombia, Costa Rica, Ecuador, El Salvador, Guatemala, Mexico, Nicaragua, Panama, Paraguay, Peru, Dominican Republic, Suriname, Uruguay and Venezuela.

$12 C f$. Interpretation of the American Declaration of the Rights and Duties of Man within the Framework of Article 64 of the American Convention on Human Rights. Advisory Opinion OC-10/89 of July 14, 1989. Series A No. 10, first and only operative paragraph.

13 Cf. "Other Treaties" Subject to the Advisory Jurisdiction of the Court (Art. 64 American Convention on Human Rights), supra, paras. 14 to 17, and Article 55 of the American Convention on Human Rights, supra, para. 18.

14 Cf. "Other Treaties" Subject to the Advisory Jurisdiction of the Court (Art. 64 American Convention on Human Rights), supra, paras. 14 to 17, and Control of Due Process in the Exercise of the Powers of the Inter-American Commission on Human Rights (Arts. 41 and 44 to 51 of the American Convention on Human Rights), Advisory Opinion OC-19/05 of November 28, 2005. Series A No. 19, para. 18.
Article 70. Interpretation of the Convention

1. Requests for an advisory opinion under Article 64 (1) of the Convention shall state with precision the specific questions on which the opinion of the Court is being sought.

2. Requests for an advisory opinion submitted by a Member State or by the Commission shall, in addition, identify the provisions to be interpreted, the considerations giving rise to the request, and the names and addresses of the Agent or the Delegates. $[\ldots]$

Article 71. Interpretation of other treaties

1. If, as provided for in Article 64(1) of the Convention, the interpretation requested refers to other treaties concerning the protection of human rights in the American States, the request shall indicate the name of the treaty and parties thereto, the specific questions on which the opinion of the Court is being sought, and the considerations giving rise to the request. $[\ldots]$

17 Cf. Reports of the Inter-American Commission on Human Rights (Art. 51 American Convention on Human Rights). Advisory Opinion OC-15/97 of November 14, 1997. Series A No. 15, para. 31, and Control of Due Process in the Exercise of the Powers of the Inter-American Commission on Human Rights (Arts. 41 and 44 to 51 of the American Convention on Human Rights), supra, para. 17.

18 Cf. Judicial Guarantees in States of Emergency (Arts. 27.2, 25 and 8 American Convention on Human Rights). Advisory Opinion OC-9/87 of October 6, 1987. Series A No. 9, para. 16, and Article 55 of the American Convention on Human Rights, supra, para. 15.

19 Cf. "Other Treaties" Subject to the Advisory Jurisdiction of the Court (Art. 64 American Convention on Human Rights), supra, para. 39, and Control of Due Process in the Exercise of the Powers of the Inter-American Commission on Human Rights (Arts. 41 and 44 to 51 of the American Convention on Human Rights), supra, para.18.

20 Cf. "Other Treaties" Subject to the Advisory Jurisdiction of the Court (Art. 64 American Convention on Human Rights), supra, para. 25, and Control of Due Process in the Exercise of the Powers of the Inter-American Commission on Human Rights (Arts. 41 and 44 to 51 of the American Convention on Human Rights), supra, para.18.

$21 C f$. Case of Fontevecchia and D'Amico v. Argentina. Merits, reparations and costs. Judgment of November 29, 2011. Series C No. 238, para. 93, and Case of Mendoza et al. v. Argentina. Preliminary objections, merits and reparations. Judgment of May 14, 2013. Series C No. 260, para. 221.

22 Cf. Case of Velásquez Rodríguez v. Honduras. Merits. Judgment of July 29, 1988. Series C No. 4, para. 164, and Case of the "Las Dos Erres" Massacre v. Guatemala. Preliminary Objection, Merits, Reparations, and Costs. Judgment of November 24, 2009. Series C No. 211, para. 197. 
23 Cf. Case of Almonacid Arellano et al. v. Chile, supra, para. 124, and Case of Likat Ali Alibux v. Suriname, supra, para. 124.

24 The Effect of Reservations on the Entry into Force of the American Convention on Human Rights. Advisory Opinion OC-2/82 of September 24, 1982. Series A No. 2, para. 29, and Case of Boyce et al. v. Barbados, Preliminary objections, merits, reparations and costs. Judgment of November 20, 2007. Series C No. 169, para. 15.

25 Cf. Case of Gelman v. Uruguay. Monitoring Compliance with Judgment. Order of the Inter-American Court of Human Rights of March 20, 2013, Considering clauses 65 to 90.

26 Cf. Juridical Status and Rights of Undocumented Migrants. Advisory Opinion OC-18/03 of September 17, 2003. Series A No. 18, para. 60 .

27 See United Nations, Department of Economic and Social Affairs, Population Division (2013). Trends in International Migrant Stock: The 2013 Revision - Migrants by Age and Sex (United Nations database, POP/DB/MIG/Stock/ Rev.2013/Age).

28 See United Nations, Department of Economic and Social Affairs, Population Division (2013). Trends in International Migrant Stock: The 2013 Revision - Migrants by Age and Sex (United Nations database, POP/DB/MIG/Stock/ Rev.2013/Age).

$29 C f$. United Nations High Commissioner for Refugees (UNHCR), War's human cost. Global Trends 2013, p. 12.

30 This figure does not include information with regard to some countries that receive requests for asylum, such as the United States of America. $C f$. United Nations High Commissioner for Refugees (UNHCR), War's human cost. Global Trends 2013, p. 28.

$31 C f$. Report of the Special Rapporteur on the human rights of migrants, Jorge Bustamante, Promotion and Protection of all Human Rights, Civil, Political, Economic, Social, and Cultural Rights, Including the Right to Development, UN Doc. A/HRC/11/7, May 14, 2009, para. 19.

32 Cf. Juridical Status and Rights of Undocumented Migrants, supra, para. 168.

33 Cf. Case of Vélez Loor v. Panama. Preliminary objections, merits, reparations and costs. Judgment of November 23, 2010. Series C No. 218, para. 97, and Case of the Pacheco Tineo Family v. Bolivia. Preliminary objections, merits, reparations and costs. Judgment of November 25, 2013. Series C No. 272, para. 129.

34 A State's immigration policy consists of any institutional act, measure, or omission (laws, decrees, decisions, directives, administrative actions, etc.) that relate to the entry, departure or permanence of nationals or foreign persons on its territory. Cf. Juridical Status and Rights of Undocumented Migrants, supra, para. 163.

Cf. Matter of Haitians and Dominicans of Haitian Origin in the Dominican Republic with regard to Dominican Republic. Provisional measures. Order of the Inter-American Court of Human Rights of August 18, 2000, Considering clause 4, and Case of Vélez Loor v. Panama, supra, para. 97.

36 Cf. Juridical Status and Rights of Undocumented Migrants, supra, para. 168, and Case of Vélez Loor v. Panama, supra, para. 97. Similarly, the Special Rapporteur on the human rights of migrants of the United Nations Human Rights
Council has indicated that: "[a]lthough it is the sovereign right of all States to safeguard their borders and regulate their migration policies, States should ensure respect for the human rights of migrants while enacting and implementing national immigration laws." Report of the Special Rapporteur on the human rights of migrants, Jorge Bustamante, Promotion and Protection of all Human Rights, Civil, Political, Economic, Social, and Cultural Rights, Including the Right to Development, UN Doc. A/HRC/20/24, February 25, 2008, para. 14.

37 Montevideo Commitment on Migration and Development of the Heads of State and Government of the Ibero-American Community, adopted during the XVI Ibero-American Summit held in Montevideo, Uruguay, on November 4 and 5, 2006, para. 25(g) [translation from Spanish].

$38 C f$. Declaration and Plan of Action of Mexico to strengthen the international protection of refugees in Latin America, Mexico City, November 16, 2004.

39 Cf. Juridical Status and Rights of Undocumented Migrants, supra, paras. 162 to 171 .

40 Cf. United Nations High Commissioner for Refugees (UNHCR), Executive Committee, Conclusion on Children at Risk, UN Doc. 107 (LVIII)-2007, published on 5 October 2007, para. (b)(x).

41 See, similarly, Report of the Special Rapporteur on the human rights of migrants, Jorge Bustamante, Promotion and Protection of all Human Rights, Civil, Political, Economic, Social, and Cultural Rights, Including the Right to Development, UN Doc. A/HRC/11/7, May 14, 2009, para. 43.

42 Cf. Juridical Condition and Human Rights of the Child. Advisory Opinion OC-17/02 of August 28, 2002. Series A No. 17, para. 42.

$43 C f$. Committee on the Rights of the Child, General Comment No. 6: Treatment of Unaccompanied and Separated Children Outside their Country of Origin, UN Doc. CRC/GC/2005/6, 1 September 2005, para. 7.

$44 C f$. Committee on the Rights of the Child, General Comment No. 6: Treatment of Unaccompanied and Separated Children Outside their Country of Origin, supra, para. 8.

45 Cf. Juridical Status and Rights of Undocumented Migrants, supra, para. 69.

46 Cf. Juridical Status and Rights of Undocumented Migrants, supra, para. 69.

47 Cf. Juridical Status and Rights of Undocumented Migrants, supra, para. 69.

48 Cf. Juridical Status and Rights of Undocumented Migrants, supra, para. 69.

49 Cf. Juridical Status and Rights of Undocumented Migrants, supra, para. 69.

50 Article 62 of the American Convention provides that:

1. A State Party may, upon depositing its instrument of ratification or adherence to this Convention, or at any subsequent time, declare that it recognizes as binding, ipso facto, and not requiring special agreement, the jurisdiction of the Court on all matters relating to the interpretation or application of this Convention.

$[\ldots]$ 
3. The jurisdiction of the Court shall comprise all cases concerning the interpretation and application of the provisions of this Convention that are submitted to it, provided that the States Parties to the case recognize or have recognized such jurisdiction, whether by special declaration pursuant to the preceding paragraphs, or by a special agreement.

51 Cf. Case of González et al. ("Cotton Field”) v. Mexico. Preliminary objection, merits, reparations and costs. Judgment of November 16, 2009. Series C No. 205, paras. 45 to 58 and 77.

52 Article 27 (Internal law and observance of treaties) of the Vienna Convention on the Law of Treaties provides that:

A party may not invoke the provisions of its internal law as justification for its failure to perform a treaty. This rule is without prejudice to Article 46.

See also, Resolution of the UN General Assembly, Responsibility of States for internationally wrongful acts, UN Doc. A/ RES/56/83, published on 28 January 2002, Article 3 (Characterization of an act of a State as internationally wrongful): "The characterization of an act of a State as internationally wrongful is governed by international law. Such characterization is not affected by the characterization of the same act as lawful by internal law."

53 Cf. Reports of the Inter-American Commission on Human Rights (Art. 51 American Convention on Human Rights), supra, paras. 25 and 26, and Juridical Status and Rights of Undocumented Migrants, supra, para. 63.

$54 C f$. Restrictions to the Death Penalty (arts. 4.2 and 4.4 American Convention on Human Rights). Advisory Opinion OC-3/ 83 of September 8, 1983. Series A No. 3, para. 22.

$55 C f$., among others, International Court of Justice, Case concerning the sovereignty over Pulau Ligitan and Pulau Sipadan (Indonesia v. Malaysia), Judgment of 17 December 2002, para. 37, and International Court of Justice, Avena and Other Mexican Nationals (Mexico v. United States of America), Judgment of 31 March 2004, para. 83.

56 The Effect of Reservations on the Entry into Force of the American Convention on Human Rights, supra, para. 29, and Case of Boyce et al. v. Barbados, supra, para. 15.

57 Cf. The Effect of Reservations on the Entry into Force of the American Convention on Human Rights, supra, para. 33.

$58 C f$. The Effect of Reservations on the Entry into Force of the American Convention on Human Rights, supra, para. 29, and Case of Furlan and family members v. Argentina. Preliminary objections, merits, reparations and costs. Judgment of August 31, 2012. Series C No. 246, para. 39.

$59 C f$. Articles 43 and 44 of the American Convention.

$60 C f$. Article 61 of the American Convention.

61 Cf. Case of González et al. ("Cotton Field”) v. Mexico, supra, para. 33.

62 Article 29. Restrictions Regarding Interpretation

No provision of this Convention shall be interpreted as:

a. permitting any State Party, group, or person to suppress the enjoyment or exercise of the rights and freedoms recognized in this Convention or to restrict them to a greater extent than is provided for herein;

b. restricting the enjoyment or exercise of any right or freedom recognized by virtue of the laws of any State Party or by virtue of another convention to which one of the said states is a party;

c. precluding other rights or guarantees that are inherent in the human personality or derived from representative democracy as a form of government, or

d. excluding or limiting the effect that the American Declaration of the Rights and Duties of Man and other international acts of the same nature may have.

63 Cf. The Right to Information on Consular Assistance within the framework of the Guarantees of Due Process of Law. Advisory Opinion OC-16/99 of October 1, 1999. Series A No. 16, para. 114, and Case of Artavia Murillo et al. ("In vitro fertilization") v. Costa Rica. Preliminary Objections, Merits, Reparations, and Costs. Judgment of November 28 , 2012. Series C No. 257, para. 245.

64 Cf. The Right to Information on Consular Assistance within the framework of the Guarantees of Due Process of Law, supra, para. 114, and Case of Artavia Murillo et al. ("In vitro fertilization") v. Costa Rica, supra, para. 245.

65 Juridical Status and Human Rights of the Child, supra, para. 42.

66 Cf. Juridical Status and Human Rights of the Child, supra, para. 54, and Case of Mendoza et al. v. Argentina, supra, para. 140.

67 Article 19. Rights of the Child

Every minor child has the right to the measures of protection required by his condition as a minor on the part of his family, society, and the State.

68 Cf. Case of the "Street Children" (Villagrán Morales et al.) v. Guatemala. Merits. Judgment of November 19, 1999. Series C No. 63, paras. 192 to 194, and Juridical Status and Human Rights of the Child, supra, para. 24.

69 Convention on the Rights of the Child, adopted on 20 November 1989, entry into force on 2 September 1990 . The following 34 OAS Member States are a party to this treaty: Antigua and Barbuda, Argentina, Bahamas, Barbados, Belize, Bolivia, Brazil, Canada, Chile, Colombia, Costa Rica, Cuba Dominica, Dominican Republic, Ecuador, El Salvador, Granada, Guatemala, Guyana, Haiti, Honduras, Jamaica, Mexico, Nicaragua, Panama, Paraguay, Peru, Saint Kitts and Nevis, Saint Lucia, Saint Vincent and the Grenadines, Suriname, Trinidad and Tobago, Uruguay and Venezuela.

70 Juridical Status and Human Rights of the Child, supra, para. 29.

71 Committee on the Rights of the Child, General Comment No. 6: Treatment of Unaccompanied and Separated Children Outside their Country of Origin, supra, para. 12.

72 The vulnerability of migrants is based, above all, on their status as non-nationals. This situation of vulnerability has an ideological dimension and occurs in a historical context that 
varies for each State, and is maintained by situations de jure (inequalities between nationals and foreigners established by law) and de facto (structural inequalities). Furthermore, undocumented migrants or those in an irregular situation are more exposed to real or potential violations of their rights. Cf. Juridical Status and Rights of Undocumented Migrants, supra, para. 112; Case of Vélez Loor v. Panama, supra, para. 99, and Case of the Pacheco Tineo Family v. Bolivia, supra, para. 128.

Evidently, the State also has jurisdiction, certainly more limited, with respect to its nationals who are abroad. However, the Court has deemed it more convenient to exclude such jurisdiction, held within the personal jurisdiction of the State, in the present Advisory Opinion.

74 The Court has already emphasized that the principle of equality and non-discrimination is fundamental and that all States shall guarantee to its citizens and all foreign persons who are in its territory. Nonetheless, it is permissible that a State provide different treatment to documented migrants that is provided to undocumented immigrants or migrants between migrants and nationals, provided that such treatment is reasonable, objective and proportionate and does not violate human rights. Cf. Juridical Status and Rights of Undocumented Migrants, supra, para. 119, and Case of Vélez Loor v. Panama, supra, para. 248.

75 Within this, the State holds the full and exclusive legal power granted to it by International Law over its entire territory, that is, all assets and all situations, activities and people who, for any cause or reason to enter, or are acting on it, thus assuming the necessary functions, whether executive, legislative or judicial, for the sake of organizing the community enters, lives, or operates within it.

76 Because of it, the State exercises its authority over its nationals who are abroad, regulating personal status and exerting its protection over them.

77 This implies the right of the State to regulate the organization, operation, as well as defense and security of their public services, even those who are abroad.

$78 C f$. Article 33 of the American Convention.

$79 C f$. Second preambular paragraph of the Convention: "Recognizing that the essential rights of man are not derived from one's being a national of a certain state, but are based upon attributes of the human personality, and that they therefore justify international protection in the form of a convention reinforcing or complementing the protection provided by the domestic law of the American states."

80 Cf. Case of "The Last Temptation of Christ" (Olmedo Bustos et al.) v. Chile. Merits, Reparations, and Costs. Judgment of February 5, 2001. Series C No. 73, para. 87, and Case of Heliodoro Portugal v. Panama. Preliminary objections, merits, reparations and costs. Judgment of August 12, 2008. Series C No. 186, para. 179

81 Cf. Case of Castillo Petruzzi et al. v. Peru. Merits, Reparations, and Costs. Judgment of May 30, 1999. Series C No. 52, para. 207, and Case of Mendoza et al. v. Argentina, supra, para. 293.

82 Cf. Case of Vélez Loor v. Panama, supra, para. 286

83 Article VII. Right to protection for mothers and children.

All women, during pregnancy and the nursing period, and all children have the right to special protection, care and aid.
84 Cf. Juridical Status and Human Rights of the Child, supra, para. 56, and Case of the Pacheco Tineo Family v. Bolivia, supra, para. 218.

85 Other provisions are Articles 4(5) (prohibition to impose capital punishment on children, persons over 70 years of age, and pregnant women); 5(5) (minors who are being prosecuted); 12(4) (right of parents or guardians with regard to the education of their children or wards); 17 (rights of the family); and 23 (right to oarticipate in government).

86 Cf. Case of Furlan and family members v. Argentina, supra, para. 203, and Case of Mendoza et al. v. Argentina, supra, para. 143. Cf. Committee on the Rights of the Child, General Comment No. 7: Implementing child rights in early childhood, U.N. Doc. CRC/C/GC/7/Rev.1, 20 September 2006, para. 17.

87 Case of the "Juvenile Reeducation Institute" v. Paraguay. Preliminary Objections, Merits, Reparations, and Costs. Judgment of September 2, 2004. Series C No. 112, para. 147, and Case of the Río Negro Massacres v. Guatemala. Preliminary Objection, Merits, Reparations, and Costs. Judgment of September 4, 2012. Series C No. 250, para. 142.

88 The other, is Article 17(1) (protection of the family by society and the State).

89 Cf. Juridical Status and Human Rights of the Child, supra, para. 91. See also, United Nations High Commissioner for Refugees (UNHCR), Executive Committee, Conclusion on Children at Risk, UN Doc. 107 (LVIII)-2007, published on 5 October 2007

90 Cf. Committee on the Rights of the Child, General Comment No. 5: General measures of implementation of the Convention on the Rights of the Child (Articles 4, 42 and paragraph 6 of Article 44), UN Doc. CRC/GC/2003/5, 27 November 2003, para. 12.

91 Article 2 of the Convention on the Rights of the Child establishes the obligation of States to respect the rights set forth in the Convention and to ensure their application to each child within their jurisdiction without discrimination of any kind, which "requires States actively to identify individual children and groups of children the recognition and realization of whose rights may demand special measures." Committee on the Rights of the Child, General Comment No. 5: General measures of implementation of the Convention on the Rights of the Child (Articles 4, 42 and paragraph 6 of Article 44), supra, para. 12. See also, Committee on the Rights of the Child, General Comment No. 6: Treatment of Unaccompanied and Separated Children Outside their Country of Origin, supra, para. 1.

92 Article 3(1) of the Convention on the Rights of the Child asserts the obligation that the best interests of the child shall be a primary consideration in all actions concerning children. $C f$. Committee on the Rights of the Child, General Comment No. 5: General measures of implementation of the Convention on the Rights of the Child (Articles 4, 42 and paragraph 6 of Article 44), supra, para. 12, and Committee on the Rights of the Child, General Comment No. 14 on the right of the child to have his or her best interests taken as a primary consideration (Article 3, paragraph 1), UN Doc. CRC/C/CG/14, 29 May 2013.

93 Article 6 of the Convention on the Rights of the Child recognizes the child's inherent right to life, and States Parties' obligation to ensure to the maximum extent possible the survival and development of the child, in its broadest sense, as a 
holistic concept embracing the child's physical, mental, spiritual, moral, psychological and social development. $C f$. Committee on the Rights of the Child, General Comment No. 5: General measures of implementation of the Convention on the Rights of the Child (Articles 4, 42 and paragraph 6 of Article 44), supra, para. 12.

94 Article 12 of the Convention on the Rights of the Child establishes the child's right to express his or her views freely in "all matters affecting the child," those views being given due weight, taking into account his or her age and degree of maturity. $C f$. Committee on the Rights of the Child, General Comment No. 5: General measures of implementation of the Convention on the Rights of the Child (Articles 4, 42 and paragraph 6 of Article 44), supra, para. 12, and Committee on the Rights of the Child, General Comment No. 12: The right of the child to be heard, UN Doc. CRC/C/GC/12, 20 July 2009.

$95 C f$. Juridical Status and Human Rights of the Child, supra, second operative paragraph.

96 Cf. Committee on the Rights of the Child, General Comment No. 12: The right of the child to be heard, supra, para. 123.

$97 C f$. Committee on the Rights of the Child, General Comment No. 14 on the right of the child to have his or her best interests taken as a primary consideration (Article 3, paragraph 1), supra, para. 75. See also, Report of the Special Rapporteur on the human rights of migrants, Jorge Bustamante, Promotion and Protection of all Human Rights, Civil, Political, Economic, Social, and Cultural Rights, Including the Right to Development, UN Doc. A/HRC/11/7, May 14, 2009, para. 23.

98 Cf. Case of the Sawhoyamaxa Indigenous Community v. Paraguay. Merits, reparations and costs. Judgment of March 29, 2006. Series C No. 146, para. 189, and Case of the Xákmok Kásek Indigenous Community v. Paraguay. Merits, reparations and costs. Judgment of August 24, 2010. Series C No. 214, para. 250.

Article 1. Obligation to Respect Rights

1. The States Parties to this Convention undertake to respect the rights and freedoms recognized herein and to ensure to all persons subject to their jurisdiction the free and full exercise of those rights and freedoms, without any discrimination for reasons of race, color, sex, language, religion, political or other opinion, national or social origin, economic status, birth, or any other social condition.

2. For the purposes of this Convention, "person" means every human being.

\section{Article 2. Domestic Legal Effects}

Where the exercise of any of the rights or freedoms referred to in Article 1 is not already ensured by legislative or other provisions, the States Parties undertake to adopt, in accordance with their constitutional processes and the provisions of this Convention, such legislative or other measures as may be necessary to give effect to those rights or freedoms.

101 Article 5. Right to Humane Treatment

1. Every person has the right to have his physical, mental, and moral integrity respected.
2. No one shall be subjected to torture or to cruel, inhuman, or degrading punishment or treatment. All persons deprived of their liberty shall be treated with respect for the inherent dignity of the human person.

3. Punishment shall not be extended to any person other than the criminal.

4. Accused persons shall, save in exceptional circumstances, be segregated from convicted persons, and shall be subject to separate treatment appropriate to their status as unconvicted persons.

5. Minors while subject to criminal proceedings shall be separated from adults and brought before specialized tribunals, as speedily as possible, so that they may be treated in accordance with their status as minors.

6. Punishments consisting of deprivation of liberty shall have as an essential aim the reform and social readaptation of the prisoners.

\section{Article 7. Right to Personal Liberty}

1. Every person has the right to personal liberty and security.

2. No one shall be deprived of his physical liberty except for the reasons and under the conditions established beforehand by the constitution of the State Party concerned or by a law established pursuant thereto.

3. No one shall be subject to arbitrary arrest or imprisonment.

4. Anyone who is detained shall be informed of the reasons for his detention and shall be promptly notified of the charge or charges against him.

5. Any person detained shall be brought promptly before a judge or other officer authorized by law to exercise judicial power and shall be entitled to trial within a reasonable time or to be released without prejudice to the continuation of the proceedings. His release may be subject to guarantees to assure his appearance for trial.

6. Anyone who is deprived of his liberty shall be entitled to recourse to a competent court, in order that the court may decide without delay on the lawfulness of his arrest or detention and order his release if the arrest or detention is unlawful. In States Parties whose laws provide that anyone who believes himself to be threatened with deprivation of his liberty is entitled to recourse to a competent court in order that it may decide on the lawfulness of such threat, this remedy may not be restricted or abolished. The interested party or another person in his behalf is entitled to seek these remedies.

7. No one shall be detained for debt. This principle shall not limit the orders of a competent judicial authority issued for nonfulfillment of duties of support. 
103 Article 8. Right to a Fair Trial

1. Every person has the right to a hearing, with due guarantees and within a reasonable time, by a competent, independent, and impartial tribunal, previously established by law, in the substantiation of any accusation of a criminal nature made against him or for the determination of his rights and obligations of a civil, labor, fiscal, or any other nature.

2. Every person accused of a criminal offense has the right to be presumed innocent so long as his guilt has not been proven according to law. During the proceedings, every person is entitled, with full equality, to the following minimum guarantees:

a. the right of the accused to be assisted without charge by a translator or interpreter, if he does not understand or does not speak the language of the tribunal or court;

b. prior notification in detail to the accused of the charges against him;

c. adequate time and means for the preparation of his defense;

d. the right of the accused to defend himself personally or to be assisted by legal counsel of his own choosing, and to communicate freely and privately with his counsel;

e. the inalienable right to be assisted by counsel provided by the State, paid or not as the domestic law provides, if the accused does not defend himself personally or engage his own counsel within the time period established by law;

f. the right of the defense to examine witnesses present in the court and to obtain the appearance, as witnesses, of experts or other persons who may throw light on the facts;

g. the right not to be compelled to be a witness against himself or to plead guilty; and

h. the right to appeal the judgment to a higher court.

3. A confession of guilt by the accused shall be valid only if it is made without coercion of any kind.

4. An accused person acquitted by a nonappealable judgment shall not be subjected to a new trial for the same cause.

5. Criminal proceedings shall be public, except insofar as may be necessary to protect the interests of justice.

104 Article 19. Rights of the Child

Every minor child has the right to the measures of protection required by his condition as a minor on the part of his family, society, and the State.

105 Article 22. Freedom of Movement and Residence

[...]

7. Every person has the right to seek and be granted asylum in a foreign territory, in accordance with the legislation of the state and international conventions, in the event he is being pursued for political offenses or related common crimes. [...]
106 Article 25. Right to Judicial Protection

1. Everyone has the right to simple and prompt recourse, or any other effective recourse, to a competent court or tribunal for protection against acts that violate his fundamental rights recognized by the constitution or laws of the state concerned or by this Convention, even though such violation may have been committed by persons acting in the course of their official duties.

2. The States Parties undertake:

a. to ensure that any person claiming such remedy shall have his rights determined by the competent authority provided for by the legal system of the state;

b. to develop the possibilities of judicial remedy; and

c. to ensure that the competent authorities shall enforce such remedies when granted.

107 Article I. Right to life, liberty, and personal security

Every human being has the right to life, liberty and the security of his person.

108 Article XXV. Right of protection from arbitrary arrest

No person may be deprived of his liberty except in the cases and according to the procedures established by pre-existing law.

No person may be deprived of liberty for nonfulfillment of obligations of a purely civil nature.

Every individual who has been deprived of his liberty has the right to have the legality of his detention ascertained without delay by a court, and the right to be tried without undue delay or, otherwise, to be released. He also has the right to humane treatment during the time he is in custody.

109 Article XXVII. Right of asylum

Every person has the right, in case of pursuit not resulting from ordinary crimes, to seek and receive asylum in foreign territory, in accordance with the laws of each country and with international agreements.

110 Cf. Case of the Pacheco Tineo Family v. Bolivia, supra, paras. 137 to 140 .

111 Cf. Case of the Pacheco Tineo Family v. Bolivia, supra, para. 137.

112 Cf. Case of the Pacheco Tineo Family v. Bolivia, supra, paras. 137 and 140.

113 Evidently, and consistent with Article 29(a) and (b) of the American Convention, domestic laws may expand the sphere of protection, but never restrict it beyond the minimum protections established by international law.

114 The right of asylum was specifically codified in regional treaties, starting with the 1889 Montevideo Treaty on International Criminal Law and up until the adoption of the Convention on Territorial Asylum and the Convention on Diplomatic Asylum, both in 1954 . 
115 Convention relating to the Status of Refugees, adopted on 28 July 1951, entered into force on 22 April 1954. The following 28 Member States of the OAS are parties to this treaty: Antigua and Barbuda, Argentina, Bahamas, Belize, Bolivia, Brazil, Canada, Chile, Colombia, Costa Rica, Dominica, Ecuador, El Salvador, Guatemala, Haiti, Honduras, Jamaica, Mexico, Nicaragua, Panama, Paraguay, Peru, Dominican Republic, Saint Kitts and Nevis, St. Vincent and the Grenadines, Suriname, Trinidad and Tobago, and Uruguay.

1161967 Protocol to the 1951 Geneva Convention relating to the Status of Refugees. adopted on 31 January 1967, entry into force on 4 October 1967. The following 29 OAS Member States are party to this protocol: Antigua and Barbuda, Argentina, Bahamas, Belize, Bolivia, Brazil, Canada, Chile, Colombia, Costa Rica, Dominica, Dominican Republic, Ecuador, El Salvador, Guatemala, Haiti, Honduras, Jamaica, Mexico, Nicaragua, Panama, Paraguay, Peru, Saint Vincent and the Grenadines, Suriname, Trinidad and Tobago, United States of America, Uruguay and Venezuela.

117 Cartagena Declaration on Refugees, adopted by the "Colloquium on the International Protection of Refugees in Central America, Mexico and Panama: Legal and Humanitarian Problems," held in Cartagena, Colombia, from 19 to 22 November 1984, which was sponsored by the Government of Colombia and co-sponsored by the Faculty of Law of the University of Cartagena de Indias, the Regional Centre for Third World Studies and the United Nations High Commissioner for Refugees.

$118 C f$. General Assembly of the OAS, Legal situation of refugees repatriated, and displaced persons in the American Hemisphere, Resolution AG/RES. 774(XV-0/85), approved in the third plenary session, held on 9 December 1985, third operative paragraph.

119 Thus, the internal laws of Argentina, Belize, Brazil, Bolivia, Chile, Colombia, Costa Rica, Dominican Republic, Ecuador, El Salvador, Guatemala, Mexico, Nicaragua, Panama, Paraguay, Peru, Uruguay and Venezuela reflect a growing consensus in the region that the protection of refugees and those requesting this status should be regulated at the domestic level in accordance with the provisions of international refugee law, so that this protection should be implemented by competent and previously established authorities, using specific procedures that respect guarantees of due process of law. Cf. Ley No. 26.165. Ley General de Reconocimiento y Protección al Refugiado, published on 28 November 2006, Articles 1 to 3 and 36 (Argentina); Refugees Act. August, 16th, 1991, section 5 (Belize); Ley $N^{\circ} 251$ de protección a personas refugiadas, 20 June 2012, Article 1 (Bolivia); Lei No. 9.474, 22 July 1997, Articles 5 and 9 (Brazil); Ley No. 20.430 - Establece disposiciones sobre protección de refugiados, published 8 April 2010, Articles 10, 19, 20, 25 and 30 (Chile); Decreto No. 2840, por el cual se establece el Procedimiento para el Reconocimiento de la Condición de Refugiado, se dictan normas sobre la Comisión Asesora para la Determinación de la Condición de Refugiado y otras disposiciones, 6 December 2013, Article 13 (Colombia); Ley General de Migración y Extranjería $N^{\circ} 8764,1^{\circ}$ September 2009, Articles 1 and 41 (Costa Rica); Decreto No. 1.182 - Reglamento para la aplicación del derecho de refugio, 30 May 2012, Articles 1 and 36 (Ecuador); Decreto Ley No. 918 - Ley para la determinación de la condición de personas refugiadas, published on 14 August 2002, Articles 2 and 15 (El Salvador); Acuerdo Gubernativo No. 383-2001, Reglamento para la protección y determinación del estatuto de refugiado en el territorio del Estado de Guatemala, 14 September 2001, Article 28 (Guatemala); Ley sobre Refugiados y Protección Complementaria, 27 January 2011, Article 5 and Reglamento de la ley sobre refugiados y protección complementaria, 21 February 2012, Article 27 (Mexico); Ley No. 655 de Protección a Refugiados, 26 June 2008, Article 24 (Nicaragua); Decreto Ejecutivo No. 23, 10 February 1998, Articles 3 and 31 (Panama); Ley No. 1938 General sobre Refugiados, 9 July 2002, Article 14 (Paraguay); Ley No. 27.891-Ley del Refugiado, published on 22 December 2002, Articles 1 and 2 (Peru); Decreto No. 2330 - Reglamento de la Comisión Nacional para los Refugiados, 10 September 1984, Article 7 (Dominican Republic); Ley No. 18.076-Derecho al refugio y a los refugiados, published on 5 January 2007, Article 31 (Uruguay), and Decreto No. 2.491 - Reglamento de la Ley Orgánica sobre refugiados o refugiadas, asilados o asiladas, 4 July 2003, Article 10 (Venezuela).

120 This is the case of Argentina, Belize, Bolivia, Brazil, Chile, Colombia, El Salvador, Guatemala, Honduras, Mexico, Nicaragua, Paraguay, Peru and Uruguay. Cf. Ley No. 26.165. Ley General de Reconocimiento y Protección al Refugiado, published on 28 November 2006, Article 4 (Argentina); Refugees Act. August, 16th, 1991, section 4(i)(c) (Belize); Ley $N^{\circ} 251$ de protección a personas refugiadas, 20 June 2012, Article 15 (Bolivia); Lei No. 9.474, 22 July 1997, Article 1(III) (Brazil); Ley No. 20.430 - Establece disposiciones sobre protección de refugiados, published on 8 April 2010, Article 2(2) (Chile); Decreto No. 2840, por el cual se establece el Procedimiento para el Reconocimiento de la Condición de Refugiado, se dictan normas sobre la Comisión Asesora para la Determinación de la Condición de Refugiado y otras disposiciones, 6 December 2013, Article 1(b) (Colombia); Decreto Ley No. 918 - Ley para la determinación de la condición de personas refugiadas, published on 14 August 2002, Article 4(c) (El Salvador); Acuerdo Gubernativo No. 383-2001, Reglamento para la protección y determinación del estatuto de refugiado en el territorio del Estado de Guatemala, 14 September 2001, Article 11(c) (Guatemala); Decreto No. 208 Ley de Migración y Extranjería, published on 3 March 2004, Article 42(3) (Honduras); Ley sobre Refugiados y Protección Complementaria, 27 January 2011, Article 13(II) and 13(III) (Mexico); Ley No. 655 de Protección a Refugiados, 26 June 2008, Article 1.c) (Nicaragua); Ley No. 1938 General sobre Refugiados, 9 July 2002, Article 1(b) (Paraguay); Ley No. 27.891-Ley del Refugiado, published on 22 December 2002, Article 3(b) (Peru), and Ley No. 18.076-Derecho al refugio y a los refugiados, published on 5 January 2007 , Article 2(b) (Uruguay).

121 Cartagena Declaration on Refugees, adopted by the "Colloquium on the International Protection of Refugees in Central America, Mexico and Panama: Legal and Humanitarian Problems," held in Cartagena, Colombia, from 19 to 22 November 1984, section III, third conclusion.

$122 C f$. United Nations High Commissioner for Refugees (UNHCR), Guidelines on international protection: Child Asylum Claims under Articles 1(A)2 and 1(F) of the 1951 Convention and/or 1967 Protocol relating to the Status of Refugees, 22 December 2009, UN Doc. HCR/GIP/09/08, para. 1.

123 According to UNHCR, even at a young age, a child may be considered the principal asylum applicant. $C f$. United Nations High Commissioner for Refugees (UNHCR), Guidelines on international protection: Child Asylum Claims under Articles 1(A)2 and 1(F) of the 1951 Convention and/or 1967 
Protocol relating to the Status of Refugees, 22 December 2009, UN Doc. HCR/GIP/09/08, para. 8.

124 According to UNHCR, "[o]ther examples include, but are not limited to, family and domestic violence, forced or underage marriage, bonded or hazardous child labour, forced labour, forced prostitution and child pornography. Such forms of persecution also encompass violations of survival and development rights as well as severe discrimination of children born outside strict family planning rules and of stateless children as a result of loss of nationality and attendant rights." $C f$. United Nations High Commissioner for Refugees (UNHCR), Guidelines on international protection: Child Asylum Claims under Articles 1(A)2 and 1(F) of the 1951 Convention and/ or 1967 Protocol relating to the Status of Refugees, 22 December 2009, UN Doc. HCR/GIP/09/08, para. 18. See also, United Nations High Commissioner for Refugees (UNHCR), Executive Committee, Conclusion on Children at Risk, UN Doc. 107 (LVIII)-2007, published on 5 October 2007, para. (g)(viii).

$125 C f$. United Nations High Commissioner for Refugees (UNHCR), Guidelines on international protection: Child Asylum Claims under Articles 1(A)2 and 1(F) of the 1951 Convention and/or 1967 Protocol relating to the Status of Refugees, 22 December 2009, UN Doc. HCR/GIP/09/08, paras. 2 to 5 .

$126 C f$. Committee on the Rights of the Child, General Comment No. 6: Treatment of Unaccompanied and Separated Children Outside their Country of Origin, supra, para. 59.

127 In light of Article 1(1) of the American Convention, States Parties are obliged to respect and ensure the rights and freedoms recognized therein and to ensure the free and full exercise to all persons subject to their jurisdiction, without discrimination. That is, this is also applicable to all children, whether asylum seekers, refugees and migrants, regardless of their nationality or statelessness, and regardless of whether they are unaccompanied or separated from family, or of their immigration status or that of their family. Cf. Committee on the Rights of the Child, General Comment No. 6: Treatment of Unaccompanied and Separated Children Outside their Country of Origin, supra, paras. 12 and 18.

128 In turn, Article 2 of the Convention requires States Parties the general obligation to adapt its domestic law to the provisions of the Convention itself, to guarantee the rights recognized therein. The provisions of national law which serve this purpose must be effective (principle of effet utile), which means that the State must take all necessary measures to ensure that the provisions of the Convention is truly fulfilled. Cf. Case of "The Last Temptation of Christ" (Olmedo Bustos et al.) v. Chile, supra, para. 87, and Case of Heliodoro Portugal v. Panama, supra, para. 179.

129 Cf. Case of the Pacheco Tineo Family v. Bolivia, supra, para. 225. See, generally, United Nations High Commissioner for Refugees (UNHCR), Procedural Standards for Refugee Status Determination under UNHCR's Mandate, and United Nations High Commissioner for Refugees (UNHCR), Guidelines on international protection: Child Asylum Claims under Articles 1(A)2 and 1(F) of the 1951 Convention and/or 1967 Protocol relating to the Status of Refugees, 22 December 2009, UN Doc. HCR/GIP/09/08, paras. 8 and 9.

130 Cf. Case of the Pacheco Tineo Family v. Bolivia, supra, para. 139, citing ECHR, Case of Jabari v. Turkey, No. 40035/98. Judgment of 11 July 2000, paras. 48 to 50 .
131 In the case of Velásquez Rodríguez, the Court established that an omission of the State that results in a violation of human rights may entail its international responsibility. $C f$. Case of Velásquez Rodríguez v. Honduras. Merits, supra, paras. 164 to 177 .

132 Cf. Committee on the Rights of the Child, General Comment No. 6: Treatment of Unaccompanied and Separated Children Outside their Country of Origin, supra, para. 20.

133 The UNHCR Executive Committee has also recognized that "individual, careful and prompt registration of children can be useful for States, UNHCR and other relevant agencies and partners in identifying children at heightened risk." Cf. United Nations High Commissioner for Refugees (UNHCR), Executive Committee, Conclusion on Children at Risk, UN Doc. 107 (LVIII)-2007, published on 5 October 2007, para. (e).

134 Committee on the Rights of the Child, General Comment No. 6: Treatment of Unaccompanied and Separated Children Outside their Country of Origin, supra, para. 20.

135 Cf. Juridical Status and Human Rights of the Child, supra, para. 96.

$136 C f$. Committee on the Rights of the Child, General Comment No. 6: Treatment of Unaccompanied and Separated Children Outside their Country of Origin, supra, para. 20.

$137 C f$. Committee on the Rights of the Child, General Comment No. 6: Treatment of Unaccompanied and Separated Children Outside their Country of Origin, supra, para. 31(ii).

$138 C f$. United Nations High Commissioner for Refugees (UNHCR), UNHCR Guidelines on determining the best interests of the child, May 2008, p. 58.

139 Cf. United Nations High Commissioner for Refugees (UNHCR), UNHCR Guidelines on determining the best interests of the child, May 2008, pp. 31 and 32.

140 Cf. United Nations High Commissioner for Refugees (UNHCR), UNHCR Guidelines on determining the best interests of the child, May 2008, p. 68.

$141 C f$. United Nations High Commissioner for Refugees (UNHCR), UNHCR Guidelines on determining the best interests of the child, May 2008, pp. 60 and 61.

$142 C f$. Committee on the Rights of the Child, General Comment No. 6: Treatment of Unaccompanied and Separated Children Outside their Country of Origin, supra, para. 71.

143 Cf. Juridical Status and Human Rights of the Child, supra, paras. 78 and 79.

$144 C f$. United Nations High Commissioner for Refugees (UNHCR), Executive Committee, Conclusion on Children at Risk, UN Doc. 107 (LVIII)-2007, published on 5 October 2007, para. (g)(viii), and United Nations High Commissioner for Refugees (UNHCR), Guidelines on international protection: Child Asylum Claims under Articles 1(A)2 and 1(F) of the 1951 Convention and/or 1967 Protocol relating to the Status of Refugees, 22 December 2009, UN Doc. HCR/GIP/ 09/08, para. 69 .

$145 C f$. United Nations High Commissioner for Refugees (UNHCR), UNHCR Guidelines on determining the best interests of the child, May 2008, pp. 59 and 60.

$146 C f$. Committee on the Rights of the Child, General Comment No. 6: Treatment of Unaccompanied and Separated Children Outside their Country of Origin, supra, paras. 29 and 30. 
$147 C f$. United Nations High Commissioner for Refugees (UNHCR), Executive Committee, Conclusion on Children at Risk, UN Doc. 107 (LVIII)-2007, published on 5 October 2007, para. (g)(ix).

$148 C f$. Committee on the Rights of the Child, General Comment No. 6: Treatment of Unaccompanied and Separated Children Outside their Country of Origin, supra, para. 31.

149 Cf. Committee on the Rights of the Child, General Comment No. 6: Treatment of Unaccompanied and Separated Children Outside their Country of Origin, supra, para. 31.

150 Committee on the Rights of the Child, General Comment No. 6: Treatment of Unaccompanied and Separated Children Outside their Country of Origin, supra, 31.

$151 C f$. Committee on the Rights of the Child, General Comment No. 6: Treatment of Unaccompanied and Separated Children Outside their Country of Origin, supra, para. 31.

152 See Article 20 of the Convention on the Rights of the Child, and Committee on the Rights of the Child, General Comment No. 6: Treatment of Unaccompanied and Separated Children Outside their Country of Origin, supra, para. 16. See also, Report of the Special Rapporteur on the human rights of migrants, Jorge Bustamante, Promotion and Protection of all Human Rights, Civil, Political, Economic, Social, and Cultural Rights, Including the Right to Development, UN Doc. A/HRC/11/7, May 14, 2009, para. 23.

$153 C f$. Committee on the Rights of the Child, General Comment No. 6: Treatment of Unaccompanied and Separated Children Outside their Country of Origin, supra, para. 31.

154 Committee on the Rights of the Child, General Comment No. 6: Treatment of Unaccompanied and Separated Children Outside their Country of Origin, supra, para. 23.

155 In order to define people trafficking it is relevant to consult Article 3 of the Protocol to prevent, suppress and punish trafficking in persons, especially women and children, which adopted the following definitions: "For the purposes of this Protocol "(a) "Trafficking in persons" shall mean the recruitment, transportation, transfer, harbouring or receipt of persons, by means of the threat or use of force or other forms of coercion, of abduction, of fraud, of deception, of the abuse of power or of a position of vulnerability, or of the giving or receiving of payments or benefits to achieve the consent of a person having control over another person, for the purpose of exploitation. Exploitation shall include, at least, the exploitation of the prostitution of others or other forms of sexual exploitation, forced labour or services, slavery or practices similar to slavery, servitude or the removal of organs." Child trafficking is accorded a differentiated treatment in paragraph (c) of Article 3 of the Protocol. In such cases, it is considered that the conduct consisting in "the recruitment, transportation, transfer, harbouring or receipt of a child for the purpose of exploitation" also constitutes "trafficking in persons" even if this does not involve any of the means set forth in subparagraph (a) of this Article. Protocol to prevent, suppress, and punish trafficking in persons, especially women and children, supplementing the United Nations Convention against Transnational Organized Crime, adopted on 15 November 2000, entry into force on 25 December 2003. The following 34 OAS Member States are party to this instrument: Antigua and Barbuda, Argentina, Bahamas, Belize, Bolivia, Brazil, Canada, Chile, Colombia, Costa Rica, Cuba, Dominica, Dominican Republic, Ecuador, El Salvador, Granada, Guatemala, Guyana, Haiti, Honduras,
Jamaica, Mexico, Nicaragua, Panama, Paraguay, Peru, Saint Kitts and Nevis, Saint Lucia, Saint Vincent and the Grenadines, Suriname, Trinidad and Tobago, United States of America, Uruguay, and Venezuela.

$156 C f$. Committee on the Rights of the Child, General Comment No. 6: Treatment of Unaccompanied and Separated Children Outside their Country of Origin, supra, para. 50.

157 Article 6(1) of the American Convention expressly prohibits the trafficking of women.

$158 C f$. Committee on the Rights of the Child, General Comment No. 6: Treatment of Unaccompanied and Separated Children Outside their Country of Origin, supra, para. 50.

159 See Article 9(1)(a) of the Protocol to prevent, suppress and punish trafficking in persons, especially women and children, supplementing the United Nations Convention against Transnational Organized Crime.

160 See Article 9(2) of the Protocol to prevent, suppress and punish trafficking in persons, especially women and children, supplementing the United Nations Convention against Transnational Organized Crime.

161 See Article 11 of the Protocol to prevent, suppress and punish trafficking in persons, especially women and children, supplementing the United Nations Convention against Transnational Organized Crime. According to the United Nations Convention for the Suppression of the Traffic in Persons and of the Exploitation of the Prostitution of Others, all the States Parties undertake: "to take appropriate measures to ensure supervision of railway stations, airports, seaports and en route, and of other public places, in order to prevent international traffic in persons for the purpose of prostitution," as well as "to take appropriate measures in order that the appropriate authorities be informed of the arrival of persons who appear, prima facie, to be the principals and accomplices in or victims of such traffic." United Nations Convention for the Suppression of the Traffic in Persons and of the Exploitation of the Prostitution of Others, adopted on 21 March 1950, entry into force 25 July 1951, Article 17. The following 10 OAS Member States are party to this Convention: Argentina, Bolivia, Brazil, Cuba, Ecuador, Guatemala, Haiti, Honduras, Mexico, and Venezuela. See also United Nations High Commissioner for Human Rights (OHCHR), Recommended Principles and Guidelines on Human Rights and Human Trafficking, UN Doc. E/2002/68/Add.1, published on 20 May 2002.

$162 C f$. United Nations High Commissioner for Human Rights (OHCHR), Recommended Principles and Guidelines on Human Rights and Human Trafficking, UN Doc. E/2002/68/ Add.1, published on 20 May 2002.

163 See Article 18 of the United Nations Convention for the Suppression of the Traffic in Persons and of the Exploitation of the Prostitution of Others. See also, United Nations High Commissioner for Human Rights (OHCHR), Recommended Principles and Guidelines on Human Rights and Human Trafficking, UN Doc. E/2002/68/Add.1, published on 20 May 2002.

$164 C f$. United Nations High Commissioner for Refugees (UNHCR), Guidelines on International Protection No. 7: The Application of Article 1A(2) of the 1951 Convention and/or 1967 Protocol Relating to the Status of Refugees to Victims of Trafficking and Persons At Risk of Being Trafficked, UN Doc. HCR/GIP/06/07, published on 7 April 2006. 
165 See Article 10(2) of the Protocol to prevent, suppress and punish trafficking in persons, especially women and children, supplementing the United Nations Convention against Transnational Organized Crime.

$166 C f$. United Nations High Commissioner for Refugees (UNHCR), UNHCR Guidelines on determining the best interests of the child, May 2008, pp. 51 and 69.

167 United Nations Convention on the Status of Stateless Persons, adopted on 28 September 1954, entry into force on 6 June 1960, Article 1. The following 17 OAS Member States are party to this treaty: Antigua and Barbuda, Argentina, Barbados, Belize, Bolivia, Brazil, Costa Rica, Ecuador, Guatemala, Honduras, Mexico, Nicaragua, Panama, Peru, Saint Vincent and the Grenadines, Trinidad and Tobago, and Uruguay.

168 Cf. Case of the Yean and Bosico Girls v. Dominican Republic. Preliminary objections, merits, reparations and costs. Judgment of September 8, 2005. Series C No. 130, para. 142.

169 The obligation of States to identify, within their jurisdiction, stateless children to provide appropriate treatment for their condition, requires the establishment or strengthening, as appropriate, of fair and efficient procedures for determining if it is a stateless person, to be responsive to the differing needs of girls and children, according to age, gender, and diversity. $C f$. United Nations High Commissioner for Refugees (UNHCR), Guidelines on Statelessness No. 2: Procedures for determining whether an individual is a stateless person, UN Doc. HCR/GS/12/02, 5 April 2012.

170 Cf. Case of the Yean and Bosico Girls v. Dominican Republic, supra, para. 140. See also, among others, Article 1(1) of the Convention on the Reduction of Statelessness; Article 29 of the International Convention on the Protection of the Rights of All Migrant Workers and Members of their Families; Article 7(1) of the Convention on the Rights of the Child, Article 7(1); and Article 24(3) of the International Covenant on Civil and Political Rights.

171 Cf. Case of the Yean and Bosico Girls v. Dominican Republic, supra, paras. 142 and 143.

$172 C f$. United Nations High Commissioner for Refugees (UNHCR), Guidelines on Statelessness No. 2: Procedures for determining whether an individual is a stateless person, published on 5 April 2012, UN Doc. HCR/GS/12/02, para. 2.

173 Convention on the Reduction of Statelessness, adopted on 30 August 1961, entry into force 13 December 1975. The following seven OAS Member States are party to this treaty: Bolivia, Brazil, Canada, Costa Rica, Guatemala, Panama, and Uruguay.

$174 C f$. United Nations High Commissioner for Refugees (UNHCR), Guidelines on Statelessness No. 2: Procedures for determining whether an individual is a stateless person, published on 5 April 2012, UN Doc. HCR/GS/12/02, para. 6.

$175 C f$. United Nations High Commissioner for Refugees (UNHCR), Guidelines on Statelessness No. 2: Procedures for determining whether an individual is a stateless person, published on 5 April 2012, UN Doc. HCR/GS/12/02, paras. 26 and 27.

$176 C f$. Committee on the Rights of the Child, General Comment No. 6: Treatment of Unaccompanied and Separated Children Outside their Country of Origin, supra, para. 31.

177 In some cases, exceptionally, UNHCR may determine that a person should have refugee status, but this is a practice that has occurred only in those countries that have not signed any international instrument on refugees, where the national authorities have asked UNHCR to play this role. $C f$. Case of the Pacheco Tineo Family v. Bolivia, supra, footnote 185.

178 Cf. Case of the Pacheco Tineo Family v. Bolivia, supra, para. 154.

$179 C f$. Committee on the Rights of the Child, General Comment No. 6: Treatment of Unaccompanied and Separated Children Outside their Country of Origin, supra, paras. 54 to 63.

$180 C f$. Report of the Special Rapporteur on the human rights of migrants, Jorge Bustamante, Promotion and Protection of all Human Rights, Civil, Political, Economic, Social, and Cultural Rights, Including the Right to Development, UN Doc. A/HRC/11/7, May 14, 2009, para. 35.

181 United Nations High Commissioner for Refugees (UNHCR), Executive Committee, Conclusion on Children at Risk, UN Doc. 107 (LVIII)-2007, published on 5 October 2007.

$182 C f$. United Nations High Commissioner for Refugees (UNHCR), Guidelines on International Protection No. 1: Gender-Related Persecution Within the Context of Article $1 \mathrm{~A}$ (2) of the 1951 Convention and/or its 1967 Protocol Relating to the Status of Refugees, UN Doc. HCR/GIP/02/01, published on 7 May 2002, and United Nations High Commissioner for Refugees (UNHCR), UNHCR Handbook for the Protection of Women and Girls, January 2008.

183 Committee on the Rights of the Child, General Comment No. 6: Treatment of Unaccompanied and Separated Children Outside their Country of Origin, supra, para. 31.

$184 C f$. Committee on the Rights of the Child, General Comment No. 6: Treatment of Unaccompanied and Separated Children Outside their Country of Origin, supra, paras. 31, 47 and 48.

$185 C f$. Committee on the Rights of the Child, General Comment No. 6: Treatment of Unaccompanied and Separated Children Outside their Country of Origin, supra, para. 44.

$186 C f$. Committee on the Rights of the Child, General Comment No. 6: Treatment of Unaccompanied and Separated Children Outside their Country of Origin, supra, paras. 41 and 42.

187 Cf. Committee on the Rights of the Child, General Comment No. 9: The rights of children with disabilities, UN Doc. CRC/ C/GC/9, 27 February 2007, paras. 42 and 43.

$188 C f$. Committee on the Rights of the Child, General Comment No. 6: Treatment of Unaccompanied and Separated Children Outside their Country of Origin, supra, paras. 13 and 31. See also, Article 10 of the Convention on the Rights of the Child.

189 See Article 9(1)(b) of the Protocol to prevent, suppress and punish trafficking in persons, especially women and children, supplementing the United Nations Convention against Transnational Organized Crime.

190 See Article 6 of the Protocol to prevent, suppress and punish trafficking in persons, especially women and children, supplementing the United Nations Convention against Transnational Organized Crime.

191 See Article 6(1) of the Protocol to prevent, suppress and punish trafficking in persons, especially women and children, supplementing the United Nations Convention against Transnational Organized Crime.

192 See Article 6(3) of the Protocol to prevent, suppress and punish trafficking in persons, especially women and children, supplementing the United Nations Convention against Transnational Organized Crime. 
193 See Article 7(1) of the Protocol to prevent, suppress and punish trafficking in persons, especially women and children, supplementing the United Nations Convention against Transnational Organized Crime. See also, United Nations High Commissioner for Human Rights (OHCHR), Recommended Principles and Guidelines on Human Rights and Human Trafficking, UN Doc. E/2002/68/Add.1, published on 20 May 2002, guideline 8 .

194 Article 1. Obligation to Respect Rights

1. The States Parties to this Convention undertake to respect the rights and freedoms recognized herein and to ensure to all persons subject to their jurisdiction the free and full exercise of those rights and freedoms, without any discrimination for reasons of race, color, sex, language, religion, political or other opinion, national or social origin, economic status, birth, or any other social condition.

2. For the purposes of this Convention, "person" means every human being.

\section{Article 2. Domestic Legal Effects}

Where the exercise of any of the rights or freedoms referred to in Article 1 is not already ensured by legislative or other provisions, the States Parties undertake to adopt, in accordance with their constitutional processes and the provisions of this Convention, such legislative or other measures as may be necessary to give effect to those rights or freedoms.

196 Article 7. Right to Personal Liberty

1. Every person has the right to personal liberty and security.

2. No one shall be deprived of his physical liberty except for the reasons and under the conditions established beforehand by the constitution of the State Party concerned or by a law established pursuant thereto.

3. No one shall be subject to arbitrary arrest or imprisonment.

4. Anyone who is detained shall be informed of the reasons for his detention and shall be promptly notified of the charge or charges against him.

5. Any person detained shall be brought promptly before a judge or other officer authorized by law to exercise judicial power and shall be entitled to trial within a reasonable time or to be released without prejudice to the continuation of the proceedings. His release may be subject to guarantees to assure his appearance for trial.

6. Anyone who is deprived of his liberty shall be entitled to recourse to a competent court, in order that the court may decide without delay on the lawfulness of his arrest or detention and order his release if the arrest or detention is unlawful. In States Parties whose laws provide that anyone who believes himself to be threatened with deprivation of his liberty is entitled to recourse to a competent court in order that it may decide on the lawfulness of such threat, this remedy may not be restricted or abolished. The interested party or another person in his behalf is entitled to seek these remedies.

7. No one shall be detained for debt. This principle shall not limit the orders of a competent judicial authority issued for nonfulfillment of duties of support.

\section{Article 8. Right to a Fair Trial}

1. Every person has the right to a hearing, with due guarantees and within a reasonable time, by a competent, independent, and impartial tribunal, previously established by law, in the substantiation of any accusation of a criminal nature made against him or for the determination of his rights and obligations of a civil, labor, fiscal, or any other nature.

2. Every person accused of a criminal offense has the right to be presumed innocent so long as his guilt has not been proven according to law. During the proceedings, every person is entitled, with full equality, to the following minimum guarantees:

a. the right of the accused to be assisted without charge by a translator or interpreter, if he does not understand or does not speak the language of the tribunal or court;

b. prior notification in detail to the accused of the charges against him;

c. adequate time and means for the preparation of his defense;

d. the right of the accused to defend himself personally or to be assisted by legal counsel of his own choosing, and to communicate freely and privately with his counsel;

e. the inalienable right to be assisted by counsel provided by the State, paid or not as the domestic law provides, if the accused does not defend himself personally or engage his own counsel within the time period established by law;

f. the right of the defense to examine witnesses present in the court and to obtain the appearance, as witnesses, of experts or other persons who may throw light on the facts;

g. the right not to be compelled to be a witness against himself or to plead guilty; and

h. the right to appeal the judgment to a higher court.

3. A confession of guilt by the accused shall be valid only if it is made without coercion of any kind.

4. An accused person acquitted by a nonappealable judgment shall not be subjected to a new trial for the same cause.

5. Criminal proceedings shall be public, except insofar as may be necessary to protect the interests of justice.

198 Article 19. Rights of the Child

Every minor child has the right to the measures of protection required by his condition as a 
minor on the part of his family, society, and the State.

199 Article 25. Right to Judicial Protection

1. Everyone has the right to simple and prompt recourse, or any other effective recourse, to a competent court or tribunal for protection against acts that violate his fundamental rights recognized by the constitution or laws of the state concerned or by this Convention, even though such violation may have been committed by persons acting in the course of their official duties.

2. The States Parties undertake:

a. to ensure that any person claiming such remedy shall have his rights determined by the competent authority provided for by the legal system of the state;

b. to develop the possibilities of judicial remedy; and

c. to ensure that the competent authorities shall enforce such remedies when granted.

3. Every human being has the right to life, liberty and the security of his person.

200 Article XXV. Right of protection from arbitrary arrest

No person may be deprived of his liberty except in the cases and according to the procedures established by pre-existing law.

No person may be deprived of liberty for nonfulfillment of obligations of a purely civil nature.

Every individual who has been deprived of his liberty has the right to have the legality of his detention ascertained without delay by a court, and the right to be tried without undue delay or, otherwise, to be released. He also has the right to humane treatment during the time he is in custody.

201 Cf. Judicial Guarantees in States of Emergency (Arts. 27(2), 25 and 8 American Convention on Human Rights), supra, para. 27; Case of the Constitutional Court v. Peru. Merits, reparations and costs. Judgment of January 31, 2001. Series C No. 71, para. 69, and Case of the Pacheco Tineo Family v. Bolivia, supra, para. 130.

202 Cf. The Right to Information on Consular Assistance within the framework of the Guarantees of Due Process of Law, supra, para. 117.

203 Cf. Case of the Constitutional Court v. Peru Merits, reparations and costs, supra, para. 71, and Case of Barbani Duarte et al. v. Uruguay. Merits, Reparations, and Costs. Judgment of October 13, 2011. Series C No. 234, paras. 118 and 119.

204 Cf. Juridical Status and Rights of Undocumented Migrants, supra, paras. 117 and 124 .

$205 C f$. Exceptions to the Exhaustion of Domestic Remedies (Arts. 46(1), 46(2)(a) and 46(2)(b), American Convention on Human Rights). Advisory Opinion OC-11/90 of August 10, 1990. Series A No. 11, para. 28, and Case of Pacheco Tineo Vs. Bolivia, supra, para. 130.
206 Cf. Case of Vélez Loor v. Panama, supra, para. 142, and Case of the Pacheco Tineo Family v. Bolivia, supra, para. 132.

207 Cf. Juridical Status and Rights of Undocumented Migrants, supra, paras. 121 and 122, and Case of Vélez Loor v. Panama, supra, para. 143.

208 Cf. Case of Vélez Loor v. Panama, supra, para. 143.

209 Cf. Juridical Status and Human Rights of the Child, supra, para. 95, and Case of Mendoza and others v. Argentina, supra, para. 148.

210 Cf. Juridical Status and Human Rights of the Child, supra, para. 96.

211 Cf. Committee on the Rights of the Child, General Comment No. 12: The right of the child to be heard, supra, para. 66.

212 Cf. Juridical Status and Human Rights of the Child, supra, paras. 96 to 98, and Case of Mendoza and others v. Argentina, supra, para. 148.

$213 C f$. Committee on the Rights of the Child, General Comment No. 14 on the right of the child to have his or her best interests taken as a primary consideration (Article 3, paragraph 1), supra, para. 14(b).

214 Cf. Juridical Status and Human Rights of the Child, supra, para. 94.

215 Cf. Case of Baena Ricardo et al. v. Panama. Merits, Reparations, and Costs. Judgment of February 2, 2001. Series C No. 72, para. 126, and Case of Vélez Loor v. Panama, supra, para. 141.

$216 C f$. Committee on the Rights of the Child, General Comment No. 6: Treatment of Unaccompanied and Separated Children Outside their Country of Origin, supra, para. 25, and Committee on the Rights of the Child, General Comment No. 12: The right of the child to be heard, supra, paras. 40 to 47 and 82 .

217 Case of Vélez Loor v. Panama, supra, para. 180.

218 Cf. Case of Nadege Dorzema et al. v. Dominican Republic. Merits Reparations and costs. Judgment of October 24, 2012. Series C No. 251, para. 175.

219 Article 12 of the Convention on the Rights of the Child stipulates that:

1. States Parties shall assure to the child who is capable of forming his or her own views the right to express those views freely in all matters affecting the child, the views of the child being given due weight in accordance with the age and maturity of the child.

2. For this purpose, the child shall in particular be provided the opportunity to be heard in any administrative and judicial proceedings affecting the child, either directly, or through a representative or an appropriate body, in a manner consistent with the procedural rules of national law.

See also, Committee on the Rights of the Child, General Comment No. 12: The right of the child to be heard, supra, paras. 65 to 67.

220 Cf. Juridical Status and Human Rights of the Child, supra, para. 102, and Case of Atala Riffo and daughters v. Chile. Merits, reparations and costs. Judgment of February 24, 
2012, Series C No 239, para. 196. See also, Committee on the Rights of the Child, General Comment No. 12: The right of the child to be heard, supra, paras. 65 to 67 .

221 Cf. Case of Atala Riffo and daughters v. Chile. Participation of the girls. Order of the Inter-American Court of Human Rights of November 29, 2011, Considering clauses 9 to 12 .

222 Cf. Committee on the Rights of the Child, General Comment No. 12: The right of the child to be heard, supra, para. 21.

223 Cf. Committee on the Rights of the Child, General Comment No. 12: The right of the child to be heard, supra, para. 21.

224 Cf. Juridical Status and Human Rights of the Child, supra, para. 129.

225 Cf. Committee on the Rights of the Child, General Comment No. 12: The right of the child to be heard, supra, para. 34.

226 See Article 40(2)(VI) of the Convention on the Rights of the Child. Cf. Committee on the Rights of the Child, General Comment No. 6: Treatment of Unaccompanied and Separated Children Outside their Country of Origin, supra, para. 31. See also, Inter-American Commission on Human Rights (IACHR), Second Progress Report of the Rapporteurship on Migrant Workers and Members of their Families, OEA/Ser./ L/V/II.111 doc. 20 rev., April 16, 2000, para. 99(c).

$227 C f$. Committee on the Rights of the Child, General Comment No. 6: Treatment of Unaccompanied and Separated Children Outside their Country of Origin, supra, para. 71.

228 Case of the Yakye Axa Indigenous Community v. Paraguay. Merits, reparations and costs. Judgment of June 17, 2005. Series C No. 125, para. 63, and Case of Rosendo Cantú et al. v. Mexico. Preliminary objection, merits, reparations and costs. Judgment of August 31, 2010. Series C No. 216, para. 184.

$229 C f$. The Right to Information on Consular Assistance within the framework of the Guarantees of Due Process of Law, supra, para. 80.

230 Consular protection does not apply in cases of asylum seekers and refugees, given the possible consequences against the principle of confidentiality and the security itself of the refugee and his next of kin.

231 This Article establishes that consular functions consist in:

e) helping and assisting nationals, both individuals and bodies corporate, of the sending State;

\section{$[\ldots]$}

h) safeguarding, within the limits imposed by the laws and regulations of the receiving State, the interests of minors and other persons lacking full capacity who are nationals of the sending State, particularly where any guardianship or trusteeship is required with respect to such persons."

232 Exceptions to the Exhaustion of Domestic Remedies (Arts. 46.1, 46.2.a and 46.2.b American Convention on Human Rights), supra, para. 28.

$233 C f$. Report of the Special Rapporteur on the Human Rights of Migrants, François Crépeau, Promotion and Protection of all Human Rights, Civil, Political, Economic, Social, and Cultural Rights, Including the Right to Development, UN Doc. A/HRC/20/24, 2 April 2012, para. 38.
$234 C f$. Inter-American Commission on Human Rights (IACHR), Second Progress Report of the Rapporteurship on Migrant Workers and Members of their Families, OEA/Ser./L/V/ II.111 doc. 20 rev., April 16, 2001, para. 99(d).

$235 C f$. Committee on the Rights of the Child, General Comment No. 6: Treatment of Unaccompanied and Separated Children Outside their Country of Origin, supra, para. 21.

$236 C f$. Committee on the Rights of the Child, General Comment No. 6: Treatment of Unaccompanied and Separated Children Outside their Country of Origin, supra, para. 33.

237 Cf. Committee on the Rights of the Child, General Comment No. 6: Treatment of Unaccompanied and Separated Children Outside their Country of Origin, supra, para. 33.

238 Cf. Committee on the Rights of the Child, General Comment No. 6: Treatment of Unaccompanied and Separated Children Outside their Country of Origin, supra, para. 33.

239 Cf. Committee on the Rights of the Child, General Comment No. 6: Treatment of Unaccompanied and Separated Children Outside their Country of Origin, supra, para. 33.

$240 C f$. Committee on the Rights of the Child, General Comment No. 6: Treatment of Unaccompanied and Separated Children Outside their Country of Origin, supra, para. 33.

241 Committee on the Rights of the Child, General Comment No. 6: Treatment of Unaccompanied and Separated Children Outside their Country of Origin, supra, para. 34.

$242 C f$. Committee on the Rights of the Child, General Comment No. 6: Treatment of Unaccompanied and Separated Children Outside their Country of Origin, supra, para. 35.

243 Cf. Case of Chaparro Álvarez and Lapo Íñiguez v. Ecuador, supra, para. 107, and Case of J. v. Peru, supra, para. 224.

244 Cf. Case of López Mendoza v. Venezuela. Merits Reparations and costs. Judgment of September 1, 2011. Series C No. 233, para. 141.

245 Cf. Case of Apitz Barbera et al. ("First Court of Administrative Disputes") v. Venezuela. Preliminary Objection, Merits, Reparations, and Costs. Judgment of August 5, 2008. Series C No. 182, para. 77, and Case of J. v. Peru, supra, para. 224.

246 Cf. Case of Yatama v. Nicaragua. Preliminary Objections, Merits, Reparations, and Costs. Judgment of June 23, 2005. Series C No. 127, para. 152, and Case of J. v. Peru, supra, para. 224.

247 Cf. Case of Claude Reyes et al. v. Chile. Merits, Reparations, and Costs. Judgment of September 19, 2006. Series C No. 151, para. 122, and Case of J. v. Peru, supra, para. 224.

248 The foregoing, in the words of the Committee on the Rights of the Child, "is a guarantee that the views of the child are not only heard as a formality, but are taken seriously." Committee on the Rights of the Child, General Comment No. 12: The right of the child to be heard, supra, para. 45.

249 Committee on the Rights of the Child, General Comment No. 12: The right of the child to be heard, supra, para. 74 .

250 Committee on the Rights of the Child, General Comment No. 12: The right of the child to be heard, supra, para. 74 .

251 Cf. Case of Nadege Dorzema et al. v. Dominican Republic, supra, para. 175, and Case of Pacheco Tineo Family v. Bolivia, supra, para. 133.

252 Cf. Case of Vélez Loor v. Panama, supra, para. 126. 
$253 C f$. Committee on the Rights of the Child, General Comment No. 14 on the right of the child to have his or her best interests taken as a primary consideration (Article 3, paragraph 1), supra, para. 98.

254 Cf. ECHR, Case of Čonka v. Belgium, No. 51564/99. Judgment of 5 February 2002, para. 79, and Case of Gebremedhin [Gaberamadhien] v. France, No. 25389/05, Judgment of 26 April 2007, para. 58.

255 Matter of L.M. with regard to Paraguay. Provisional Measures. Order of the Inter-American Court of Human Rights of July 1, 2011, Considering paragraph 16. See also, ECHR, Case of $H$ v. the United Kingdom, No. 9580/81. Judgment of 8 July 1987, para. 85; Case of Paulsen-Medalen and Svensson v. Sweden, No. 149/1996/770/967. Judgment of 19 February 1998, paras. 39 and 42; Case of Laino v. Italy, No. 33158/ 96. Judgment of 18 February 1999, para. 18; Case of Monory v. Romania and Hungary, No. 71099/01. Judgment of 5 April 2005, para. 82; and Case of V.A.M. v. Serbia, No. 39177/05. Judgment of 13 March 2007, paras. 99 and 101.

256 Cf. Matter of L.M. with regard to Paraguay. Provisional Measures, supra, Considering paragraph 16.

257 Article 1. Obligation to Respect Rights

1. The States Parties to this Convention undertake to respect the rights and freedoms recognized herein and to ensure to all persons subject to their jurisdiction the free and full exercise of those rights and freedoms, without any discrimination for reasons of race, color, sex, language, religion, political or other opinion, national or social origin, economic status, birth, or any other social condition.

2. For the purposes of this Convention, "person" means every human being.

Article 7. Right to Personal Liberty

1. Every person has the right to personal liberty and security.

2. No one shall be deprived of his physical liberty except for the reasons and under the conditions established beforehand by the constitution of the State Party concerned or by a law established pursuant thereto.

3. No one shall be subject to arbitrary arrest or imprisonment.

4. Anyone who is detained shall be informed of the reasons for his detention and shall be promptly notified of the charge or charges against him.

5. Any person detained shall be brought promptly before a judge or other officer authorized by law to exercise judicial power and shall be entitled to trial within a reasonable time or to be released without prejudice to the continuation of the proceedings. His release may be subject to guarantees to assure his appearance for trial.

6. Anyone who is deprived of his liberty shall be entitled to recourse to a competent court, in order that the court may decide without delay on the lawfulness of his arrest or detention and order his release if the arrest or detention is unlawful. In States Parties whose laws provide that anyone who believes himself to be threatened with deprivation of his liberty is entitled to recourse to a competent court in order that it may decide on the lawfulness of such threat, this remedy may not be restricted or abolished. The interested party or another person in his behalf is entitled to seek these remedies.

7. No one shall be detained for debt. This principle shall not limit the orders of a competent judicial authority issued for nonfulfillment of duties of support.

259 Article 8. Right to a Fair Trial

1. Every person has the right to a hearing, with due guarantees and within a reasonable time, by a competent, independent, and impartial tribunal, previously established by law, in the substantiation of any accusation of a criminal nature made against him or for the determination of his rights and obligations of a civil, labor, fiscal, or any other nature.

2. Every person accused of a criminal offense has the right to be presumed innocent so long as his guilt has not been proven according to law. During the proceedings, every person is entitled, with full equality, to the following minimum guarantees:

a. the right of the accused to be assisted without charge by a translator or interpreter, if he does not understand or does not speak the language of the tribunal or court;

b. prior notification in detail to the accused of the charges against him;

c. adequate time and means for the preparation of his defense;

d. the right of the accused to defend himself personally or to be assisted by legal counsel of his own choosing, and to communicate freely and privately with his counsel;

e. the inalienable right to be assisted by counsel provided by the State, paid or not as the domestic law provides, if the accused does not defend himself personally or engage his own counsel within the time period established by law;

f. the right of the defense to examine witnesses present in the court and to obtain the appearance, as witnesses, of experts or other persons who may throw light on the facts;

g. the right not to be compelled to be a witness against himself or to plead guilty; and

h. the right to appeal the judgment to a higher court.

3. A confession of guilt by the accused shall be valid only if it is made without coercion of any kind.

4. An accused person acquitted by a nonappealable judgment shall not be subjected to a new trial for the same cause.

5. Criminal proceedings shall be public, except insofar as may be necessary to protect the interests of justice. 
260

Article 19. Rights of the Child

Every minor child has the right to the measures of protection required by his condition as a minor on the part of his family, society, and the State.

261 Article 29. Restrictions Regarding Interpretation No provision of this Convention shall be interpreted as:

a. permitting any State Party, group, or person to suppress the enjoyment or exercise of the rights and freedoms recognized in this Convention or to restrict them to a greater extent than is provided for herein;

b. restricting the enjoyment or exercise of any right or freedom recognized by virtue of the laws of any State Party or by virtue of another convention to which one of the said states is a party;

c. precluding other rights or guarantees that are inherent in the human personality or derived from representative democracy as a form of government; or

d. excluding or limiting the effect that the American Declaration of the Rights and Duties of Man and other international acts of the same nature may have.

262 Article XXV. Right of protection from arbitrary arrest

No person may be deprived of his liberty except in the cases and according to the procedures established by pre-existing law.

No person may be deprived of liberty for nonfulfillment of obligations of a purely civil nature.

Every individual who has been deprived of his liberty has the right to have the legality of his detention ascertained without delay by a court, and the right to be tried without undue delay or, otherwise, to be released. He also has the right to humane treatment during the time he is in custody.

263 Article 4(2) of the Optional Protocol to the Convention against Torture and Other Cruel, Inhuman or Degrading Treatment or Punishment establishes that "deprivation of liberty means any form of detention or imprisonment or the placement of a person in a public or private custodial setting which that person is not permitted to leave at will by order of any judicial, administrative or other authority." Optional Protocol to the Convention Against Torture and other Cruel, Inhuman and Degrading Treatment or Punishment, adopted on 9 January 2003, entry into force on 22 June 2006. According to Rule 11(b) of the United Nations Rules for the Protection of Juveniles deprived of their Liberty, "deprivation of liberty means any form of detention or imprisonment or the placement of a person in a public or private custodial setting, from which this person is not permitted to leave at will, by order of any judicial, administrative or other public authority." United Nations Rules for the Protection of Juveniles deprived of their Liberty, UN Doc. A/RES/45/113, adopted on 14 December 1990. According to the Principles and Best Practices on the Protection of Persons Deprived of Liberty in the Americas adopted by the Inter-American Commission in 2008, "deprivation of liberty" is: "Any form of detention, imprisonment, institutionalization, or custody of a person in a public or private institution which that person is not permitted to leave at will, by order of or under de facto control of a judicial, administrative or any other authority, for reasons of humanitarian assistance, treatment, guardianship, protection, or because of crimes or legal offenses. This category of persons includes not only those deprived of their liberty because of crimes or infringements or non-compliance with the law, whether they are accused or convicted, but also those persons who are under the custody and supervision of certain institutions, such as: psychiatric hospitals and other establishments for persons with physical, mental, or sensory disabilities; institutions for children and the elderly; centers for migrants, refugees, asylum or refugee status seekers, stateless and undocumented persons; and any other similar institution the purpose of which is to deprive persons of their liberty." Inter American Court of Human Rights (IACHR), Resolution 1/08: Principles and Best Practices on the Protection of Persons Deprived of Liberty $n$ the Americas, adopted during the 131st regular period of sessions, held from March 3-14, 2008.

264 In particular, considering the provisions of Article 27 of the Vienna Convention on the Law of Treaties, which refers to internal law and the observance of treaties, and establishes that "[a] party may not invoke the provisions of its internal law as justification for its failure to perform a treaty. This rule is without prejudice to Article 46."

265 In other words, whether this is called arrest, detention, imprisonment, internment, institutionalization, etc.

266 United Nations High Commissioner for Refugees (UNHCR), Guidelines on the Applicable Criteria and Standards relating to the Detention of Asylum-Seekers and Alternatives to Detention, published in 2012, para. 5.

267 United Nations High Commissioner for Refugees (UNHCR), Guidelines on the Applicable Criteria and Standards relating to the Detention of Asylum-Seekers and Alternatives to Detention, published in 2012, para. 6 .

268 United Nations High Commissioner for Refugees (UNHCR), Guidelines on the Applicable Criteria and Standards relating to the Detention of Asylum-Seekers and Alternatives to Detention, published in 2012, para. 7, citing ECHR, Case of Guzzardi v. Italy, No. 7367/76. Judgment of 6 November 1980, para. 93.

269 ECHR, Case of Amuur v. France, No. 19776/92. Judgment of 25 June 1996, para. 42.

270 With respect to not detaining asylum seekers and refugees due to immigration reasons, the specific safeguards of Article 31 of the 1951 Convention and the UNHCR guidelines apply. $C f$. Guidelines on the Applicable Criteria and Standards relating to the Detention of Asylum-Seekers and Alternatives to Detention, published in 2012.

271 Cf. Case of Vélez Loor v. Panama, supra, para. 169. The Special Rapporteur of the United Nations on the Human Rights of Migrants has recommended that "[d]etention of migrants on the ground of their irregular status should under no circumstance be of punitive nature" Report of the Special Rapporteur, Ms. Gabriela Rodríguez Pizarro, Specific Groups and Individuals: Migrant Workers, pursuant to Commission on Human Rights resolution 2002/62, UN Doc. E/CN.4/2003/85, 30 December 2002, para. 73. Similarly, the Working Group on Arbitrary Detention has affirmed that "criminalizing illegal entry into a country exceeds the legitimate interest of States to control and regulate illegal immigration and leads to unnecessary detention." Working Group on 
Arbitrary Detention, Report of the Working Group, Promotion and Protection of all Human Rights, Civil, Political, Economic, Social, and Cultural Rights, Including the Right to Development, UN Doc. A/HRC/7/4, 10 January 2008, para. 53. See also, Report of the Special Rapporteur on the human rights of migrants, Jorge Bustamante, Promotion and Protection of all Human Rights, Civil, Political, Economic, Social, and Cultural Rights, Including the Right to Development, UN Doc. A/HRC/11/7, May 14, 2009, para. 65.

272 See Rule 13(1) of the United Nations Standard Minimum Rules for the Administration of Juvenile Justice (The Beijing Rules), UN Doc. A/RES/40/33, adopted on 29 November 1985; Rule 6(1) of the United Nations Standard Minimum Rules for Non-custodial Measures (Tokyo Rules), UN Doc. A/RES/45/110, adopted on 14 December 1990; Rule 17 of the United Nations Rules for the Protection of Juveniles deprived of their Liberty (Rules of Havana), UN Doc. A/ RES/45/113, adopted on 14 December 1990; and, Principle III of the Principles and Best Practices on the Protection of Persons Deprived of Liberty in the Americas of the InterAmerican Commission on Human Rights, adopted during the 131st regular period of sessions, held from March 3-14, 2008.

273 Article 37(b) of the Convention on the Rights of the Child stipulates that the States Parties must ensure that:

No child shall be deprived of his or her liberty unlawfully or arbitrarily. The arrest, detention or imprisonment of a child shall be in conformity with the law and shall be used only as a measure of last resort and for the shortest appropriate period of time.

274 Cf. Case of the "Children's Rehabilitation Institute" v. Paraguay, supra, paras. 230 and 231, and Case of Mendoza et al. v. Argentina, supra, para. 162.

$275 C f$. Committee on the Rights of the Child, General Comment No. 10: Children's rights in juvenile justice, UN Doc. CRC/C/ GC/10, 25 April 2007, paras. 77, 79 and 80. See also, Committee on the Rights of the Child, General Comment No. 6: Treatment of Unaccompanied and Separated Children Outside their Country of Origin, supra, para. 61.

$276 C f$. Committee on the Rights of the Child, General Comment No. 10: Children's rights in juvenile justice, supra, para. 51.

277 See Article 37(b) and (d) of the Convention on the Rights of the Child.

278 Cf. Case of the "Children's Rehabilitation Institute" v. Paraguay, supra, para. 230. See also, Rule 13(1) and 13 (2) of the United Nations Standard Minimum Rules for the Administration of Juvenile Justice (The Beijing Rules).

279 In fact, the Committee on the Rights of the Child has emphasized that compliance with the requirements of paragraph (b) of Article 37 of the Convention, in stating that " $[\mathrm{t}]$ he arrest, detention or imprisonment of a child shall be in conformity with the law and shall be used only as a measure of last resort and for the shortest appropriate period of time", shall proceed in cases where deprivation of liberty of unaccompanied and separated children outside their country of origin is exceptionally justified "for other reasons." Committee on the Rights of the Child, General Comment No. 6: Treatment of Unaccompanied and Separated Children Outside their Country of Origin, supra, para. 61.

280 Cf. Case of Vélez Loor v. Panama, supra, paras. 163 to 172.

281 Cf. Case of Vélez Loor v. Panama, supra, paras. 169 and 171.
282 Cf. Case of Vélez Loor v. Panama, supra, para. 171, citing Human Rights Committee, C. v. Australia, (Communication No. 900/1999) UN Doc. (CCPR/C/76/D/900/1999), decision adopted on November 13, 2002, para. 8(2).

283 Cf. Case of Vélez Loor v. Panama, supra, para. 166.

284 This requirement means that the measure must be absolutely essential to achieve the objective sought and that there is no measure that is less severe in relation to the right restricted, among all those measures that are equally appropriate, to achieve the proposed objective. Cf. Case of Vélez Loor v. Panama, supra, para. 166.

285 See, similarly, STEPS Consulting Social, The conditions in centres for third country nationals (detention camps, open centres as well as transit centres and transit zones) with a particular focus on provisions and facilities for persons with special needs in the $25 \mathrm{EU}$ member states, study prepared at the request of the European Parliament Committee on Civil Liberties, Justice and Home Affairs, Ref. IP/C/LIBE/IC/ 2006-181, Ref. 12/2007, December 2007 p. 22, affirming that "The confinement of minors should be banned. The best interests of the child should form the basis of any decision made about that child. Depriving a child of their freedom can in no way be in their best interests, other practices can be used and have already been implemented in some countries."

$286 C f$. Working Group on Arbitrary Detention, Report of the Working Group, Civil and political rights, including questions of Torture and Detention, UN Doc. E/CN.4/1999/63/Add.3, 18 December 1998, para. 33, and Report of the Special Rapporteur, Ms. Gabriela Rodríguez Pizarro, Specific Groups and Individuals: Migrant Workers, pursuant to Commission on Human Rights resolution 2002/62, UN Doc. E/CN.4/ 2003/85, 30 December 2002, paras. 39 and 40.

$287 C f$. Committee on the Rights of the Child, General Comment No. 6: Treatment of Unaccompanied and Separated Children Outside their Country of Origin, supra, para. 63.

$288 C f$. Report of the Special Rapporteur on the human rights of migrants, Jorge Bustamante, Promotion and Protection of all Human Rights, Civil, Political, Economic, Social, and Cultural Rights, Including the Right to Development, UN Doc. $\mathrm{A} / \mathrm{HRC} / 11 / 7$, May 14, 2009, paras. 60 to 62.

$289 C f$. Case of Furlan and family members v. Argentina, supra, para. 126.

290 See Article 3(2), and its relation to Articles 18 and 27 of the Convention on the Rights of the Child.

291 See Article 20(1) of the Convention on the Rights of the Child, which establishes "[a] child temporarily or permanently deprived of his or her family environment, or in whose own best interests cannot be allowed to remain in that environment, shall be entitled to special protection and assistance provided by the State."

292 Cf. Case of Furlan and family members v. Argentina, supra, para. 126.

293 Committee on the Rights of the Child, General Comment No. 6: Treatment of Unaccompanied and Separated Children Outside their Country of Origin, supra, para. 61. See also, Report of the Special Rapporteur, Ms. Gabriela Rodríguez Pizarro, Specific Groups and Individuals: Migrant Workers, pursuant to Commission on Human Rights resolution 2002/ 62, UN Doc. E/CN.4/2003/85, 30 December 2002, para. $75(a)$. 
294 Juridical Status and Human Rights of the Child, supra, para. 71, and Case of Fornerón and daughter v. Argentina. Merits, reparations and costs. Judgment of April 27, 2012. Series C No. 242, para. 46. See also, Article 9 of the Convention on the Rights of the Child.

295 Cf. Report of the Special Rapporteur on the Human Rights of Migrants, François Crépeau, Promotion and Protection of all Human Rights, Civil, Political, Economic, Social, and Cultural Rights, Including the Right to Development, UN Doc. A/HRC/20/24, 2 April 2012, para. 40. See also, Committee on the Rights of the Child, Report of the 2012 Day of General Discussion on the rights of all children in the context of international migration, 28 September 2012, recommendation in paragraph 78 provides that "[c]hildren should not be criminalized or subject to punitive measures because of their or their parents' migration status. The detention of a child because of their or their parent's migration status constitutes a child rights violation and always contravenes the principle of the best interests of the child. In this light, States should expeditiously and completely cease the detention of children on the basis of their immigration status."

296 Cf. Report of the Special Rapporteur on the human rights of migrants, Jorge Bustamante, Promotion and Protection of all Human Rights, Civil, Political, Economic, Social, and Cultural Rights, Including the Right to Development, UN Doc. A/HRC/11/7, May 14, 2009, para. 62; Report of the Special Rapporteur on the Human Rights of Migrants, Jorge Bustamante, UN Doc. A/65/222, 3 August 2010, para. 48; and ECHR, Case of Popov v. France, Nos. 39472/07 and 39474/ 07, Judgment of 19 January 2013, paras. 140, 141 and 147. See also, Report of the Special Rapporteur on the human rights of migrants, Jorge Bustamante, Addendum: Mission to the United States of America, UN Doc. A/HRC/7/12/Add.2, 5 March 2008, para. 125.

\section{Article 2. Domestic Legal Effects}

Where the exercise of any of the rights or freedoms referred to in Article 1 is not already ensured by legislative or other provisions, the States Parties undertake to adopt, in accordance with their constitutional processes and the provisions of this Convention, such legislative or other measures as may be necessary to give effect to those rights or freedoms.
Article 7. Right to Personal Liberty

1. Every person has the right to personal liberty and security.

2. No one shall be deprived of his physical liberty except for the reasons and under the conditions established beforehand by the constitution of the State Party concerned or by a law established pursuant thereto.

3. No one shall be subject to arbitrary arrest or imprisonment.

4. Anyone who is detained shall be informed of the reasons for his detention and shall be promptly notified of the charge or charges against him.

5. Any person detained shall be brought promptly before a judge or other officer authorized by law to exercise judicial power and shall be entitled to trial within a reasonable time or to be released without prejudice to the continuation of the proceedings. His release may be subject to guarantees to assure his appearance for trial.

6. Anyone who is deprived of his liberty shall be entitled to recourse to a competent court, in order that the court may decide without delay on the lawfulness of his arrest or detention and order his release if the arrest or detention is unlawful. In States Parties whose laws provide that anyone who believes himself to be threatened with deprivation of his liberty is entitled to recourse to a competent court in order that it may decide on the lawfulness of such threat, this remedy may not be restricted or abolished. The interested party or another person in his behalf is entitled to seek these remedies.

7. No one shall be detained for debt. This principle shall not limit the orders of a competent judicial authority issued for nonfulfillment of duties of support.
299

\section{Article 19. Rights of the Child}

Every minor child has the right to the measures of protection required by his condition as a minor on the part of his family, society, and the State.

\section{Article 25. Right to Judicial Protection}

1. Everyone has the right to simple and prompt recourse, or any other effective recourse, to a competent court or tribunal for protection against acts that violate his fundamental rights recognized by the constitution or laws of the state concerned or by this Convention, even though such violation may have been committed by persons acting in the course of their official duties.

2. The States Parties undertake:

a. to ensure that any person claiming such remedy shall have his rights determined by the competent authority provided for by the legal system of the state;

b. to develop the possibilities of judicial remedy; and

c. to ensure that the competent authorities shall enforce such remedies when granted.

\section{Article 29. Restrictions regarding Interpretation}

No provision of this Convention shall be interpreted as:

a. permitting any State Party, group, or person to suppress the enjoyment or exercise of the rights and freedoms recognized in this Convention or to restrict them to a greater extent than is provided for herein;

b. restricting the enjoyment or exercise of any right or freedom recognized by virtue of the laws of any State Party or by virtue of another convention to which one of the said states is a party;

c. precluding other rights or guarantees that are inherent in the human personality or 
derived from representative democracy as a form of government; or

d. excluding or limiting the effect that the American Declaration of the Rights and Duties of Man and other international acts of the same nature may have.

302 Article XXV. Right of protection from arbitrary arrest

No person may be deprived of his liberty except in the cases and according to the procedures established by pre-existing law.

No person may be deprived of liberty for nonfulfillment of obligations of a purely civil nature.

Every individual who has been deprived of his liberty has the right to have the legality of his detention ascertained without delay by a court, and the right to be tried without undue delay or, otherwise, to be released. He also has the right to humane treatment during the time he is in custody.

$303 C f$. Working Group on Arbitrary Detention, Report of the Working Group, Promotion and Protection of all Human Rights, Civil, Political, Economic, Social, and Cultural Rights, Including the Right to Development, UN Doc. A/ $\mathrm{HRC} / 13 / 30,18$ January 2010, paras. 61 and 65.

304 Cf. Juridical Status and Human Rights of the Child, supra, paras. 26 and 88.

305 In this regard, the Court has indicated that "according to the obligation of special protection for children established in Article 19 of the American Convention, interpreted in light of the Convention on the Rights of the Child and the Additional Protocol to the American Convention on Human Rights in the Area of Economic, Social and Cultural Rights, in relation to the progressive development stipulated in Article 26 of the Convention, the State must provide free primary education to all children, in an environment and under conditions appropriate to their full intellectual development." Case of the Yean and Bosico Girls v. Dominican Republic, supra, para. 185.

$306 C f$. Committee on the Rights of the Child, General Comment No. 14 on the right of the child to have his or her best interests taken as a primary consideration (Article 3, paragraph 1), supra, paras. 71 to 74 .

307 See also, Committee on the Rights of the Child, Report of the 2012 Day of General Discussion on the rights of all children in the context of international migration, 28 September 2012, para. 57.

308 See Article 20 of the Convention on the Rights of the Child. Cf. Committee on the Rights of the Child, General Comment No. 6: Treatment of Unaccompanied and Separated Children Outside their Country of Origin, supra.

$309 C f$. Declaration on Social and Legal Principles relating to the Protection and Welfare of Children, with Special Reference to Foster Placement and Adoption Nationally and Internationally, UN Doc. A/RES/41/85, adopted on 3 December 1986, and Guidelines for the Alternative Care of Children, UN Doc. A/RES/64/142, adopted on 18 December 2009.

310 Guidelines for the Alternative Care of Children, para. 139.

$311 C f$. International Committee of the Red Cross and others, Inter-Agency Guiding Principles on Unaccompanied or Separated Children, January 2004, p. 26.
312 Cf. ECHR, Case of Mubilanzila Mayeka and Kaniki Mitunga v. Belgium, No. 13178/03. Judgment of 12 October 2006, para. 85.

$313 C f$. Committee on the Rights of the Child, General Comment No. 6: Treatment of Unaccompanied and Separated Children Outside their Country of Origin, supra, para. 80.

314 Cf. Committee on the Rights of the Child, General Comment No. 6: Treatment of Unaccompanied and Separated Children Outside their Country of Origin, supra, paras. 89 to 92.

315 Case of Chitay Nech v. Guatemala. Preliminary objections, merits, reparations and costs. Judgment of May 25, 2010. Series C, No. 212, para. 169.

$316 C f$. Committee on the Rights of the Child, General Comment No. 11, Indigenous children and their rights under the Convention, UN Doc. CRC/GC/2009/11, 11 February 2009.

317 Cf. Committee on the Rights of the Child, General Comment No. 14 on the right of the child to have his or her best interests taken as a primary consideration (Article 3, paragraph 1), supra, para. 89.

$318 C f$. Committee on the Rights of the Child, General Comment No. 14 on the right of the child to have his or her best interests taken as a primary consideration (Article 3, paragraph 1), supra.

319 Cf. Committee on the Rights of the Child, General Comment No. 14 on the right of the child to have his or her best interests taken as a primary consideration (Article 3, paragraph 1), supra, para. 98 .

320 Article 1. Obligation to Respect Rights

1. The States Parties to this Convention undertake to respect the rights and freedoms recognized herein and to ensure to all persons subject to their jurisdiction the free and full exercise of those rights and freedoms, without any discrimination for reasons of race, color, sex, language, religion, political or other opinion, national or social origin, economic status, birth, or any other social condition.

2. For the purposes of this Convention, "person" means every human being.

\section{Article 2. Domestic Legal Effects}

Where the exercise of any of the rights or freedoms referred to in Article 1 is not already ensured by legislative or other provisions, the States Parties undertake to adopt, in accordance with their constitutional processes and the provisions of this Convention, such legislative or other measures as may be necessary to give effect to those rights or freedoms.

322 Article 4. Right to Life

1. Every person has the right to have his life respected. This right shall be protected by law and, in general, from the moment of conception. No one shall be arbitrarily deprived of his life. [...]

323 Article 5. Right to Humane Treatment

1. Every person has the right to have his physical, mental, and moral integrity respected. 
2. No one shall be subjected to torture or to cruel, inhuman, or degrading punishment or treatment. All persons deprived of their liberty shall be treated with respect for the inherent dignity of the human person.

3. Punishment shall not be extended to any person other than the criminal.

4. Accused persons shall, save in exceptional circumstances, be segregated from convicted persons, and shall be subject to separate treatment appropriate to their status as unconvicted persons.

5. Minors while subject to criminal proceedings shall be separated from adults and brought before specialized tribunals, as speedily as possible, so that they may be treated in accordance with their status as minors.

6. Punishments consisting of deprivation of liberty shall have as an essential aim the reform and social readaptation of the prisoners.

\section{Article 7. Right to Personal Liberty}

1. Every person has the right to personal liberty and security.

2. No one shall be deprived of his physical liberty except for the reasons and under the conditions established beforehand by the constitution of the State Party concerned or by a law established pursuant thereto.

3. No one shall be subject to arbitrary arrest or imprisonment.

4. Anyone who is detained shall be informed of the reasons for his detention and shall be promptly notified of the charge or charges against him.

5. Any person detained shall be brought promptly before a judge or other officer authorized by law to exercise judicial power and shall be entitled to trial within a reasonable time or to be released without prejudice to the continuation of the proceedings. His release may be subject to guarantees to assure his appearance for trial.

6. Anyone who is deprived of his liberty shall be entitled to recourse to a competent court, in order that the court may decide without delay on the lawfulness of his arrest or detention and order his release if the arrest or detention is unlawful. In States Parties whose laws provide that anyone who believes himself to be threatened with deprivation of his liberty is entitled to recourse to a competent court in order that it may decide on the lawfulness of such threat, this remedy may not be restricted or abolished. The interested party or another person in his behalf is entitled to seek these remedies.

7. No one shall be detained for debt. This principle shall not limit the orders of a competent judicial authority issued for nonfulfillment of duties of support.

325 Article 17. Rights of the Family
1. The family is the natural and fundamental group unit of society and is entitled to protection by society and the state.

2 . The right of men and women of marriageable age to marry and to raise a family shall be recognized, if they meet the conditions required by domestic laws, insofar as such conditions do not affect the principle of nondiscrimination established in this Convention.

3. No marriage shall be entered into without the free and full consent of the intending spouses.

4. The States Parties shall take appropriate steps to ensure the equality of rights and the adequate balancing of responsibilities of the spouses as to marriage, during marriage, and in the event of its dissolution. In case of dissolution, provision shall be made for the necessary protection of any children solely on the basis of their own best interests.

5. The law shall recognize equal rights for children born out of wedlock and those born in wedlock.

326 Article 19. Rights of the Child

Every minor child has the right to the measures of protection required by his condition as a minor on the part of his family, society, and the State.

327 Article I. Right to life, liberty, and personal security

Every human being has the right to life, liberty and the security of his person.

328 Article XXV. Right of protection from arbitrary arrest

No person may be deprived of his liberty except in the cases and according to the procedures established by pre-existing law.

No person may be deprived of liberty for nonfulfillment of obligations of a purely civil nature.

Every individual who has been deprived of his liberty has the right to have the legality of his detention ascertained without delay by a court, and the right to be tried without undue delay or, otherwise, to be released. He also has the right to humane treatment during the time he is in custody.

329 Cf. Case of Bulacio v. Argentina. Merits, reparations and costs. Judgment of September 18, 2003. Series C No. 100, paras. 126 and 138; Case of the Children's Rehabilitation Institute v. Paraguay, supra, para. 151; and Case of Ximenes Lopes v. Brazil. Merits, reparations and costs. Judgment of July 4, 2006. Series C No. 149, para. 138.

330 Cf. Case of Vélez Loor v. Panama, supra, para. 208.

$331 C f$., mutatis mutandi, Case of Ximenes Lopes v. Brazil, supra, para. 96.

332 Cf. Guidelines for the Alternative Care of Children, paras. 127 to 129 . 
333 Case of the Children's Rehabilitation Institute v. Paraguay, supra, para. 175.

334 Committee on the Rights of the Child, General Comment No. 6: Treatment of Unaccompanied and Separated Children Outside their Country of Origin, supra, para. 63.

$335 C f$. Committee on the Rights of the Child, General Comment No. 6: Treatment of Unaccompanied and Separated Children Outside their Country of Origin, supra, para. 63.

336 Cf. Case of Vélez Loor v. Panama, supra, para. 209.

337 Cf. ECHR, Case of Mubilanzila Mayeka and Kaniki Mitunga v. Belgium, No. 13178/03. Judgment of 12 October 2006, para. 103.

338 Cf. Committee on the Rights of the Child, General Comment No. 6: Treatment of Unaccompanied and Separated Children Outside their Country of Origin, supra, para. 12, and Report of the Special Rapporteur on the Human Rights of Migrants, Jorge Bustamante, Promotion and Protection of all Human Rights, Civil, Political, Economic, Social, and Cultural Rights, Including the Right to Development, UN Doc. A/ HRC/14/30, 16 April 2010, paras. 56 and 57.

339 Cf. Guidelines for the Alternative Care of Children, para. 141, and Report of the Special Rapporteur on the Human Rights of Migrants, Jorge Bustamante, Promotion and Protection of all Human Rights, Civil, Political, Economic, Social, and Cultural Rights, Including the Right to Development, UN Doc. A/HRC/14/30, 16 April 2010, para. 61.

340 Cf. Committee on the Rights of the Child, General Comment No. 9, The rights of children with disabilities, UN Doc. CRC/ C/GC/9, 27 February 2007.

$341 C f$. Committee on the Rights of the Child, General Comment No. 3 (2003), HIV/AIDS and the Rights of the Child, UN Doc. $\mathrm{CRC} / \mathrm{GC} / 2003 / 3,17$ March 2003.

342 Cf. Committee on the Rights of the Child, General Comment No. 7: Implementing child rights in early childhood, U.N. Doc. CRC/C/GC/7/Rev.1, 20 September 2006.

$343 C f$. Committee on the Rights of the Child, General Comment No. 6: Treatment of Unaccompanied and Separated Children Outside their Country of Origin, supra, para. 96.

344 Article 1. Obligation to Respect Rights:

1. The States Parties to this Convention undertake to respect the rights and freedoms recognized herein and to ensure to all persons subject to their jurisdiction the free and full exercise of those rights and freedoms, without any discrimination for reasons of race, color, sex, language, religion, political or other opinion, national or social origin, economic status, birth, or any other social condition.

2. For the purposes of this Convention, "person" means every human being.

345 Article 2. Domestic Legal Effects

Where the exercise of any of the rights or freedoms referred to in Article 1 is not already ensured by legislative or other provisions, the States Parties undertake to adopt, in accordance with their constitutional processes and the provisions of this Convention, such legislative or other measures as may be necessary to give effect to those rights or freedoms.

346 Article 7. Right to Personal Liberty

1. Every person has the right to personal liberty and security.

2. No one shall be deprived of his physical liberty except for the reasons and under the conditions established beforehand by the constitution of the State Party concerned or by a law established pursuant thereto.

3. No one shall be subject to arbitrary arrest or imprisonment.

4. Anyone who is detained shall be informed of the reasons for his detention and shall be promptly notified of the charge or charges against him.

5. Any person detained shall be brought promptly before a judge or other officer authorized by law to exercise judicial power and shall be entitled to trial within a reasonable time or to be released without prejudice to the continuation of the proceedings. His release may be subject to guarantees to assure his appearance for trial.

6. Anyone who is deprived of his liberty shall be entitled to recourse to a competent court, in order that the court may decide without delay on the lawfulness of his arrest or detention and order his release if the arrest or detention is unlawful. In States Parties whose laws provide that anyone who believes himself to be threatened with deprivation of his liberty is entitled to recourse to a competent court in order that it may decide on the lawfulness of such threat, this remedy may not be restricted or abolished. The interested party or another person in his behalf is entitled to seek these remedies.

7. No one shall be detained for debt. This principle shall not limit the orders of a competent judicial authority issued for nonfulfillment of duties of support.

\section{Article 8. Right to a Fair Trial}

1. Every person has the right to a hearing, with due guarantees and within a reasonable time, by a competent, independent, and impartial tribunal, previously established by law, in the substantiation of any accusation of a criminal nature made against him or for the determination of his rights and obligations of a civil, labor, fiscal, or any other nature.

2. Every person accused of a criminal offense has the right to be presumed innocent so long as his guilt has not been proven according to law. During the proceedings, every person is entitled, with full equality, to the following minimum guarantees:

a. the right of the accused to be assisted without charge by a translator or interpreter, if he does 
not understand or does not speak the language of the tribunal or court;

b. prior notification in detail to the accused of the charges against him;

c. adequate time and means for the preparation of his defense;

d. the right of the accused to defend himself personally or to be assisted by legal counsel of his own choosing, and to communicate freely and privately with his counsel;

e. the inalienable right to be assisted by counsel provided by the State, paid or not as the domestic law provides, if the accused does not defend himself personally or engage his own counsel within the time period established by law;

f. the right of the defense to examine witnesses present in the court and to obtain the appearance, as witnesses, of experts or other persons who may throw light on the facts;

g. the right not to be compelled to be a witness against himself or to plead guilty; and

h. the right to appeal the judgment to a higher court.

3. A confession of guilt by the accused shall be valid only if it is made without coercion of any kind.

4. An accused person acquitted by a nonappealable judgment shall not be subjected to a new trial for the same cause.

5. Criminal proceedings shall be public, except insofar as may be necessary to protect the interests of justice.

348 Article 19. Rights of the Child

Every minor child has the right to the measures of protection required by his condition as a minor on the part of his family, society, and the State.

349 Article 25. Right to Judicial Protection

1. Everyone has the right to simple and prompt recourse, or any other effective recourse, to a competent court or tribunal for protection against acts that violate his fundamental rights recognized by the constitution or laws of the state concerned or by this Convention, even though such violation may have been committed by persons acting in the course of their official duties.

2. The States Parties undertake:

a. to ensure that any person claiming such remedy shall have his rights determined by the competent authority provided for by the legal system of the state;

b. to develop the possibilities of judicial remedy; and

c. to ensure that the competent authorities shall enforce such remedies when granted.

350 Article XXV. Right of protection from arbitrary arrest

No person may be deprived of his liberty except in the cases and according to the procedures established by pre-existing law.
No person may be deprived of liberty for nonfulfillment of obligations of a purely civil nature.

Every individual who has been deprived of his liberty has the right to have the legality of his detention ascertained without delay by a court, and the right to be tried without undue delay or, otherwise, to be released. He also has the right to humane treatment during the time he is in custody.

351 Cf. ECHR, Case of Guzzardi v. Italy, No. 7367/76. Judgment of 6 November 1980, paras. 92 and 93; Case of Nielsen v. Denmark, No. 10929/84. Judgment of 28 November 1988, para. 67; and Case of Medvedyez v. France, No. 3394/ 03. Judgment of 29 March 2010, para. 73. See also, United Nations High Commissioner for Refugees (UNHCR), Guidelines on the Applicable Criteria and Standards relating to the Detention of Asylum-Seekers and Alternatives to Detention, published in 2012.

$352 C f$. ECHR, Case of Engel and Others v. the Netherlands, Nos. 5100/71, 5101/71, 5102/71, 5354/72, and 5370/72. Judgment of 8 June 1976, paras. 58 and 59; Case of Guzzardi v. Italy, No. 7367/76. Judgment of 6 November 1980, para. 93; Case of Amuur v. France, No. 19776/92. Judgment of 25 June 1996, para. 42; and Case of Medvedyez v. France, No. 3394/03. Judgment of 29 March 2010, para. 73.

$353 C f$. Case of Torres Millacura et al. v. Argentina. Merits, reparations and costs. Judgment of August 26, 2011. Series C No. 229, para. 76 .

354 Cf. Judicial Guarantees in States of Emergency (Arts. 27.2, 25 and 8 American Convention on Human Rights), supra, para. 27, and Case of Yatama v. Nicaragua, supra, para. 147.

355 Cf. Case of Chaparro Álvarez and Lapo Íñiguez v. Ecuador, supra, para. 53, and Case of Cabrera Garcia and Montiel Flores v. Mexico. Preliminary objection, merits, reparations and costs. Judgment of November 26, 2010. Series C No. 220 , para. 80 .

356 This means that no one may be deprived of their liberty unless it is for reasons, cases or circumstances explicitly defined by law (material aspect), but also, strictly subject to proceedings objectively defined by law (formal aspect). Case of Gangaram Panday v. Suriname. Merits, reparations and costs. Judgment of January 21, 1994. Series C No. 16, para. 47

357 Thus, there is a prohibition of detention or imprisonment based on methods that may be legal, but that in the practice are unreasonable, unpredictable, or disproportionate. In addition, the detention may become arbitrary if, while it is underway, acts occur that can be attributed to the State that are incompatible with respect for the human rights of the detainee. Cf. Case of Gangaram Panday v. Surinam, supra, para. 47, and Case of López Álvarez v. Honduras. Reparations and costs. Judgment of February 1, 2006. Series C. No. 141, para 66. $C f$. Working Group on Arbitrary Detention, Report of the Working Group, Civil and political rights, including questions of Torture and Detention, UN Doc. E/CN.4/1999/ 63, 18 December 1998, para. 70.

358 Cf. Case of Vélez Loor v. Panama, supra, para. 152.

359 Cf. The Right to Information on Consular Assistance within the framework of the Guarantees of Due Process of Law, supra, para. 119; Juridical Status and Rights of Undocumented Migrants, supra, para. 121, and Case of Vélez Loor v. Panama, supra, para. 152. 
360 Cf. Case of Vélez Loor v. Panama, supra, para. 152.

361 Case of Nadege Dorzema et al. v. Dominican Republic, supra, para. 126.

362 Case of Gangaram Panday v. Surinam, supra, para. 47, and Case of Nadege Dorzema et al. v. Dominican Republic, supra, para. 133.

363 Case of Chaparro Álvarez and Lapo Íñiguez v. Ecuador, supra, para. 91, and Case of Nadege Dorzema et al. v. Dominican Republic, supra, para. 133.

$364 C f$. Committee on the Elimination of Racial Discrimination (CERD), General recommendation No. 30: Discrimination against Non-citizens, U.N. Doc. A/59/18, 1 October 2004, paras. 19 and 21.

$365 C f$. Committee on the Elimination of Racial Discrimination (CERD), General recommendation No. 30: Discrimination against Non-citizens, supra, paras. 19 and 21.

366 Cf. Case of Vélez Loor v. Panama, supra, para. 117. See also, ECHR, Case of Amuur v. France, No. 19776/92. Judgment of 25 June 1996, para. 43.

367 Case of Juan Humberto Sánchez v. Honduras. Preliminary objection, merits, reparations and costs. Judgment of June 7, 2003. Series C No. 99, para. 82, and Case of Chaparro Álvarez and Lapo Íniguez v. Ecuador, supra, para. 70.

368 Case of Chaparro Álvarez and Lapo Íñiguez v. Ecuador, supra, para. 70.

369 Cf. Case of Chaparro Álvarez and Lapo Íñiguez v. Ecuador, supra, para. 71.

370 Cf. Case of Chaparro Álvarez and Lapo Íñiguez v. Ecuador, supra, para. 71.

371 In this regard, it should be indicated that the United Nations Working Group on Arbitrary Detention has established that: "[a]ny [...] immigrant placed in custody must be brought promptly before a judicial or other authority." Working Group on Arbitrary Detention, Report of the Working Group Annex II, Deliberation No. 5: Situation regarding immigrants and asylum seekers, UN Doc. E/CN.4/2000/4, 18 December 1998, Principle 3. See also, Working Group on Arbitrary Detention, Report of the Working Group, Civil and political rights, including questions of Torture and Detention, UN Doc. E/CN.4/1999/63, 18 December 1998, para. 69, Guarantee 3 .

372 Cf. Case of Vélez Loor v. Panama, supra, para. 107, and Case of Nadege Dorzema et al. v. Dominican Republic, supra, para. 136.

373 Cf. Case of Vélez Loor v. Panama, supra, para. 107, and Case of Nadege Dorzema et al. v. Dominican Republic, supra, para. 136.

374 Cf. Case of Vélez Loor v. Panama, supra, para. 108, and Case of Nadege Dorzema et al. v. Dominican Republic, supra, para. 137.

375 Cf. Case of Bayarri v. Argentina. Preliminary objection, merits, reparations and costs. Judgment of October 30, 2008. Series C No. 187, para. 67, and Case of Nadege Dorzema et al. v. Dominican Republic, supra, para. 137.

376 Cf. Case of Vélez Loor v. Panama, supra, para. 108, and Case of Nadege Dorzema et al. v. Dominican Republic, supra, para. 137.

377 Cf. Case of Bulacio v. Argentina, supra, para. 130, and Case of Tibi v. Ecuador. Preliminary objections, merits, reparations and costs. Judgment of September 7, 2004. Series C No. 114, para. 112.

378 Cf. Case of Tibi v. Ecuador, supra, para. 112, and Working Group on Arbitrary Detention, Report of the Working Group, Civil and political rights, including questions of Torture and Detention, UN Doc. E/CN.4/1999/63, 18 December 1998, para. 69, Guarantees 6 and 7 .

379 The Court has indicated that "The right to establish contact with a family member is particularly important in the case of detentions of minors. In this situation, the authority that carries out the detention and the one in charge of the place where the child is located, must immediately notify the family members or, failing this, their representatives so that the child may receive promptly the assistance of the person notified." Case of Bulacio v. Argentina, supra, para. 130.

380 Cf. The Right to Information on Consular Assistance within the Framework of the Guarantees of Due Process of Law, supra, para. 106.

381 Cf. Case of Bulacio v. Argentina, supra, para. 130.

$382 C f$. Working Group on Arbitrary Detention, Report of the Working Group Annex II, Deliberation No. 5: Situation regarding immigrants and asylum seekers, UN Doc. E/ CN.4/2000/4, 18 December 1998, Principle 2, and Committee on the Rights of the Child, General Comment No. 6: Treatment of Unaccompanied and Separated Children Outside their Country of Origin, supra, para. 63.

383 Cf. Working Group on Arbitrary Detention, Report of the Working Group Annex II, Deliberation No. 5: Situation regarding immigrants and asylum seekers, UN Doc. E/ CN.4/2000/4, 18 December 1998, Principle 10, and Working Group on Arbitrary Detention, Report of the Working Group, Civil and political rights, including questions of Torture and Detention, UN Doc. E/CN.4/1999/63, 18 December 1998, para. 69, Guarantee 14.

384 See Article 36 of the 1963 Vienna Convention on Consular Relations, adopted on 24 April 1963, entry into force on 19 march 1967, of which 35 Member States of the OAS are party to this Convention; and, Article 16(7) of the Convention for the Protection of the Rights of All Migrant Workers and Members of their Families, UN Doc. A/RES/45/158, adopted on 18 December 1990, entry into force on 1 July 2003. The following 17 Member States of the OAS are party to this treaty: Argentina, Belize, Bolivia, Chile, Colombia, Ecuador, El Salvador, Guatemala, Guyana, Honduras, Jamaica, Mexico, Nicaragua, Paraguay, Peru, Saint Vincent and the Grenadines, and Uruguay.

385 Cf. Case of Vélez Loor v. Panama, supra, para. 153.

386 Thus, the foreign detainee has the right to be informed of his right: (1) that the receiving State inform the competent consular post of his situation, and (2) that the receiving State transmit without delay "any communication addressed to the consular post" by the detainee. $C f$. Article 36(1)(b) of the Vienna Convention on Consular Relations. This notification must be made before "he makes his first statement." In addition to the other rights of the person deprived of liberty, this "constitutes a mechanism to avoid illegal or arbitrary detentions from the very moment of the deprivation of liberty and, in turn, guarantees the right of defense of the individual." The Right to Information on Consular Assistance within the framework of the Guarantees of Due Process of Law, para. 106, and Case of Vélez Loor v. Panama, supra, footnote 157. 
387 Cf. The Right to Information on Consular Assistance within the Framework of the Guarantees of Due Process of Law, supra, paras. 106 and 120, and Case of Vélez Loor v. Panama, supra, para. 154.

$388 C f$. The Right to Information on Consular Assistance within the Framework of the Guarantees of Due Process of Law, supra, para. 86, and Case of Vélez Loor v. Panama, supra, para. 154.

389 See Article 37(d) of the Convention on the Rights of the Child. $C f$. Report of the Special Rapporteur on the Human Rights of Migrants, François Crépeau, Promotion and Protection of all Human Rights, Civil, Political, Economic, Social, and Cultural Rights, Including the Right to Development, UN Doc. A/HRC/20/24, 2 April 2012, para. 38.

390 Cf. Case of Vélez Loor v. Panama, supra, para. 132.

$391 C f$. Committee on the Rights of the Child, General Comment No. 6: Treatment of Unaccompanied and Separated Children Outside their Country of Origin, supra, para. 33.

392 See also, Working Group on Arbitrary Detention, Report of the Working Group, Civil and political rights, including questions of Torture and Detention, UN Doc. E/CN.4/1999/63, 18 December 1998, para. 69, Guarantee 3.

393 Habeas Corpus in Emergency Situations (Arts. 27(2), 25(1) and 7(6) American Convention on Human Rights). Advisory Opinion OC-8/87 of January 30, 1987. Series A No. 8, para. 44. See also, Judicial Guarantees in States of Emergency (Arts. 27.2, 25 and 8 American Convention on Human Rights), supra, para. 30, and Case of Neira Alegría et al. v. Peru. Merits. Judgment of January 19, 1995. Series C No. 20, paras. 82 to 84 .

394 Cf. Habeas Corpus in Emergency Situations (Arts. 27.2, 25.1 and 7.6 American Convention on Human Rights), supra, para. 33, and Case of Vélez Loor v. Panama, supra, para. 124. See also, Article 37 (d) of the International Convention on the Protection of the Rights of Migrant Workers and Members of their Families.

395 Cf. Case of Vélez Loor v. Panama, supra, para. 126.

396 Cf. Case of Vélez Loor v. Panama, supra, para. 129, and Case of Nadege Dorzema et al. v. Dominican Republic, supra, para. 141. In this regard, the observations of the Special Rapporteur on Migrants are instructive: "Some national laws do not provide for judicial review of administrative detention of migrants. In other instances, the judicial review of administrative detention is initiated only upon request of the migrant. In these cases, lack of awareness of the right to appeal, lack of awareness of the grounds for detention, difficult access to relevant files, lack of access to free legal counsel, lack of interpreters and translation services, and a general absence of information in a language detainees can understand on the right to instruct and retain counsel and the situation of the facilities where they are being held can prevent migrants from exercising their rights in practice. In the absence of lawyers and/or interpreters, migrants can often feel intimidated and obliged to sign papers without understanding their content," Report of the Special Rapporteur on the human rights of migrants, Jorge Bustamante, Promotion and Protection of all Human Rights, Civil, Political, Economic, Social, and Cultural Rights, Including the Right to Development, UN Doc. A/HRC/7/12, 25 February 2008, para. 46.

$397 C f$. Report of the Special Rapporteur on the Human Rights of Migrants, François Crépeau, Promotion and Protection of all Human Rights, Civil, Political, Economic, Social, and
Cultural Rights, Including the Right to Development, UN Doc. A/HRC/20/24, 2 April 2012, para. 38.

398 Article 1. Obligation to Respect Rights

1. The States Parties to this Convention undertake to respect the rights and freedoms recognized herein and to ensure to all persons subject to their jurisdiction the free and full exercise of those rights and freedoms, without any discrimination for reasons of race, color, sex, language, religion, political or other opinion, national or social origin, economic status, birth, or any other social condition.

2. For the purposes of this Convention, "person" means every human being.

\section{Article 2. Domestic Legal Effects}

Where the exercise of any of the rights or freedoms referred to in Article 1 is not already ensured by legislative or other provisions, the States Parties undertake to adopt, in accordance with their constitutional processes and the provisions of this Convention, such legislative or other measures as may be necessary to give effect to those rights or freedoms.

Article 4. Right to Life

Every person has the right to have his life respected. This right shall be protected by law and, in general, from the moment of conception. No one shall be arbitrarily deprived of his life.

401 Article 5: Right to Humane Treatment

1. Every person has the right to have his physical, mental, and moral integrity respected.

2. No one shall be subjected to torture or to cruel, inhuman, or degrading punishment or treatment. All persons deprived of their liberty shall be treated with respect for the inherent dignity of the human person.

3. Punishment shall not be extended to any person other than the criminal.

4. Accused persons shall, save in exceptional circumstances, be segregated from convicted persons, and shall be subject to separate treatment appropriate to their status as unconvicted persons.

5. Minors while subject to criminal proceedings shall be separated from adults and brought before specialized tribunals, as speedily as possible, so that they may be treated in accordance with their status as minors.

6. Punishments consisting of deprivation of liberty shall have as an essential aim the reform and social readaptation of the prisoner

402 Article 7. Right to Personal Liberty

1. Every person has the right to personal liberty and security. 
2. No one shall be deprived of his physical liberty except for the reasons and under the conditions established beforehand by the constitution of the State Party concerned or by a law established pursuant thereto.

3. No one shall be subject to arbitrary arrest or imprisonment.

4. Anyone who is detained shall be informed of the reasons for his detention and shall be promptly notified of the charge or charges against him.

5. Any person detained shall be brought promptly before a judge or other officer authorized by law to exercise judicial power and shall be entitled to trial within a reasonable time or to be released without prejudice to the continuation of the proceedings. His release may be subject to guarantees to assure his appearance for trial.

6. Anyone who is deprived of his liberty shall be entitled to recourse to a competent court, in order that the court may decide without delay on the lawfulness of his arrest or detention and order his release if the arrest or detention is unlawful. In States Parties whose laws provide that anyone who believes himself to be threatened with deprivation of his liberty is entitled to recourse to a competent court in order that it may decide on the lawfulness of such threat, this remedy may not be restricted or abolished. The interested party or another person in his behalf is entitled to seek these remedies.

7. No one shall be detained for debt. This principle shall not limit the orders of a competent judicial authority issued for nonfulfillment of duties of support.

\section{Article 8. Right to a Fair Trial}

1. Every person has the right to a hearing, with due guarantees and within a reasonable time, by a competent, independent, and impartial tribunal, previously established by law, in the substantiation of any accusation of a criminal nature made against him or for the determination of his rights and obligations of a civil, labor, fiscal, or any other nature.

2. Every person accused of a criminal offense has the right to be presumed innocent so long as his guilt has not been proven according to law. During the proceedings, every person is entitled, with full equality, to the following minimum guarantees:

a. the right of the accused to be assisted without charge by a translator or interpreter, if he does not understand or does not speak the language of the tribunal or court;

b. prior notification in detail to the accused of the charges against him;

c. adequate time and means for the preparation of his defense;

d. the right of the accused to defend himself personally or to be assisted by legal counsel of his own choosing, and to communicate freely and privately with his counsel;

e. the inalienable right to be assisted by counsel provided by the State, paid or not as the domestic law provides, if the accused does not defend himself personally or engage his own counsel within the time period established by law;

f. the right of the defense to examine witnesses present in the court and to obtain the appearance, as witnesses, of experts or other persons who may throw light on the facts;

g. the right not to be compelled to be a witness against himself or to plead guilty; and

h. the right to appeal the judgment to a higher court

3. A confession of guilt by the accused shall be valid only if it is made without coercion of any kind.

4. An accused person acquitted by a nonappealable judgment shall not be subjected to a new trial for the same cause.

5. Criminal proceedings shall be public, except insofar as may be necessary to protect the interests of justice.

404 Article 19. Rights of the Child

Every minor child has the right to the measures of protection required by his condition as a minor on the part of his family, society, and the State.

Article 22. Freedom of Movement and Residence

$[\ldots]$

7. Every person has the right to seek and be granted asylum in a foreign territory, in accordance with the legislation of the state and international conventions, in the event he is being pursued for political offenses or related common crimes. $[\ldots]$

Article 22. Freedom of Movement and Residence [...]

8. In no case may an alien be deported or returned to a country, regardless of whether or not it is his country of origin, if in that country his right to life or personal freedom is in danger of being violated because of his race, nationality, religion, social status, or political opinions.

407 Article 25. Right to Judicial Protection

1. Everyone has the right to simple and prompt recourse, or any other effective recourse, to a competent court or tribunal for protection against acts that violate his fundamental rights recognized by the constitution or laws of the state concerned or by this Convention, even though such violation may have been committed by persons acting in the course of their official duties.

2. The States Parties undertake:

a. to ensure that any person claiming such remedy shall have his rights determined by the 
competent authority provided for by the legal system of the state;

b. to develop the possibilities of judicial remedy; and

c. to ensure that the competent authorities shall enforce such remedies when granted.

408 Article 13, fourth paragraph:

$$
[\ldots]
$$

Extradition shall not be granted nor shall the person sought be returned when there are grounds to believe that his life is in danger, that he will be subjected to torture or to cruel, inhuman or degrading treatment, or that he will be tried by special or ad hoc courts in the requesting State.

409 Article I. Right to life, liberty, and personal security Every human being has the right to life, liberty and the security of his person.

410 Article XXV. Right of protection from arbitrary arrest No person may be deprived of his liberty except in the cases and according to the procedures established by pre-existing law.

No person may be deprived of liberty for nonfulfillment of obligations of a purely civil nature.

Every individual who has been deprived of his liberty has the right to have the legality of his detention ascertained without delay by a court, and the right to be tried without undue delay or, otherwise, to be released. He also has the right to humane treatment during the time he is in custody.

411 Article XXVII. Right of asylum

Every person has the right to seek and be granted asylum in a foreign territory, in accordance with the legislation of the state and international conventions, in the event he is being pursued for political offenses or related common crimes.

412 Cf. Case of the Pacheco Tineo Family v. Bolivia, supra, para. 151, citing United Nations High Commissioner for Refugees (UNHCR), Executive Committee, General conclusion on international protection, UN Doc. 65 (XLII)-1991, published on 11 October 1991, para. (c).

413 Even though the 1951 Convention does not explicitly establish the right of asylum as a right, it is considered to be incorporated implicitly into its text. Cf. Case of the Pacheco Tineo Family v. Bolivia, supra, para. 139.

414 Cf. Case of the Pacheco Tineo Family v. Bolivia, supra, para. 139 , which affirms that " $[\mathrm{t}]$ his is evident from the Preamble to the 1951 Convention, which indicates the importance of international cooperation to ensure the granting of asylum by means of the treaty, and has been reiterated by the UNHCR Executive Committee." The latter has stated that "the institution of asylum, which derives directly from the right to seek and enjoy asylum set out in Article 14(1) of the 1948 Universal Declaration of Human Rights, is among the most basic mechanisms for the international protection of refugees." United Nations High Commissioner for Refugees (UNHCR), Executive Committee, Conclusion on Safeguarding Asylum,
UN Doc. 82 (XLVIII)-1997, published on 17 October 1997, para. (b). In its Conclusion No. 5 of 1977, the Executive Committee had already appealed to the States Parties to the 1951 Convention and the 1967 Protocol to apply "liberal practices in granting permanent or at least temporary asylum to refugees who have come directly to their territory." $C f$. United Nations High Commissioner for Refugees (UNHCR), Executive Committee, Asylum, UN Doc. 5 (XXVIII) - 1977, published in 1977, para. (a).

415 Cf. Case of the Pacheco Tineo Family v. Bolivia, supra, para. 152.

416 The Court has noted that "[a]ccording to the 1951 Convention, a person is a refugee as soon as he meets the requirements set out in the definition, which necessarily occurs before his refugee status has been decided formally. Thus, the recognition of the refugee status of a person is of a declarative rather than a constitutive nature." Case of the Pacheco Tineo Family v. Bolivia, supra, para. 145.

417 The 1967 Protocol expands the applicability of the 1951 Convention by eliminating its geographical and temporal restrictions. Cf. Case of the Pacheco Tineo Family v. Bolivia, supra, para. 144.

418 The Court clarifies that, technically, "asylum seeker" is equivalent in International Law to "applicant for recognition of refugee status." Cf. Case of the Pacheco Tineo Family v. Bolivia, supra, footnote 141 .

$419 C f$. United Nations High Commissioner for Refugees (UNHCR), Advisory Opinion on the Extraterritorial Application of Non-refoulement Obligations under the 1951 Convention relating to the Status of Refugees and its 1967 Protocol, published on 26 January 2007, para. 6, and United Nations High Commissioner for Refugees (UNHCR), Handbook and Guidelines on Procedures and Criteria for Determining Refugee Status under the 1951 Convention and the 1967 Protocol relating to the Status of Refugees, UN Doc. HCR/1P/4/ ENG/REV.3, December 2011, para. 28.

420 See Ley No. 26.165. Ley General de Reconocimiento y Protección al Refugiado, published on 28 November 2006, Articles 2, 3 and 39 (Argentina); Decreto Supremo No. 1440 - Reglamento de la Ley $N^{\circ} 251$ de protección a personas refugiadas, 19 December 2012, Articles 4 and 30 (Bolivia); Ley No. 9.474, 22 July 1997, Articles 8, 9 and (Brazil); Ley No. 20.430 - Establece disposiciones sobre protección de refugiados, published on 8 April 2010, Articles 3 and 4 (Chile); Decreto No. 36831G de 2011, Reglamento de Personas Refugiadas, 28 September 2008, Article 134 (Costa Rica); Decreto No. 1.182 - Reglamento para la aplicación del derecho de refugio, 30 May 2012, Articles 5 and 9 (Ecuador); Decreto No. 208 - Ley de Migración y Extranjería, published on 3 March 2004, Article 44 (Honduras); Ley sobre Refugiados y Protección Complementaria, 27 January 2011, Articles 6 and 21, and Reglamento de la ley sobre refugiados y protección complementaria, 21 February 2012, Article 9 (México); Decreto Ejecutivo No. 23, 10 February 1998, Articles 28, 53 and 82 (Panamá); and Ley No. 18.076 - Derecho al refugio y a los refugiados, published on 5 January 2007, Articles 10, 12 and 32, as well as Article 45 of Ley No. 18.250 de Migración, published on 17 January 2008 (Uruguay).

$421 C f$. United Nations High Commissioner for Refugees (UNHCR), Executive Committee, "Non-refoulement," UN Doc. No. 6 (XXVIII)-1977, published in 1997, reaffirming the fundamental importance of the observance of the principle of non-refoulement, both at the border and within the territory 
of a State, of persons who may be subjected to persecution if returned to their country of origin, regardless of whether they have or have not formally recognized as refugees. (“(c) Reaffirms the fundamental importance of the observance of the principle of non-refoulement, both at the border and within the territory of a State of persons who may be subjected to persecution if returned to their country of origin, irrespective of whether or not they have been formally recognized as refugees"). The preamble to the Brasilia Declaration on the Protection of Refugees and Stateless Persons in the Americas establishes the following: "Reiterating our unrestricted respect for the principle of non-refoulement, including nonrejection at the border and indirect non-refoulement, as well as for the non-penalization of illegal entry, and nondiscrimination, as the fundamental principles of international refugee law." United Nations High Commissioner for Refugees (UNHCR), Brasilia Declaration on the Protection of Refugees and Stateless Persons in the Americas, published on 11 November 2010, p. 1. See also, the laws of several countries of the continent, including Argentina, Bolivia, Chile, Ecuador, Honduras, Mexico, Panama and Uruguay, which expressly prohibit rejection at the border. Cf. Ley No. 26.165. Ley General de Reconocimiento y Protección al Refugiado, published on 28 de noviembre de 2006, Article 2 (Argentina); Ley $N^{\circ} 251$ de protección a personas refugiadas, 20 June 2012, Article 4(II) (Bolivia); Ley No. 20.430 - Establece disposiciones sobre protección de refugiados, published on 8 April 2010, Article 3 (Chile); Decreto No. 1.182 - Reglamento para la aplicación del derecho de refugio, 30 May 2012, Article 9 (Ecuador); Ley de Migración y Extranjería, 3 May 2004, Article 44 (Honduras); Ley sobre Refugiados y Protección Complementaria, 27 January 2011, Article 6, and Reglamento de la ley sobre refugiados y protección complementaria, 21 February 2012, Article 9 (Mexico); Decreto Ejecutivo No. 23, 10 February 1998, Articles 53 and 82 (Panama); and Ley No. 18.076-Derecho al refugio y a los refugiados, published on 5 January 2007, Article 12 (Uruguay).

422 Cf. Case of the Pacheco Tineo Family v. Bolivia, supra, para. 153, citing Inter-American Commission on Human Rights (IACHR), Report on the situation of human rights of asylum seekers within the Canadian refugee determination system, OEA/Ser.L/V/II.106. Doc. 40. Rev. 1, February 28, 2000, para. 25. See also, United Nations High Commissioner for Refugees (UNHCR) Advisory Opinion on the Extraterritorial Application of Non-refoulement Obligations under the 1951 Convention relating to the Status of Refugees and its 1967 Protocol, published on 26 January 2007, para. 8.

423 Cf. Case of the Pacheco Tineo Family v. Bolivia, supra, para. 151, citing United Nations High Commissioner for Refugees (UNHCR), Global consultations on international protection: Ministerial Meeting of the States Parties to the 1951 Convention and/or the 1967 Protocol relating to the Status of Refugees (12-13 December 2001)-Declaration of the States Parties to the 1951 Convention and/or the 1967 Protocol relating to the Status of Refugees, UN Doc. HCR/MMSP/ 2001/9, adopted on 13 December 2001, paragraph 4 of which indicates: "Acknowledging the continuing relevance and resilience of this international regime of rights and principles, including at its core the principle of non-refoulement, whose applicability is embedded in customary international law." See also, United Nations High Commissioner for Refugees (UNHCR) Advisory Opinion on the Extraterritorial Application of Non-refoulement Obligations under the 1951 Convention relating to the Status of Refugees and its 1967 Protocol, published on 26 January 2007, paras. 14 to 16 .
424 In the Americas, 28 OAS Member States are party to the 1951 Convention and 29 States of the OAS are parties to the 1967 Protocol. The following five OAS Member States are not are not party to the international refugee instruments: Barbados, Cuba, Granada, Guyana and St. Lucia. See also, United Nations High Commissioner for Refugees (UNHCR), Advisory Opinion on the Extraterritorial Application of Nonrefoulement Obligations under the 1951 Convention relating to the Status of Refugees and its 1967 Protocol, published on 26 January 2007, para. 15.

425 In particular, Article 33(2) establishes that: "The benefit of the present provision may not, however, be claimed by a refugee whom there are reasonable grounds for regarding as a danger to the security of the country in which he is, or who, having been convicted by a final judgment of a particularly serious crime, constitutes a danger to the community of that country."

426 Cf. United Nations High Commissioner for Refugees (UNHCR), UNHCR Note on the Principle of Nonrefoulement, November 1997, section (F).

427 Cartagena Declaration on Refugees, adopted by the "Colloquium on the International Protection of Refugees in Central America, Mexico and Panama: Legal and Humanitarian Problems," held in Cartagena, Colombia, from 19 to 22 November 1984, section III, third conclusion. The Inter-American Commission on Human Rights has affirmed that: "[i]n the Americas and elsewhere, the principle of non-refoulement has gradually been broadened to cover persons fleeing from situations of widespread political violence or civil war (Cartagena Declaration (1984), Declaration of San José (1994))". Inter-American Commission on Human Rights (IACHR), Second Progress Report of the Rapporteurship on Migrant Workers and Members of their Families, OEA/Ser./L/V/ II.111 doc. 20 rev., April 16, 2000, para. 97(2). A similar calling had been made in the Annual Report for 1984-1985.

428 Cf. Case of the Pacheco Tineo Family v. Bolivia, supra, para. 153, citing United Nations High Commissioner for Refugees, Submission by the Office of the United Nations High Commissioner for Refugees in the case of Hirsi and Others v. Italy, March 2010, para. 4(3)(4).

429 Case of the Pacheco Tineo Family v. Bolivia, supra, para. 134.

430 Case of the Pacheco Tineo Family v. Bolivia, supra, para. 135.

431 Secretariat of the OAS, Inter-American Specialized Conference on Human Rights, San José, Costa Rica, held from November 7 to 22, 1969, Acts and Documents, OEA/Ser.K/ XVI/1.2, Washington, D.C., 1978, p. 301.

$432 C f$. Secretariat of the OAS, Inter-American Specialized Conference on Human Rights, San José, Costa Rica, held from November 7 to 22, 1969, Acts and Documents, OEA/Ser.K/ XVI/1.2, Washington, D.C., 1978, pp. 244, 245, 247, 249, and 301 .

433 That is, every human being, in the terms of Article 1(2) of the American Convention.

434 See, similarly, United Nations, Report of the SecretaryGeneral, UN, Human rights and arbitrary deprivation of nationality, UN Doc. A/HRC/25/28, 19 December 2013, para. 26.

435 Similarly, Article 1 of the European Convention establishes that "The High Contracting Parties shall secure to everyone within their jurisdiction the rights and freedoms defined in Section I of this Convention." Council of Europe, European 
Convention for the Protection of Human Rights and Fundamental Freedoms, adopted on 4 November 1950, entry into force on 3 September 1953, Article 1. The European Court of Human Rights has indicated that the duty to ensure human rights contained in the European Convention to all persons under the jurisdiction of the State is not limited to the territory of the State Party, but extends to all the persons under its authority and responsibility, both if that authority is exercised within the territory, or outside it. Cf. ECHR, Loizidou c. Turkey (Preliminary Exceptions), No. 15318/89. Judgment of 23 March 1995, para. 62. See also Case of Medvedyez v. France, No. 3394/03. Judgment of 29 March 2010, para. 62 to 67. Although Article 2(1) of the International Covenant on Civil and Political Rights establishes that "Each State Party to the present Covenant undertakes to respect and to ensure to all individuals within its territory and subject to its jurisdiction the rights recognized in the present Covenant," it has been interpreted that this is applicable with regard to the acts of a State in exercise of its jurisdiction outside its own territory ("... the International Covenant on Civil and Political Rights is applicable in respect of acts done by a State in the exercise of its jurisdiction outside its own territory)." $C f$. International Court of Justice, Legal Consequences of the Construction of a Wall in the Occupied Palestinian Territory, Advisory Opinion of 9 July 2004, p. 136, paras. 108 to 110. See also, Human Rights Committee, General Comment No. 31: The Nature of the General Legal Obligation Imposed on States Parties to the Covenant, U.N. Doc. CCPR/C/21/ Rev.1/Add.13, 26 May 2004, para. 10, stating that "[t]his means that a State party must respect and ensure the rights laid down in the Covenant to anyone within the power or effective control of that State party, even if not situated within the territory of the State party."

436 Likewise, the decision of the Inter-American Commission: "The Commission does not believe, however, that the term 'jurisdiction' in the sense of Article 1(1) is limited to or merely coextensive with national territory. Rather, the Commission is of the view that a State party to the American Convention may be responsible under certain circumstances for the acts and omissions of its agents which produce effects or are undertaken outside that State's own territory [...]," and that "This understanding of jurisdiction-and therefore responsibility for compliance with international obligations - as a notion linked to authority and effective control, and not merely to territorial boundaries, has been confirmed and elaborated on in other cases decided by the European Commission and Court." Inter-American Commission on Human Rights (IACHR), Admissibility Report No. 38/99, Victor Saldaño v. Argentina, March 11, 1999, paras. 17 and 19.

437 Committee on the Rights of the Child, General Comment No. 6: Treatment of Unaccompanied and Separated Children Outside their Country of Origin, supra, para. 12. See also, ECHR, Case of Amuur v. France, No. 19776/92. Judgment of 25 June 1996, para. 52.

$438 C f$. Inter-American Commission on Human Rights (IACHR), Report on the merits No. 51/96, Case 10.675, Haitian Interdiction v. the United States of America, March 13, 1997, paras. 156, 157, and 163, and ECHR, Case of Hirsi Jamaa and others v. Italy, No. 27765/09. Judgment of 23 February 2012, paras. 133 and 134.

439 In this regard, the Committee on the Rights of the Child has stressed that "enjoyment of economic, social and cultural rights is inextricably intertwined with enjoyment of civil and political rights." Committee on the Rights of the Child, General Comment No. 5: General measures of implementation of the Convention on the Rights of the Child (Articles 4, 42 and paragraph 6 of Article 44), supra, para. 6. See also, Juridical Status and Human Rights of the Child, supra, p.86, eight operative paragraph; Article 26 of the American Convention, and Article 4 Convention on the Rights of the Child.

$440 C f$. Committee on the Rights of the Child, General Comment No. 5: General measures of implementation of the Convention on the Rights of the Child (Articles 4, 42 and paragraph 6 of Article 44), supra, para. 12.

441 Cf. Case of the Children's Rehabilitation Institute v. Paraguay, supra, para. 172.

$442 C f$. Committee on the Rights of the Child, General Comment No. 6: Treatment of Unaccompanied and Separated Children Outside their Country of Origin, supra, paras. 84 and 85.

443 Cf. Case of Ximenes Lopes v. Brazil, supra, para. 126.

444 Cf. Case of Cantoral Benavides v. Peru, Merits. Judgment of August 18, 2000. Series C No. 69, para. 95, and Case of Bayarri v. Argentina, supra, para. 81.

445 Cf. Case of Cantoral Benavides v. Peru, supra, para. 102, and Case of the Miguel Castro Castro Prison v. Peru. Merits, reparations and costs. Judgment of November 25, 2006. Series C No. 160, para. 272.

446 Cf. Case of Velásquez Rodriguez v. Honduras. Merits, supra, para. 162; Case of Godinez Cruz v. Honduras. Judgment of January 20, 1989. Series C No. 5, para. 171; and Case of Neira Alegría et al. v. Peru, supra, para. 85.

447 Cf. Case of Vargas Areco v. Paraguay. Merits, reparations and costs. Judgment of September 26, 2006. Series C No. 155, para. 73, and Case of García Prieto et al. v. El Salvador. Preliminary objection, merits, reparations and costs. Judgment of November 20, 2007. Series C No. 168, para. 98.

448 Cf. ECHR, Case of Soering v. the United Kingdom, No. $14038 / 88$. Judgment of 7 July 1989, para. 88.

$449 C f$. Report presented by the Special Rapporteur on torture, Theo van Boven, Civil and political rights, including questions oftorture and detention, UN Doc. E/CN.4/2002/137, 26 February 2002, para. 14.

450 Likewise, Article 7 of the International Covenant on Civil and Political Rights establishes that: "[n]o one shall be subjected to torture or to cruel, inhuman or degrading treatment or punishment. In particular, no one shall be subjected without his free consent to medical or scientific experimentation." International Covenant of Civil and Political Rights, adopted on 16 December 1966, entry into force on 23 March 1976. The following 31 member states of the OAS are parties to this treaty: Argentina, Bahamas, Barbados, Belize, Bolivia, Brazil, Canada, Chile, Colombia, Costa Rica, Dominica, Ecuador, El Salvador, United States of America, Granada, Guatemala, Guyana, Haiti, Honduras, Jamaica, Mexico, Nicaragua, Panama, Paraguay, Peru, Dominican Republic, St. Vincent and the Grenadines, Suriname, Trinidad and Tobago, Uruguay and Venezuela. The United Nations Human Rights Committee has interpreted this provision in the sense of including an obligation that "States parties must not expose individuals to the danger of torture or cruel, inhuman or degrading treatment or punishment upon return to another 
country by way of their extradition, expulsion or refoulement." Human Rights Committee, General Comment No. 20, Article 7. Prohibition of torture, or other cruel, inhuman or degrading treatment or punishment (replaces general comment No. 7) UN. Doc. HRI/GEN/1/Rev.7, 10 March 1992, para. 9. This obligation arises from the general obligation under Article 2 of the Covenant, which require each States party to "respect and to ensure to all individuals within its territory and subject to its jurisdiction the rights recognized in the present Covenant," which "entails an obligation not to extradite, deport, expel or otherwise remove a person from their territory, where there are substantial grounds for believing that there is a real risk of irreparable harm, such as that contemplated by Articles 6 [right to life] and 7 [prohibition of torture and all cruel, inhuman or degrading treatment] of the Covenant, either in the country to which removal is to be effected or in any country to which the person may subsequently be removed." Human Rights Committee, General Comment No. 31: The Nature of the General Legal Obligation Imposed on States Parties to the Covenant, U.N. Doc. CCPR/ C/21/Rev.1/Add.13, 26 May 2004, para. 12. In addition, in several decision on individual cases, the Committee has affirmed that it is not possible to extradite, deport, expel or otherwise remove a person from the territory of a State if there are sufficient grounds for believing that there is a real risk of irreparable harm to his rights, and without previously taking into consideration the arguments of the person about the risk that exists. Human Rights Committee, Joseph Kindler v. Canada (Communication No. 470/1991), UN Doc. CCPR/C/48/D/ 470/1991, decision adopted on 11 November 1993, para. 6.2; Charles Ng Chitat v. Canada (Communication No. 469/ 991), UN Doc. CCPR/C/49/D/469/1991, Views adopted on January 7, 1994, para. 6.2; Jonny Rubin Byahuranga v. Denmark (Communication No. 1222/2003), UN Doc. CCPR/C/82/D/1222/2003, decision adopted on December 9, 2004, para. 11.3; and, Jama Warsame v. Canada (Communication No. 1959/2010), UN Doc. CCPR/C/102/D/1959/ 2010, decision adopted on 1 September 2011, para. 8.3.

451 See the Convention against Torture and Other Cruel, Inhuman or Degrading Treatment or Punishment, Article 3 of which stipulates:

1. No State Party shall expel, return ("refouler") or extradite a person to another State where there are substantial grounds for believing that he would be in danger of being subjected to torture.

2. For the purpose of determining whether there are such grounds, the competent authorities shall take into account all relevant considerations including, where applicable, the existence in the State concerned of a consistent pattern of gross, flagrant or mass violations of human rights.

Convention Against Torture and Other Cruel, Inhuman or Degrading Treatment or Punishment, adopted on 10 December 1984, entry into force on 26 June 1987. The following 25 Member States of the OAS are parties to this treaty: Antigua and Barbuda, Argentina, Belize, Bolivia, Brazil, Canada, Chile, Colombia, Costa Rica, Cuba, Ecuador, El Salvador, United States, Guatemala, Guyana, Honduras, Mexico, Nicaragua, Panama, Paraguay, Peru, Dominican Republic, St. Vincent and the Grenadines, Uruguay and Venezuela.
452 See, for example, the Preamble to the Inter-American Convention to Prevent and Punish Torture, adopted on 9 December 1985, entry into force on 28 February 1987.

453 Cf. Committee Against Torture, General Comment No. 2, Application of Article 2 by the States Parties UN Doc. CAT/ $\mathrm{C} / \mathrm{GC} / 2$, published on 24 January 2008, paras. 1 and 2.

454 Cf. Case of Vera Vera et al. v. Ecuador. Preliminary objection, merits, reparations and costs. Judgment of May 19, 2011. Series C No. 226, para. 43.

455 See, under the European system, ECHR, Case of D. v. the United Kingdom, No. 30240/96. Judgment of 2 May 1997, para. 53 ("In view of these exceptional circumstances and bearing in mind the critical stage now reached in the applicant's fatal illness, the implementation of the decision to remove him to St Kitts would amount to inhuman treatment by the respondent State in violation of Article 3 (Art. 3). [...] Although it cannot be said that the conditions which would confront him in the receiving country are themselves a breach of the standards of Article 3 (Art. 3), his removal would expose him to a real risk of dying under most distressing circumstances and would thus amount to inhuman treatment").

456 See Human Rights Committee, C. v. Australia, UN Doc. CCPR/C/76/D/990/1999, decision adopted on 28 October 2002, para. 8(5) ("[...] In circumstances where the State party has recognized a protection obligation towards the author, the Committee considers that deportation of the author to a country where it is unlikely that he would receive the treatment necessary for the illness caused, in whole or in part, because of the State party's violation of the author's rights would amount to a violation of Article 7 of the Covenant").

457 See Inter-American Commission on Human Rights (IACHR), Case of Andrea Mortlock v. the United States, Report on admissibility and merits No. 63/08, July 25, 2008, para. 94 ("Under these circumstances, the Commission finds that knowingly sending Ms. Mortlock to Jamaica with the knowledge of her current health care regime and the country's substandard access to similar health for those with HIV/AIDS would violate Ms. Mortlock's rights, and would constitute a de facto sentence to protracted suffering and unnecessarily premature death").

458 Cf. Case of Vélez Loor v. Panama, supra.

459 Cf. Case of Nadege Dorzema et al. v. Dominican Republic, supra.

460 Cf. Case of the Pacheco Tineo Family v. Bolivia, supra.

461 See within the European system, ECHR, Case of Chahal v. the United Kingdom [GS], No. 22414/93. Judgment of 15 November 1996, para. 79; ECHR, Case of Al-Moayad v. Germany, No. 35865/03. Decision of 20 February 2007, paras. 100102; ECHR, Saadi v. Italy [GS], No. 37201/06. Judgment of 28 February 2008, para. 127; ECHR, Case of $Z$ and $T$ v. the United Kingdom, No. 27034/05. Decision of 28 February 2006; ECHR, Case of Bader and Kanbor v. Sweden, No. 13284/04. Decision of 26 October 2004, para. 48; ECHR, Case of Ahmed v. Austria, No. 25964/94. Decision of 2 March 1995, and ECHR, Case of Páez v. Sweden, No. 29482/95. Decision of 18 April 1996.

\section{Article 6:}

1. States Parties recognize that every child has the inherent right to life. 
2. States Parties shall ensure to the maximum extent possible the survival and development of the child.

463 Article 37. States Parties shall ensure that:

(a) No child shall be subjected to torture or other cruel, inhuman or degrading treatment or punishment. Neither capital punishment nor life imprisonment without possibility of release shall be imposed for offences committed by persons below eighteen years of age;

(b) No child shall be deprived of his or her liberty unlawfully or arbitrarily. The arrest, detention or imprisonment of a child shall be in conformity with the law and shall be used only as a measure of last resort and for the shortest appropriate period of time;

(c) Every child deprived of liberty shall be treated with humanity and respect for the inherent dignity of the human person, and in a manner which takes into account the needs of persons of his or her age. In particular, every child deprived of liberty shall be separated from adults unless it is considered in the child's best interest not to do so and shall have the right to maintain contact with his or her family through correspondence and visits, save in exceptional circumstances;

(d) Every child deprived of his or her liberty shall have the right to prompt access to legal and other appropriate assistance, as well as the right to challenge the legality of the deprivation of his or her liberty before a court or other competent, independent and impartial authority, and to a prompt decision on any such action.

464 Committee on the Rights of the Child, General Comment No. 6: Treatment of Unaccompanied and Separated Children Outside their Country of Origin, supra, paras. 26 and 27.

465 Committee on the Rights of the Child, General Comment No. 6: Treatment of Unaccompanied and Separated Children Outside their Country of Origin, supra, paras. 26 and 27.

466 Committee on the Rights of the Child, General Comment No. 6: Treatment of Unaccompanied and Separated Children Outside their Country of Origin, supra, para. 84.

467 Cf. Case of the Pacheco Tineo Family v. Bolivia, supra, para. 136.

468 Cf. Case of the Pacheco Tineo Family v. Bolivia, supra, para. 136.

469 The Commission has indicated that "[f]or persons who have been subject to certain forms of persecution, such as torture, return to their home country would place them at a risk which is impermissible under international law. As noted above, the prohibition of torture as a norm of ius cogens - as codified in the American Declaration generally, and Article 3 of the UN Convention against Torture in the context of expulsion - applies beyond the terms of the 1951 Convention. The fact that a person is suspected of or deemed to have some relation to terrorism does not modify the obligation of the State to refrain from return where substantial grounds of a real risk of inhuman treatment are at issue. Return is also highly problematic as a practical matter in the case of stateless persons, or persons with respect to whom it is not possible to obtain travel documents. The information before the Commission is unclear in indicating what other effective options are available to such persons, or that there are adequate safeguards in place to ensure that expulsion does not place their lives or physical integrity at risk." Inter-American Commission on Human Rights (IACHR), Report on the situation of human rights of asylum seekers within the Canadian refugee determination system, OEA/Ser.L/V/II.106. Doc. 40. Rev. 1, February 28, 2000, para. 154

$470 C f$. ECHR, Case of M.S.S. v. Belgium and Greece [GC], No. 30696/09. Judgment of 21 January 2011, paras. 249 to 264.

471 See, Ley sobre Refugiados y Protección Complementaria, 27 January 2011, Article 2(IV) (Mexico); Ley No. 761-Ley General de Migración y Extranjería, 7 July 2011, Article 220 (Nicaragua), and Ley General de Migración y Extranjería $N^{\circ} 8764,1^{\circ}$ September 2009, Articles 6(6) and 94(12) (Costa Rica).

472 In some countries humanitarian visas are granted when persons do not otherwise receive formal recognition by the State because they do not qualify as refugees and cannot be returned. The same practice in different variations, is used in: Argentina, Brazil, Costa Rica, Honduras, Jamaica, Mexico, Nicaragua, Panama, Uruguay, Venezuela.

$473 C f$. United Nations High Commissioner for Refugees (UNHCR), Observations on the European Commission's proposal for a Council Directive on minimum standards for the qualification and status of third country nationals and stateless persons as refugees or as persons who otherwise need international protection (Brussels, 12 September 2001, $\operatorname{COM}(2001) 510$ final, 2001/10207 (CNS)), 1 November 2001.

474 Committee on the Rights of the Child, General Comment No. 6: Treatment of Unaccompanied and Separated Children Outside their Country of Origin, supra, para. 77.

475 Committee on the Rights of the Child, General Comment No. 6: Treatment of Unaccompanied and Separated Children Outside their Country of Origin, supra, para. 77.

476 Article 22. Freedom of Movement and Residence

Every person has the right to seek and be granted asylum in a foreign territory, in accordance with the legislation of the state and international conventions, in the event he is being pursued for political offenses or related common crimes.

477 Article XXVII. Right of asylum

Every person has the right, in case of pursuit not resulting from ordinary crimes, to seek and receive asylum in foreign territory, in accordance with the laws of each country and with international agreements.

478 Cf. Case of the Pacheco Tineo Family v. Bolivia, supra, paras. 147 and 159. The UNHCR Executive Committee has indicated "the importance of establishing and ensuring access consistent with the 1951 Convention and the 1967 Protocol for all asylum-seekers to fair and efficient procedures for the determination of refugee status in order to ensure that refugees and other persons eligible for protection under international or 
national law are identified and granted protection". $C f$. United Nations High Commissioner for Refugees (UNHCR), Executive Committee, General Conclusion on International Protection, published on 8 October 1993, UN Doc. 71 (XLIV)-1993, para. (i). See also, United Nations High Commissioner for Refugees (UNHCR), Global consultations on international protection: Ministerial Meeting of the States Parties to the 1951 Convention and/or the 1967 Protocol relating to the Status of Refugees (12-13 December 2001)- Declaration of the States Parties to the 1951 Convention and/or the 1967 Protocol relating to the Status of Refugees, UN Doc. HCR/ MMSP/2001/9, adopted on 13 December 2001, operative paragraph 6. Also, United Nations, General Assembly Resolution 52/132 Human rights and mass exoduses, adopted and published on 27 February 1998, UN Doc. A/RES/52/132; United Nations, General Assembly Resolution 49/169 Office of the United Nations High Commissioner for Refugees, adopted and published on 24 February 1995, UN Doc. A/ RES/49/169; United Nations, General Assembly Resolution 45/140 Office of the United Nations High Commissioner for Refugees, UN Doc. A/RES/45/140, adopted and published on 14 December 1990. The Committee against Torture has indicated the importance of "regulating procedures for dealing with and deciding on applications for asylum and refugee status which envisage the opportunity for the applicant to attend a formal hearing and to make such submissions as may be relevant to the right which he invokes, including pertinent evidence, with protection of the characteristics of due process of law." Committee against Torture, Recommendations of the Committee against Torture: Venezuela, UN Doc. A/54/44, 5 May 1999, para. 148.

479 Case of the Pacheco Tineo Family v. Bolivia, supra, para. 157.

480 Cf. Case of the Pacheco Tineo Family v. Bolivia, supra, para. 154.

481 Cf. Case of the Pacheco Tineo Family v. Bolivia, supra, para. 157.

$482 C f$. United Nations High Commissioner for Refugees (UNHCR), Guidelines on international protection: Child Asylum Claims under Articles 1(A)2 and 1(F) of the 1951 Convention and/or 1967 Protocol relating to the Status of Refugees, UN Doc. HCR/GIP/09/08, 22 December 2009, para. 5.

$483 C f$. United Nations High Commissioner for Refugees (UNHCR), Guidelines on international protection: Child Asylum Claims under Articles 1(A)2 and 1(F) of the 1951 Convention and/or 1967 Protocol relating to the Status of Refugees, UN Doc. HCR/GIP/09/08, 22 December 2009, para. 65.

484 Cf. Case of the Pacheco Tineo Family v. Bolivia, supra, para. 224.

485 Case of the Pacheco Tineo Family v. Bolivia, supra, para. 220.

486 Which provides that:

1. States Parties shall take appropriate measures to ensure that a child who is seeking refugee status or who is considered a refugee in accordance with applicable international or domestic law and procedures shall, whether unaccompanied or accompanied by his or her parents or by any other person, receive appropriate protection and humanitarian assistance in the enjoyment of applicable rights set forth in the present
Convention and in other international human rights or humanitarian instruments to which the said States are Parties.

2. For this purpose, States Parties shall provide, as they consider appropriate, cooperation in any efforts by the United Nations and other competent intergovernmental organizations or non-governmental organizations co-operating with the United Nations to protect and assist such a child and to trace the parents or other members of the family of any refugee child in order to obtain information necessary for reunification with his or her family. In cases where no parents or other members of the family can be found, the child shall be accorded the same protection as any other child permanently or temporarily deprived of his or her family environment for any reason, as set forth in the present Convention.

487 United Nations High Commissioner for Refugees (UNHCR), Executive Committee, Conclusion on Children at Risk, UN Doc. 107 (LVIII)-2007, published on 5 October 2007, para. (g)(viii).

$488 C f$. Executive Committee of the United Nations High Commissioner for Refugees, Determination of Refugee Status, UN Doc. 8 (XXVIII) - 1977, published on 5 October 2007, para. (e)(ii).

489 Cf. Case of the Pacheco Tineo Family v. Bolivia, supra, para. 159(a). See also, United Nations High Commissioner for Refugees (UNHCR), Executive Committee, Determination of Refugee Status, UN Doc. 8 (XXVIII) - 1977, published on 12 October 1977, para. (e)(iv).

490 Cf. Case of the Pacheco Tineo Family v. Bolivia, supra, para. 159(a). See also, United Nations High Commissioner for Refugees (UNHCR), Fair and efficient asylum proceedings: a non-exhaustive overview of applicable international standards, September 2, 2005, p. 3.

491 Cf. Case of the Pacheco Tineo Family v. Bolivia, supra, para. 159(a). See also, United Nations High Commissioner for Refugees (UNHCR), Fair and efficient asylum proceedings: a non-exhaustive overview of applicable international standards, September 2, 2005, p. 3.

492 Cf. Case of the Pacheco Tineo Family v. Bolivia, supra, para 159(a). United Nations High Commissioner for Refugees (UNHCR), Fair and efficient asylum proceedings: a nonexhaustive overview of applicable international standards, September 2, 2005, p. 3.

493 Cf. Case of the Pacheco Tineo Family v. Bolivia, supra, para. 159(a).

$494 C f$. Committee on the Rights of the Child, General Comment No. 14 on the right of the child to have his or her best interests taken as a primary consideration (Article 3, paragraph 1), supra, paras. 94 and 96, and United Nations High Commissioner for Refugees (UNHCR), Guidelines on international protection: Child Asylum Claims under Articles 1(A)2 and 1 (F) of the 1951 Convention and/or 1967 Protocol relating to the Status of Refugees, UN Doc. HCR/GIP/09/08, 22 December 2009, supra, para. 69.

$495 C f$. United Nations High Commissioner for Refugees (UNHCR), Guidelines on international protection: Child 
Asylum Claims under Articles 1(A)2 and 1(F) of the 1951 Convention and/or 1967 Protocol relating to the Status of Refugees, UN Doc. HCR/GIP/09/08, 22 December 2009, para. 69.

496 Cf. Case of the Pacheco Tineo Family v. Bolivia, supra, para. 159(b).

497 Cf. Case of the Pacheco Tineo Family v. Bolivia, supra, para. 159(b).

498 The Convention on the Rights of the Child does not establish any lower age limit for the child to freely express its views, because it is evident that children can and do have opinions from a very early age. $C f$. Committee on the Rights of the Child, General Comment No. 12: The right of the child to be heard, supra, para. 21.

499 Cf. Case of the Pacheco Tineo Family v. Bolivia, supra, para. 223.

$500 C f$. United Nations High Commissioner for Refugees (UNHCR), Executive Committee, Conclusion on Children at Risk, UN Doc. 107 (LVIII)-2007, published on 5 October 2007, para. (g)(viii).

501 Cf. Case of the Pacheco Tineo Family v. Bolivia, supra, para. 159(d).

$502 C f$. United Nations High Commissioner for Refugees (UNHCR), Asylum procedures (Fair and efficient asylum proceedings). Global consultations on international protection, UN Doc. EC/GC/01/12, published on 31 May 2001, para. 50(m). See also, United Nations High Commissioner for Refugees (UNHCR), Guidelines on international protection No. 5: Application of the Exclusion Clauses: Article $1 F$ of the 1951 Convention relating to the Status of Refugees, UN Doc. HCR/GIP/03/05, 4 September 2003, para. 33.

503 Cf. United Nations High Commissioner for Refugees (UNHCR), Guidelines on Policies and Procedures dealing with Unaccompanied Children Seeking Asylum, February 1997.

504 Cf. Case of the Pacheco Tineo Family v. Bolivia, supra, paras. 159(c) and 171. See also: United Nations High Commissioner for Refugees (UNHCR), Handbook on Procedures and Criteria for Determining Refugee Status under the 1951 Convention and the 1967 Protocol relating to the Status of Refugees, UN Doc. HCR/1P/4/ENG/REV.3, December 2011, paras. 29, 203 and 204.

$505 C f$. United Nations High Commissioner for Refugees (UNHCR), Guidelines on international protection: Child Asylum Claims under Articles 1(A)2 and 1(F) of the 1951 Convention and/or 1967 Protocol relating to the Status of Refugees, UN Doc. HCR/GIP/09/08, 22 December 2009, para. 77.

506 Cf. Case of the Pacheco Tineo Family v. Bolivia, supra, para. 159(e). See also, United Nations High Commissioner for Refugees (UNHCR), Executive Committee, Determination of Refugee Status, UN Doc. 8 (XXVIII)-1977, para. (e)(vi), and United Nations High Commissioner for Refugees (UNHCR), Improving asylum procedures: Comparative analysis and recommendations for law and practice - a UNHCR research project on the application of key provisions of the Asylum Procedures Directive in selected Member States, Key findings and recommendations, March 2010, p. 89.

507 Cf. United Nations High Commissioner for Refugees (UNHCR), Guidelines on international protection: Child Asylum Claims under Articles 1(A)2 and 1(F) of the 1951
Convention and/or 1967 Protocol relating to the Status of Refugees, UN Doc. HCR/GIP/09/08, 22 December 2009, para. 77.

508 Cf. Case of the Pacheco Tineo Family v. Bolivia, supra, para. 159(f). See also, United Nations High Commissioner for Refugees (UNHCR), Asylum procedures (Fair and efficient asylum proceedings). Global consultations on international protection, UN Doc. EC/GC/01/12, published on 31 May 2001, para. 43.

509 Cf. United Nations High Commissioner for Refugees (UNHCR), Conclusion on the reception of asylum seekers in the context of individual asylum systems, UN Doc. 93 (LIII)2002, published on 8 October 2002, para. b(i) to (ix).

$510 C f$. United Nations High Commissioner for Refugees (UNHCR), Guidelines on international protection: Child Asylum Claims under Articles 1(A)2 and 1(F) of the 1951 Convention and/or 1967 Protocol relating to the Status of Refugees, UN Doc. HCR/GIP/09/08, 22 December 2009, paras. 65 to 77 .

511 See, United Nations High Commissioner for Refugees (UNHCR), UNHCR Guidelines on determining the best interests of the child, May 2008.

512 The UNHCR has indicated that it is not possible to define what constitutes a "mass or large-scale influx" in absolute terms, but this must be defined in function of the resources available to the receiving country. In this regard, it has indicated that " $[t]$ he expression should be understood as referring to a significant number of arrivals in a country, over a short time period, of persons from the same home country who have been displaced under circumstances indicating that members of the group would qualify for international protection, and for whom, due to their numbers, individual refugee status determination is procedurally impractical." United Nations High Commissioner for Refugees (UNHCR), Commentary on the Draft Directive on Temporary Protection in the Event of a Mass Influx, 15 September 2000, para. 3(a) citing United Nations High Commissioner for Refugees (UNHCR), Handbook and Guidelines on Procedures and Criteria for Determining Refugee Status under the 1951 Convention and the 1967 Protocol relating to the Status of Refugees, UN Doc. HCR/1P/4/ENG/REV.3, December 2011, para. 44. Furthermore, the UNHCR Executive Committee has observed that mass influx is a phenomenon that has not been defined, but that this situation is characterized by aspects such as the following: (i) considerable numbers of people arriving over an international border; (ii) a rapid rate of arrival; (iii) inadequate absorption or response capacity in host States, particularly during the emergency; (iv) individual asylum procedures, where they exist, which are unable to deal with the assessment of such large numbers. $C f$. United Nations High Commissioner for Refugees (UNHCR), Executive Committee, Conclusion on International Cooperation and Burden and Responsibility Sharing in Mass Influx Situations, UN Doc. A/AC.96/1003, No.100 (XLV), published on 12 October 2004.

513 United Nations High Commissioner for Refugees (UNHCR), Protection of Refugees in Mass Influx Situations: Overall Protection Framework, UN Doc. EC/GC/01/4, 19 February 2001, para. 6.

514 Article 8. Right to Fair Trial

1. Every person has the right to a hearing, with due guarantees and within a reasonable 
time, by a competent, independent, and impartial tribunal, previously established by law, in the substantiation of any accusation of a criminal nature made against him or for the determination of his rights and obligations of a civil, labor, fiscal, or any other nature.

2. Every person accused of a criminal offense has the right to be presumed innocent so long as his guilt has not been proven according to law. During the proceedings, every person is entitled, with full equality, to the following minimum guarantees:

a. the right of the accused to be assisted without charge by a translator or interpreter, if he does not understand or does not speak the language of the tribunal or court;

b. prior notification in detail to the accused of the charges against him;

c. adequate time and means for the preparation of his defense;

d. the right of the accused to defend himself personally or to be assisted by legal counsel of his own choosing, and to communicate freely and privately with his counsel;

e. the inalienable right to be assisted by counsel provided by the State, paid or not as the domestic law provides, if the accused does not defend himself personally or engage his own counsel within the time period established by law;

f. the right of the defense to examine witnesses present in the court and to obtain the appearance, as witnesses, of experts or other persons who may throw light on the facts;

g. the right not to be compelled to be a witness against himself or to plead guilty; and

$\mathrm{h}$. the right to appeal the judgment to a higher court.

3. A confession of guilt by the accused shall be valid only if it is made without coercion of any kind.

4. An accused person acquitted by a nonappealable judgment shall not be subjected to a new trial for the same cause.

5. Criminal proceedings shall be public, except insofar as may be necessary to protect the interests of justice.

\section{Article 17. Rights of the Family}

1. The family is the natural and fundamental group unit of society and is entitled to protection by society and the state.

2. The right of men and women of marriageable age to marry and to raise a family shall be recognized, if they meet the conditions required by domestic laws, insofar as such conditions do not affect the principle of nondiscrimination established in this Convention.
3. No marriage shall be entered into without the free and full consent of the intending spouses.

4. The States Parties shall take appropriate steps to ensure the equality of rights and the adequate balancing of responsibilities of the spouses as to marriage, during marriage, and in the event of its dissolution. In case of dissolution, provision shall be made for the necessary protection of any children solely on the basis of their own best interests.

5. The law shall recognize equal rights for children born out of wedlock and those born in wedlock.

516 Article 19. Rights of the Child

Every minor child has the right to the measures of protection required by his condition as a minor on the part of his family, society, and the State.

517 Article 25. Right to Judicial Protection

1. Everyone has the right to simple and prompt recourse, or any other effective recourse, to a competent court or tribunal for protection against acts that violate his fundamental rights recognized by the constitution or laws of the state concerned or by this Convention, even though such violation may have been committed by persons acting in the course of their official duties.

2. The States Parties undertake:

a. to ensure that any person claiming such remedy shall have his rights determined by the competent authority provided for by the legal system of the state;

b. to develop the possibilities of judicial remedy; and

c. to ensure that the competent authorities shall enforce such remedies when granted.

\section{Article VI. Right to family and to protection thereof}

Every person has the right to establish a family, the basic element of society, and to receive protection therefor.

519 Article XXV. Right of protection from arbitrary arrest

No person may be deprived of his liberty except in the cases and according to the procedures established by pre-existing law.

No person may be deprived of liberty for nonfulfillment of obligations of a purely civil nature.

Every individual who has been deprived of his liberty has the right to have the legality of his detention ascertained without delay by a court, and the right to be tried without undue delay or, otherwise, to be released. He also has the right to humane treatment during the time he is in custody. 
520 Cf. Juridical Status and Human Rights of the Child, supra, para. 66, and Case of Pacheco Tineo Family v. Bolivia, supra, para. 226.

521 Cf. Juridical Status and Human Rights of the Child, supra, para. 72, and Case of Fornerón and daughter v. Argentina, supra, para. 226.

522 Article 11 Right to Privacy

[...]

2. No one may be the object of arbitrary or abusive interference with his private life, his family, his home, or his correspondence, or of unlawful attacks on his honor or reputation. $[\ldots]$

$523 C f$. Case of Atala Riffo and daughters v. Chile. Merits, reparations and costs, supra, para. 170.

$524 C f$. United Nations High Commissioner for Refugees (UNHCR), Master Glossary of Terms related to the international protection of refugees, June 2006, Rev. 1.

$525 C f$. International Law Commission, Expulsion of aliens: Memorandum by the Secretariat, UN Doc. A/CN.4/565, published on 10 July 2006, para. 67.

$526 C f$. International Law Commission, Expulsion of aliens: Memorandum by the Secretariat, UN Doc. A/CN.4/565, published on 10 July 2006, paras. 91 and 92.

527 This Article stipulates that:

An alien lawfully in the territory of a State Party to the present Covenant may be expelled therefrom only in pursuance of a decision reached in accordance with law and shall, except where compelling reasons of national security otherwise require, be allowed to submit the reasons against his expulsion and to have his case reviewed by, and be represented for the purpose before, the competent authority or a person or persons especially designated by the competent authority.

528 Human Rights Committee, General Comment No. 15: The position of aliens under the Covenant, UN Doc HRI/GEN/1/ Rev7, 11 April 1986, para. 9.

529 See Article 22(6) of the American Convention and Article 13 of the International Covenant on Civil and Political Rights.

530 Cf. Case of Nadege Dorzema et al. v. Dominican Republic, supra, para. 161. See also, Human Rights Committee, General Comment No. 15: The position of aliens under the Covenant, supra, para. 9.

531 Cf. Case of Fornerón and daughter v. Argentina, supra, para. 119.

$532 C f$. Committee for the Elimination of Discrimination against Women, General recommendation No. 21: Equality in marriage and family relations, 1994, para. 13 ("The form and concept of the family can vary from State to State, and even between regions within a State. Whatever form it takes, and whatever the legal system, religion, custom or tradition within the country, the treatment of women in the family both at law and in private must accord with the principles of equality and justice for all people, as Article 2 of the Convention requires."); Committee on the Rights of the Child, General Comment No. 7. Implementing child rights in early childhood, supra, paras. 15 and 19 ("The Committee recognizes that "family" here refers to a variety of arrangements that can provide for young children's care, nurturance and development, including the nuclear family, the extended family, and other traditional and modern community-based arrangements, provided these are consistent with children's rights and best interests. [...] The Committee notes that in practice family patterns are variable and changing in many regions, as is the availability of informal networks of support for parents, with an overall trend towards greater diversity in family size, parental roles and arrangements for bringing up children."); Committee on Human Rights, General Comment No. 19: The family (Article 23), UN Doc. HRI/GEN/1/Rev.9 (Vol. I), 27 may 2008, para. 2 ("The Committee notes that the concept of the family may differ in some respects from State to State, and even from region to region within a State, and that it is therefore not possible to give the concept a standard definition"), and Committee on Human Rights, General Comment No. 16: Right to privacy (Article 17), UN Doc. HRI/GEN/1/Rev.9 (Vol. I), 8 April 1998, para. 5 ("Regarding the term "family", the objectives of the Covenant require that for purposes of Article 17 this term be given a broad interpretation to include all those comprising the family as understood in the society of the State party concerned"); and, ECHR $X, Y$, and $Z$, v. the United Kingdom, No. 21830/93. Judgment of 22 April 1997, para. 36 ("When deciding whether a relationship can be said to amount to "family life", a number of factors may be relevant, including whether the couple live together, the length of their relationship and whether they have demonstrated their commitment to each other by having children together or by any other means."). See also, ECHR, Case of Marckx v. Belgium, No. 6833/74. Judgment of 13 June 1979, para. 31; ECHR, Case of Keegan v. Ireland, No. 16969/90. Judgment of 26 May 1994, para. 44, and ECHR, Case of Kroon and Others $v$. the Netherlands, No. 18535/91. Judgment of 27 October 1994, para. 30.

533 Cf. Case of Atala Riffo and daughters v. Chile. Merits, reparations and costs, supra, para. 177.

534 Committee on the Rights of the Child, General Comment No. 14 on the right of the child to have his or her best interests taken as a primary consideration (Article 3, paragraph 1), supra, para. 59.

535 Committee on the Rights of the Child, General Comment No. 14 on the right of the child to have his or her best interests taken as a primary consideration (Article 3, paragraph 1), supra, para. 60 .

536 Cf. Case of Vélez Loor v. Panama, supra, para. 97.

537 Cf. Juridical Status and Human Rights of the Child, supra, para. 65 .

538 Juridical Status and Human Rights of the Child, supra, para. 73.

539 Juridical Status and Human Rights of the Child, supra, para. 77.

540 Cf. Juridical Status and Human Rights of the Child, supra, para. 77, and Case of Fornerón and daughter v. Argentina, supra, para. 116.

541 Cf. Committee on the Rights of the Child, General Comment No. 14 on the right of the child to have his or her best interests taken as a primary consideration (Article 3, paragraph 1), supra, para. 60 .

542 Article 9 of the Convention on the Rights of the Child: 
1. States Parties shall ensure that a child shall not be separated from his or her parents against their will, except when competent authorities subject to judicial review determine, in accordance with applicable law and procedures, that such separation is necessary for the best interests of the child. Such determination may be necessary in a particular case such as one involving abuse or neglect of the child by the parents, or one where the parents are living separately and a decision must be made as to the child's place of residence. $[\ldots]$

543 Article 9 of the Convention on the Rights of the Child: [...] 4. Where such separation results from any action initiated by a State Party, such as the detention, imprisonment, exile, deportation or death (including death arising from any cause while the person is in the custody of the State) of one or both parents or of the child, that State Party shall, upon request, provide the parents, the child or, if appropriate, another member of the family with the essential information concerning the whereabouts of the absent member(s) of the family unless the provision of the information would be detrimental to the well-being of the child. States Parties shall further ensure that the submission of such a request shall of itself entail no adverse consequences for the person (s) concerned.

544 The first step to assess whether a restriction of a right established in the American Convention is permitted in light of Article 30 of this instrument consists in examining whether the restrictive measure complies with the requirement of legality. This means that the general circumstances and conditions authorizing a restriction to the exercise of a specific human right must be clearly established by law. The norm that establishes the restriction must be a law in the formal and material sense. Cf. Case of Castañeda Gutman v. United Mexican States. Preliminary objections, merits, reparations and costs. Judgment of August 6, 2008. Series C No. 184, para. 176, and The Word "Laws" in Article 30 of the American Convention on Human Rights, Advisory Opinion OC-6/86 of May 9, 1986. Series A. No. 6, paras. 27 and 32.

545 The Inter-American Court has maintained that in order for a restriction to be permitted in light of the Convention it must be necessary in a democratic society. This requirement, which the American Convention establishes explicitly for certain rights (Right of Assembly, Article 15; Freedom of Association, Article 16, and Freedom of Movement and Residence, Article 22), has been incorporated by the Court as a standard of interpretation and as a requirements that qualifies any restriction of the rights recognized in the Convention. $C f$. Case of Castañeda Gutman v. United Mexican States, supra, para. 185.

546 The second limit to any restriction is related to the purpose of the restrictive measures; in other words, the reasons invoked to justify the restriction must be one of those permitted by the American Convention that are established in specific provisions included in certain rights (for example, the purpose of protecting public order or public health, in Articles 12(3), 13 (2)(b) and 15), or else in norms that establish legitimate general purposes (for example, "the rights and freedoms of others," or "the just demands of the general welfare, in a democratic society," both in Article 32). Cf. Case of Castañeda Gutman v. United Mexican States, supra, para. 180. See also, Compulsory Membership in an Association Prescribed by Law for the Practice of Journalism (Arts. 13 and 29 American Convention on Human Rights). Advisory Opinion OC-5/ 85 of November 13, 1985. Series A No. 5, para. 67.

547 Cf. Committee on the Rights of the Child, Report of the 2012 Day of General Discussion on the rights of all children in the context of international migration, 28 September 2012, recommendation in para. 84 .

548 Cf. Case of Castañeda Gutman v. United Mexican States, supra, para. 186.

$549 C f$. Committee on the Rights of the Child, General Comment No. 14 on the right of the child to have his or her best interests taken as a primary consideration (Article 3, paragraph 1), supra.

550 Cf. Juridical Status and Human Rights of the Child, supra, para. 72.

551 The Court recalls that " $[\mathrm{t}]$ he migratory status of a person is not transmitted to the children", and "[t]he fact that a person has been born on the territory of a State is the only fact that needs to be proved for the acquisition of nationality, in the case of those persons who would not have the right to another nationality if they did not acquire that of the State where they were born." Juridical Status and Rights of Undocumented Migrants, supra, para. 134, and Case of the Yean and Bosico Girls v. Dominican Republic, supra, para. 156.

552 In most countries in the region ius soli applies, which determines that the person acquires the nationality of the State in whose territory she or he was born. Article 20(2) of the American Convention establishes the right to the nationality of the State in whose territory the person was born, if this person "does not have the right to any other nationality." On this point, the Court underscores that it is necessary, as a guarantee of the right to identity and to the exercise of other rights, that State ensure that all births in their territory are duly registered. See Article 7.1 of the Convention on the Rights of the Child, Article 29 of the International Convention on the Protection of the Rights of All Migrant Workers and Members of Their Families. Cf. Inter-American Juridical Committee, Advisory Opinion "on the scope of the right to identity," 71st regular session, Río de Janeiro, Brazil, Document CJI/doc. 276/07 rev. 1, of August 10, 2007, para. 18(3)(6), approved during the same session by Resolution CJI/RES.137 (LXXI-O/07), of August 10, 2007, second operative paragraph.

553 Article 22(9) of the American Convention establishes that: "[ $t]$ he collective expulsion of aliens is prohibited." Under the inter-American system for the protection of human rights, the Court has considered that the "collective" character of an expulsion implies a decision that has not made an objective analysis of the individual circumstances of each alien and, consequently, is based on arbitrariness. Also, proceedings that may result in the expulsion or deportation of an alien must, in addition to being individual, respect certain basic guarantees of due process. Cf. Case of Nadege Dorzema et al. v. Dominican Republic, supra, paras. 171 and 175.

$554 C f$. Committee on the Rights of the Child, General Comment No. 14 on the right of the child to have his or her best interests taken as a primary consideration (Article 3, paragraph 1), supra, para. 58. 
555 See Article 12 on the Convention of the Rights of the Child. $C f$. Report of the Special Rapporteur on the human rights of migrants, Jorge Bustamante, Promotion and Protection of all Human Rights, Civil, Political, Economic, Social, and Cultural Rights, Including the Right to Development, UN Doc. A/HRC/11/7, May 14, 2009, para. 59, and Committee on the
Rights of the Child, Report of the 2012 Day of General Discussion on the rights of all children in the context of international migration, 28 September 2012, para. 84.

556 Cf. Case of the Pacheco Tineo Family v. Bolivia, supra, para. 227. 